\title{
CAN STATISTICS BASED EARLY WARNING SYSTEMS DETECT PROBLEM BANKS BEFORE MARKETS?
}

A dissertation submitted to:

Kent State University Graduate School of Management in partial fulfillment of the requirements for the degree of

Doctor of Philosophy

by

Randall K. Kimmel

August, 2011 
Dissertation written by

\author{
Randall K. Kimmel
}

B.A., Mercyhurst College, 1992

M.B.A., Case Western Reserve University, 1995

Ph.D., Kent State University, 2011

Approved by

Chair, Doctoral Dissertation Committee

Member, Doctoral Dissertation Committee

Member, Doctoral Dissertation Committee

Accepted by

Doctoral Director, Graduate School of

Management

Dean, Graduate School of Management 
KIMMEL, Randall, Ph.D. December, 2008 Finance

\section{CAN STATISTICS BASED EARLY WARNING SYSTEMS DETECT PROBLEM BANKS BEFORE MARKETS? (86 pp.)}

\section{Director of Dissertation: $\quad$ John H. Thornton}

Many statistical early-warning models have proven to have some predictive power. These models involve five basic approaches: logit, discriminant analysis, proportional hazard models, trait, and robust regression.

If markets are at least semi-strong form efficient, then prices must already incorporate any information that could be obtained by using these statistical early warning systems. In this case, either early warning systems do not have special predictive power, or the information they provide is quickly obtained by markets, probably through industry analysts who utilize such models in their analysis. If these systems can be used to earn abnormal profits, then the efficiency of equity markets is called into question.

In this dissertation, I utilize these five early warning systems to find problematic banks using data from 1986 through 2009. A zero cost arbitrage portfolio is formed each quarter by shorting the banks identified by the models as potential problems and going long the remaining non-problematic banks in the sample. The risk adjusted returns on the arbitrage portfolio and its long and short components is compared to risk adjusted returns on a long portfolio of all banks in the sample. If the returns on any of these portfolios are statistically greater than the "all bank" we can infer that the early warning system is able to provide information not available to investors and can conclude that the market is not semi-strong form efficient.

I find that using market returns for portfolios formed by bank EWS is a viable universal standard to judge their ability to discern problematic banks and conclude that newer and/or more complex EWS do not perform better than older and/or simpler models over long periods of time. Only two of the models are able to beat the naïve all bank portfolio on a risk adjusted basis over the entire term and none are able to beat the market on a risk adjusted basis, but all are able to form a long portfolio able to screen out some underperforming stocks and so beat a naïve strategy on an unadjusted for risk basis. From this, I conclude that the market for publicly traded commercial banks is highly, but not perfectly, semi-strong form efficient. 


\section{Table of Contents}

1

2 A Survey of Relevant Literature ............................................................................... 3

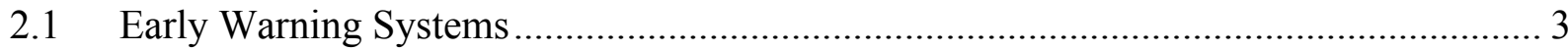

2.1.A. Current Practice in the use of bank Early Warning Systems ................................... 7

2.1.B. The future direction of research for bank Early Warning Systems .......................... 9

2.2 Winner and Loser Portfolios, and Market Efficiency .................................................... 12

2.3 Two-Factor Model.............................................................................................. 15

2.4 The Contribution of this Dissertation to the Literature …............................................. 18

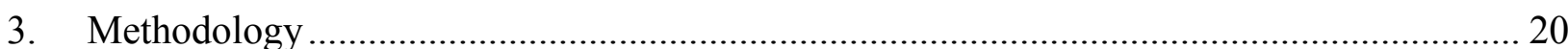

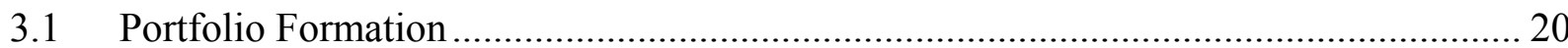

3.1.A Portfolio Formation: logit analysis based on the work of Martin (1977) ............... 21

3.1.B Portfolio Formation: discriminant analysis based on the work of Pettway and

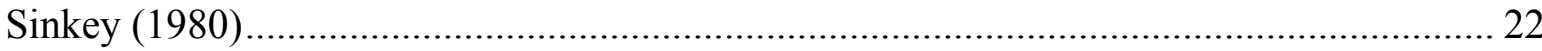

3.1.C Portfolio Formation: Cox proportional hazard model based on the work of Lane et

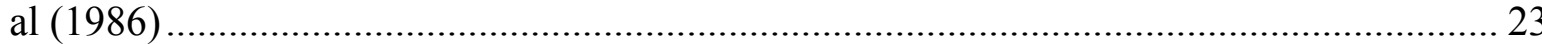

3.1.D Portfolio Formation: trait recognition based on the work of Kolari et al (2002).... 24

3.1.E Portfolio Formation: robust regression based on the work of Kimmel et al (2010)25

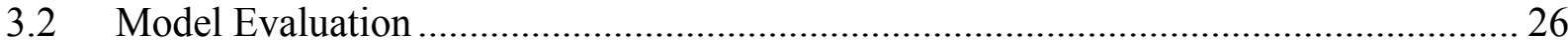

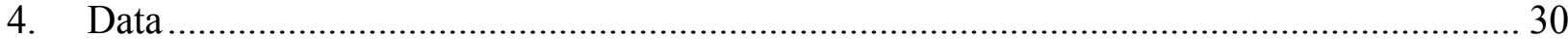

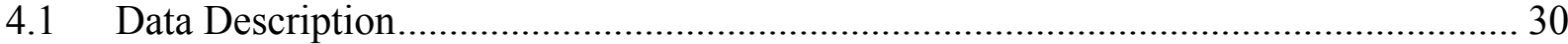

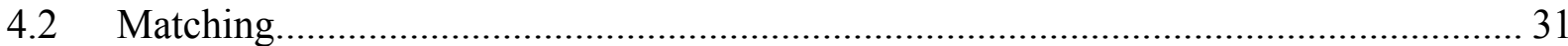

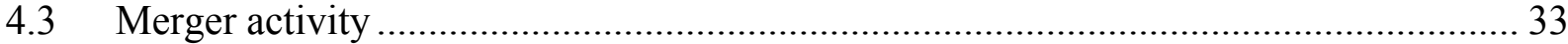

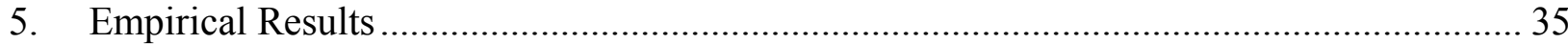

5.1.A Empirical Results: logit analysis based on the work of Martin (1977)................... 36

5.1.B Empirical Results: discriminant analysis based on the work of Pettway and Sinkey (1980) 37

5.1.C Empirical Results: Cox Proportional Hazard Model based on the work of Lane et al (1986) 38

5.1.D Empirical Results: Trait Analysis based on the work of Kolari et al (2000).......... 39

5.1.E Empirical Results: LOESS based on the work of Kimmel et al (2010).................. 41

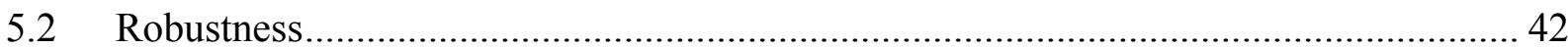

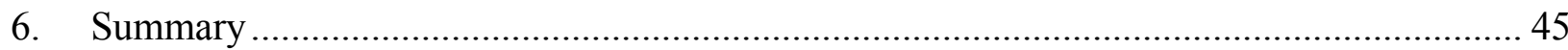

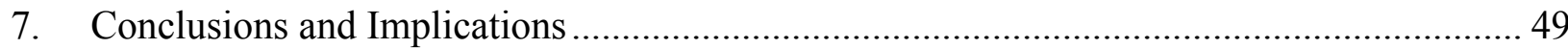

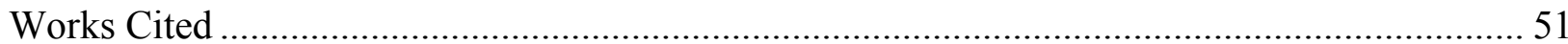




\section{Tables}

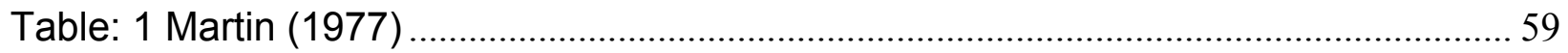

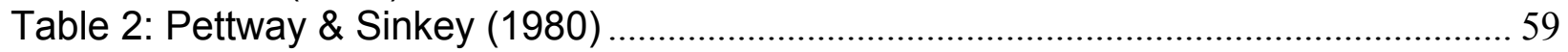

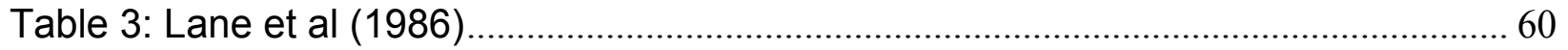

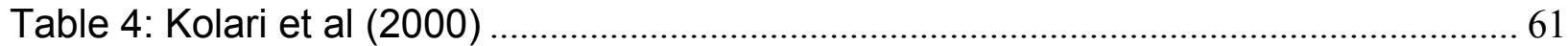

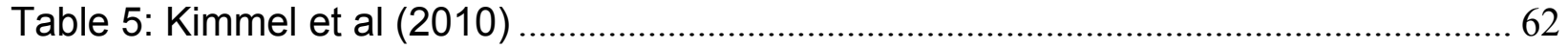

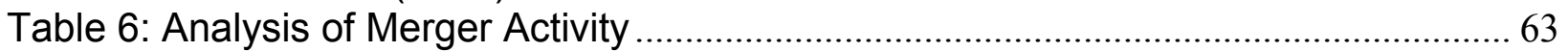

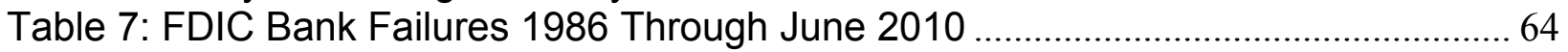

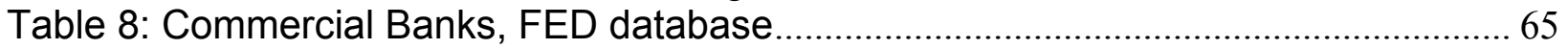

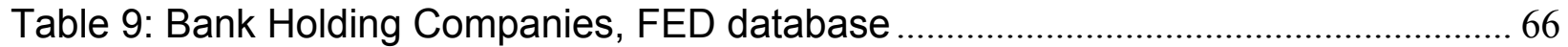

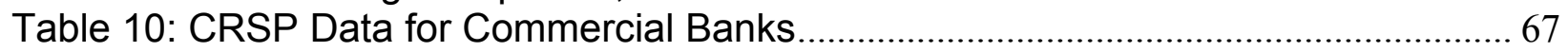

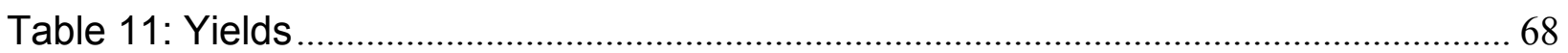

Table 12: Prediction Success by 1 Year and 2 Year Ahead Models ................................ 69

Table 13: Martin (1977) Total Cumulative Returns Over the Period ...................................... 70

Table 14: Pettway \& Sinkey (1980) Total Cumulative Returns Over the Period ............. 72

Table 15: Lane et al (1986) Total Cumulative Returns Over the Period .............................. 74

Table 16: Kolari et al (2002) Total Cumulative Returns Over the Period.......................... 76

Table 17: Kimmel et al (2010) Total Cumulative Returns Over the Period......................... 78

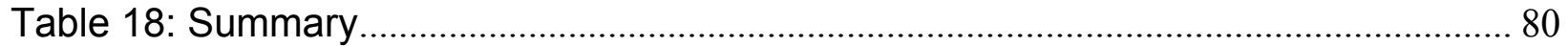

Table 19: Summary Financial Crisis $(2006$ - 2009)..................................................... 81

Table 20: Publicly Traded Banks (1996) Flagged as Potential Problems by Model and Data Set83

Table 21: Analysis of Matching Method Original Matching VS no Matching ..................... 86

Table 22: Significant Variables by Statistical Method ....................................................... 86

Table 23: Analysis of Statistical Methods using Common Variables VS Original Model

Variables 86 


\section{Figures}

Figure 1: Martin (1977) 1 Y Prediction CAPM Cumulative Abnormal Returns ....................... 71

Figure 2: Martin (1977) 1 Y Prediction Cumulative RET (-RETX for short) .......................... 71

Figure 3: Pettway \& Sinkey (1980) 1 Y Prediction CAPM Cumulative Abnormal Returns ...... 73

Figure 4: Pettway \& Sinkey (1980) 1 Y Prediction Cumulative RET (-RETX for short) ......... 73

Figure 5: Lane et al (1986) 1 Y Prediction CAPM Cumulative Abnormal Returns ................ 75

Figure 6: Lane et al (1986) 1 Y Prediction Cumulative RET (-RETX for short)..................... 75

Figure 7: Kolari et al (2002) 1 Y Prediction CAPM Cumulative Abnormal Returns ................ 77

Figure 8: Kolari et al (2002) 1 Y Prediction Cumulative RET (-RETX for short) .................... 77

Figure 9: Kimmel et al (2010) 1 Y Prediction CAPM Cumulative Abnormal Returns ............. 79

Figure 10: Kimmel et al (2010) 1 Y Prediction Cumulative RET (-RETX for short) ................ 79

Figure 11: 1 Y Prediction CAPM Cumulative Abnormal Returns, Long Portfolio.................... 82

Figure 12: 1 Y Prediction Cumulative RET (-RETX for short), Long Portfolio ....................... 82 


\section{Introduction}

Almost as long as there have been banks, people have been trying to predict their failure. Bank regulators want to prevent the failure from occurring, and investors and depositors want to keep from losing their money. Many early-warning systems (EWS) or statistical models have proven to have some predictive power. These models involve six basic approaches: logit analysis (logit), multiple discriminant analysis (MDA), proportional hazard models (PHM), trait recognition (trait), robust regression, and intelligent systems typified by neural networks (NN). The methodology used in the first five models are widely accepted and these models are now used to analyze which characteristics are most closely associated with problematic banks, while the sixth, NN, is still under development and most research in the area is focused on refining the model rather than utilizing it.

If markets are at least semi-strong form efficient, then prices must already incorporate any information that could be obtained by using these statistical early warning systems. In this case, either early warning systems do not have special predictive power, or the information they provide is quickly obtained by markets, probably through industry analysts who utilize such models in their analysis. If these systems can be used to earn abnormal profits, then the efficiency of equity markets is called into question. By comparing the ability of various EWS to form portfolios that earn abnormal profits, we have established a "universal standard" with which to judge the various models. We use this universal standard to determine if newer and/or more complex EWS perform better than older and/or simpler models.

In this dissertation I utilize the five "established" or "archetypical" EWS to find problematic banks using data from 1986 through 2009. A zero cost arbitrage portfolio is formed each year by shorting the banks identified by the models as potential problems and going long 
the remaining non-problematic banks in the sample. The risk adjusted returns on the arbitrage portfolio and its long and short components are compared to risk adjusted returns on a long portfolio of all banks in the sample, which represents a "naïve" strategy. If the returns on any of these portfolios are statistically greater than the "all bank, naïve strategy" long portfolio we can infer that the early warning system is able to provide information not available to investors and can conclude that the market is not semi-strong form efficient.

To utilize some of these models over the above time span, which includes a long period of time when relatively few bank failures occur, I have to utilize a novel method of accumulating data over time which also tests the stability of the predictive power of the variables used.

I find that using market returns for portfolios formed by bank EWS is a viable universal standard to judge their ability to discern problematic banks. Based on this standard and their ability to predict the failure of specific banks, I conclude that newer and/or more complex EWS do not perform better than older and/or simpler models over long periods of time. Over the period from 1986 through 2009, the financial variables used in this study remain stable and do not lose their ability to predict bank failure during the financial crisis of 2008. Only two of the models are able to beat the naïve all bank portfolio on a risk adjusted basis over the entire term and none are able to beat the market on a risk adjusted basis, but all are able to form a long portfolio able to screen out some underperforming stocks and so beat a naïve strategy on an unadjusted for risk basis. From this, I conclude that the market for publicly traded commercial banks is highly, but not perfectly, semi-strong form efficient. 


\section{A Survey of Relevant Literature}

\subsection{Early Warning Systems}

Some of the earliest attempts at predicting bank failures utilize univariate ratio analysis. Secrist (1938) studies bank failures over 10 years using univariate analysis of 4 ratios and concludes that more sophisticated statistical methods would be required to predict likely bank failures. Sinkey (1974) conducts perhaps the most complete univariate study by using a matched sample of 110 problem and non-problem banks over 7 years to identify performance characteristics that might be used in an early warning system. He analyzes 21 size related ratios, 18 ratios related to the sources and uses of revenue, 2 measures of profitability, 2 ratios for capital adequacy, and 1 measure of managerial quality. He concludes that there are significant differences in the studied characteristics between the problem and nonproblem banks, and that the differences increase slowly over time as a sound bank becomes problematic.

One of the first attempts in constructing an early warning system, by Meyer and Pifer (1970), is a precursor of the logit regression method using untransformed variables. They examine a matched sample of 30 banks over 18 years using 32 variables and the rate of change of these variables over the period. Their study finds that failure can be predicted with reasonable accuracy ( 80 percent of failed banks are flagged) for up to 2 years prior to failure, even when embezzlement or other financial irregularities contribute to the failure, but trends in the data must be considered for the model to work.

Martin (1977) refines the work of Meyer and Pifer (1970) by using logit regression to analyze 5,700 banks over 6 years. He draws from a set of 25 ratios from four broad groups: asset risk, liquidity, capital adequacy, and earnings. He compares results using logit and discriminant 
analysis, finding that discriminant analysis works better when the sample size is small, but otherwise both models produce similar results. Unlike MDA, logit analysis provides an estimate of the probability of failure during the next 1 or 2 year period, which may be of considerable importance to bank authorities and business.

During the same period (1975 - 1980), Sinkey (1975, 1977, and 1978) and Pettway and Sinkey (1980) use MDA to successfully screen for problem banks. In the 1975 study, Sinkey use MDA on a matched sample of 110 banks with 4 years of data and 10 ratios representing asset composition, loan characteristics, capital adequacy, sources and uses of revenue, efficiency, and profitability and conclude that they are "good discriminators." In the 1977 study, Sinkey modifies the discriminant analysis to use only one group instead of the usual two because of the extremely small number of failed large banks with which to form a sample. Using data on the 50 largest US banks over 5 years with 7 variables he shows that such an "outlier" model is able to detect potentially problematic banks. In their 1980 study, Pettway and Sinkey use a paired sample of 66 banks over 6 years with a two-variable linear discriminant function and are able to detect problematic banks a little over a year before failure.

Both logit regression and MDA are subject to the effects of outliers, especially for large bank studies where sample sizes are small and the population is not normally distributed. Booth (1980) shows that a non-parametric statistical method, M-estimator robust regression, can be used to identify problem banks as outliers without the need to identify problem banks a priori or to meet the more stringent assumptions of discriminant analysis and logit regression. In addition, the method is much less computationally intensive than the outlier identification method which Sinkey uses in 1977. 
Subsequent research on EWS concentrates on improving the predictive power of the model or finding additional risk factors associated with bank failures. Sinkey (1977) combines discriminant analysis with a second screen based on stock market performance using a capital asset pricing model (CAPM) and finds that the market screen performs nearly as well as discriminant analysis on financial ratios. Booth (1982) combines M-estimator robust regression, robustified Mahalanobis distance analysis, and principal component analysis on a sample of 50 large banks using 3 years of data with 3 accounting ratios. He finds that the combination may provide earlier warning than methods using a single identification method.

Tam and Kiang (1992) use a NN approach to nonlinear discriminant analysis (see section 2.1.B for more on their research). Yeh (1996) uses data envelopment analysis with twelve financial ratios to study the efficiency of 54 Taiwanese banks in converting inputs into outputs. The method categorizes banks into high, medium and low efficiency and is able to find problem banks and link their performance to operating strategies.

Lane, Looney, and Wansley (1986) use a PHM, a semiparametric model, that does not require distributional assumptions for the estimation of the baseline hazard function or probability that an average bank will fail. The model is designed to estimate of the probable time to failure, providing more information than models that only predict how likely banks are to fail. They use a sample of 130 failed banks and 334 matched nonfailed banks with a set of 21 financial ratios over five years and find that different variables work better when used over a one year prediction period versus a two year period. Wheelock and Wilson (2000) use a PHM with time-varying covariates to study which characteristics are likely to lead banks to fail or be acquired. They use three measures of managerial efficiency, 10 financial ratios and five other factors (total assets, holding company affiliation, branching, and age) on a $9 \frac{1}{2}$ year sample of 
4,022 banks. They find that the characteristics associated with failure (high leverage, low earnings, low liquidity, and risky asset portfolios) are different from those associated with being acquired (small size, branching legal, low capitalization).

Kolari, Glennon, Shin, and Caputo (2002) use a nonparametric trait recognition model that allows for complex two- and three-variable interactions between financial and accounting variables. They use 23 financial ratios and 12 measures of the rate of change for most of these variables on a sample of 55 large failed banks that are matched to over 1,000 large unfailed banks over a 4 year period. They find that the model is able to outperform logit analysis in predicting out of sample bank failures.

Tung, Quek, and Cheng (2004) use a Generic Self-organizing Fuzzy Neural Network (GenSoFNN) based on the compositional rule of inference (CRI) to both predict bank failure and determine financial traits associated with bank failure (see section 2.1.B for more on their research). Curry, Elmer and Fissel (2007) add stock market factors to financial ratios in a logit regression utilizing a sample ranging from 75 to 99 banks and thrifts combined over a seven year period with 6 accounting ratios, five market variables and 3 risk related variables. They find the addition of market factors improve the predictive accuracy of the model.

Kimmel, Booth and Booth (2010) use a nonparametric LOESS model with a single financial ratio to analyze the performance of 46 large banks over 3 years. The model is similar to Sinkey's 1977 model in that it does not require the a priori identification of failed banks, but rather identifies banks that are significantly different from peer banks on one key dimension (three ratios are examined) while being similar along other dimensions, such as size (total assets or deposits). They find that the model works as well as earlier parametric models in predicting 
failures among the sample of large banks and has the potential to provide superior performance during period when bank failures are uncommon.

\subsection{A. Current Practice in the use of bank Early Warning Systems}

Research using bank EWS is following a very different path than research on bank EWS. Research using bank EWS, for example to understand the causes of so many bank failures during the financial crisis of 2008, is largely being conducted using some of the simplest and oldest statistical models. A survey of recent literature turned up 5 studies using logit ${ }^{1}$ (one of them combined with binary tree analysis ${ }^{2}$ ), one using a variant of the $\mathrm{PHM}^{3}$, and one using MDA ${ }^{4}$. Researchers probably use these methods because they are proven and widely accepted, while newer, more complex models are still under development and no clear consensus exists as to which version or implementation is best.

Barrell, Davis, Karim, and Liadze (2010) use logit analysis to examine some of the causes of 14 systemic and 14 non-systemic financial crises in 14 OECD countries from 1979 through 2007. They use a set of six variables that earlier research has shown effective in predicting bank crises and add three new variables: liquidity ratio, unweighted capital adequacy ratio and real property price growth to the model and find that the new variables better predict crises than the variables from prior research.

Caporale, Matousek, and Stewart (2009) use ordered logit and probit regression models in an effort to reverse engineer the Fitch Ratings of banks before and during the financial crisis of 2008, add a country specific variable and then compare the accuracy of their model to actual

\footnotetext{
${ }^{1}$ Barrell, Davis, Karim, and Liadze (2010), Caporale, Matousek, and Stewart (2009), Cole and White (2010), and Poghosyan and Čihák, (2009).

${ }^{2}$ Davis and Karim (2008)

${ }^{3}$ Demyanyk and Van Hemert (2009)

${ }^{4}$ Jordan, Rice, Sanchez, Walker, and Wort (2010)
} 
ratings given by Fitch of three of the first banks to fail during the crisis. They examine 681 international banks over seven years using seven lagged (up to four years) financial variables. They find that capital adequacy, size, return on assets, and the stability of the home country have positive effects on a bank's rating, while the ratio of operating expenses to total operating income has a negative effect on the bank's rating.

Cole and White (2010) run 10 different logistic models on data from 2004 through 2008 using "standard proxies for the CAMELS components" as well as various measures of real estate loans. 117 commercial banks failed in 2009 and they conjecture that many more will fail during 2010 - 2012. To account for this, they create a measure of "technical failure" and add banks that meet this requirement to the sample of failed banks, yielding 265 failed banks. They find that traditional CAMELS measures do an excellent job in explaining the failures of banks but the real estate measures do a better job at long lead times. They also find that residential mortgagebacked securities played little role in determining which banks failed.

Davis and Karim (2008) use logit analysis as well as a nonparametric binary recursive tree technique to examine whether or not the US subprime crisis was predicted by ex ante macroeconomic and financial data from 105 countries during the period from 1979 through 2003 using 12 macroeconomic, financial and institutional variables. They are unable to predict the crisis using these models and the variables studied, so either the crisis is unpredictable from ex ante macroeconomic and financial data or, is unpredictable using these two models.

Poghosyan and Čihák (2009) use several version of the logistic regression model with a new dataset for 5,708 European banks from 1996 through 2007. They combine the usual financial variables with data on individual bank distress gathered by hand; searching a news database for selected keywords. By comparing their distress measure to CAMEL variables, they 
find that capitalization, asset quality and profitability are good predictors of distress while costto-income ratios and basic liquidity indicators are not.

Demyanyk and Van Hemert (2009) use a discrete-time analogue to the PHM, called a proportional odds model, with a random sample of 1 million loans from the First American CoreLogic LoanPerformance database, as of June 2008, which includes loan-level data on about 85 percent of all securitized subprime mortgages; (more than half of the U.S. subprime mortgage market). They conclude that the crisis is "a classic lending boom-bust scenario with rapid market growth, loosening underwriting standards, deteriorating loan performance, and decreasing risk premiums."

Jordan, Rice, Sanchez, Walker, and Wort (2010) use MDA to examine 225 banks that failed between February 2007 and April 2010, using a random sample of nonfailed banks as a control. They use six financial ratios and three institutional characteristic variables. Their model is able to predict failure up to four years in advance.

\subsection{B. The future direction of research for bank Early Warning Systems}

While some researchers are working to refine some of the older models, such as Cole and Wu's $(2009,2010)$ work with hazard models and Güvenir and Çakir (2010) with a variant of trait analysis called voting features based classifier with feature construction (VFCC), most research is being done in the area of artificial intelligence or neural networks.

Kunihiko Fukushima (1975) first proposed using a computer algorithm to mimic the processing of a biological neural network. A neural net is a set of interconnected computational nodes and are distinguished by the algorithms used by the nodes, the number of nodes, the complexity and direction of the interconnections, and the weights given to the inputs and outputs of the nodes. Tam and Kiang (1992) are among the first to apply the concept to the prediction of 
bank failure. They use a multilayer NN with a backpropagation learning algorithm (a connectionist model) to perform discriminant analysis on a matched, 3 year sample of 118 Texas banks with 20 financial ratios. They find the NN model to be accurate, adaptable, and robust compared to earlier methods.

Tung et al (2004) use a Generic Self-organizing Fuzzy Neural Network (GenSoFNN) based on the compositional rule of inference (CRI). This model is based on a set of IF-THEN rules to model the problem which allows for better control and understanding of both the functioning and interpretation of the linkages between nodes and their weights. $\mathrm{Ng}$, Quek, and Jiang (2008) modify the GenSoFNN model of Tung et al (2004) by allowing for localized learning in the training phase, calling their model "fuzzy cerebellar model articulation controller based on compositional rule of inference (FCMAC-CRI(S))". They believe that their model prevents false or spurious associations from forming in the model and leads to better results. Ravisankar and Ravi (2010) add three additional variations of NN to the bank EWS literature: Group Method of Data Handling (GMDH), Counter Propagation Neural Network (CPNN) and fuzzy Adaptive Resonance Theory Map (fuzzy ARTMAP). Using datasets from Spain, Turkey, the UK and the United States, they find that the GMDH model outperforms the other models introduced in the paper as well as earlier NN models in terms of average accuracy, sensitivity, and specificity.

Can a perfect model for the prediction of bank failures exist? It is probably impossible to create a model that can eliminate type I errors, or false positives, at least as long as the model is designed to predict failure and not just underperformance. At best, a model can indicate, at the time of the forecast, that ceteris paribus, the bank will fail, but exogenous changes in the economy, or actions by bank regulators or bank management, can intervene and prevent the 
failure of the bank. Type II errors, or false negatives, are also impossible to eliminate as between the time of the model's forecast and the bank's ultimate failure, exogenous changes in the economy, or bank management, such as fraud, can intervene in ways that would not have informed the model and still cause the bank to fail.

Instead of defining model perfection in terms of prediction accuracy, we could go back to the premise of this research and define the perfect bank EWS as one that is able to inform markets, and in doing so, makes the market informationally efficient. Given the results in sections 5 and 6 , the market for publicly traded commercial banks became much more efficient after 1994. The fact that none of the models tested here is clearly able to beat the market after 1994 on a risk adjusted basis indicates that the market is informationally efficient (if not perfectly so), indicating that collectively bank EWS are able to inform markets, and do.

Simon (1955) argues that people (investors) can only make rational decisions to the extent that they have access to information and the computational capacities to make sense of the information they have. In terms of market efficiency, insiders and bank regulators will have better access to information than outside investors, and since they are forbidden to trade on this inside information, markets can at best be semi-strong from efficient. Per Simon (1955), better information and better computational models will result in more rational decisions, and therefore more efficient markets.

Arora, Barak, Brunnermeier, and Ge (2010) show that the proper pricing of financial instruments (derivatives) can be so computationally inefficient as to bound or limit market efficiency. Maymin (2011) shows that if $\mathrm{P}=\mathrm{NP}$, meaning that every computational problem whose solution can be verified in polynomial time can also be solved in polynomial time, markets must be at least weak form efficient. He also argues that if $\mathrm{P} \neq \mathrm{NP}$, then markets cannot 
be weak form efficient (though questioned by this researcher, he modified this to "if $\mathrm{P} \neq \mathrm{NP}$, then markets cannot be proven to be weak form efficient.") He argues that information is accumulating faster than computational power, and so markets will become more inefficient as time goes on. Applied to the problem of bank EWS, this would mean we could not be sure our model is perfectly efficient without trying every possible permutation and every possible alternative model. Even if we somehow stumbled on the perfect model, we couldn't prove that we had, and lacking such proof, it would not be universally accepted, so could not completely inform the market, and therefore the market would remain inefficient, and the model should earn abnormal profits on a risk adjusted basis.

\subsection{Winner and Loser Portfolios, and Market Efficiency}

An efficient market is one in which prices always "fully reflect" available information (Fama 1970). Following Fama's terminology, $\Phi_{\mathrm{t}}$ is used to symbolize the set of information that is "fully reflected" in the price of a stock at time t. If the conditions of market equilibrium can be stated in terms of expected returns and equilibrium expected returns are formed on the basis of $\Phi_{\mathrm{t}}$, then trading systems based only on $\Phi_{\mathrm{t}}$ cannot have expected profits or returns in excess of equilibrium expected profits or returns, or markets are not efficient. Mere disagreement among investors about the implications of $\Phi_{t}$ does not imply market inefficiency, but the existence of investors who can consistently make better evaluations of available information than are implicit in market prices does.

Jensen (1978) modifies this definition of efficient markets by noting that a trading rule would have to produce "economic profits" or a "risk adjusted return[s] net of all costs." Fama (1991) interprets this to mean that prices reflect information to the point where the marginal benefits of acting on information (the profits to be made) do not exceed the marginal costs. 
Berkowitz, Logue and Noser (1988) estimate the total transaction costs average 23 basis points measured against the principal value of trades.

Alexander (1961) postulates that information would diffuse through the market causing prices to follow a trend which could be recognized by a trading rule that would filter out noise. His rule calls for going long a stock if its price goes up $\mathrm{x} \%$ and holding it until it subsequently drops the same percentage at which time the stock would be shorted and the position maintained until stock goes up x\%. Fama and Blume (1966) point out that Alexander ignores the effect of dividends on short sales and of transaction costs on all sales.

King (1966) improves on the work of Alexander (1961) in two ways. First, he includes the effect of dividends on short sales. Second, and more importantly, he recognizes that new information will affect the value of more than one stock so price changes are correlated across stocks. He uses a portfolio of 63 stocks from the NYSE and finds that about $31 \%$ of individual stock price change is explained by market movement and an additional $10 \%$ of total variance is explained by industry affiliation.

Levy (1967) creates a precursor to the winner and loser portfolios of Beaver and Landsman (1981) by using percentage changes in stock prices to rank them and then looks for serial correlation in the ranks to determine if the relative strength of a stock's performance persists over time. Levy feels that using relative ranks would filter out market and industry effects. Unfortunately, he does not check to see if his results are due to differences in risk.

Beaver and Landsman (1981) create the first research design using "winner" (whose risk adjusted abnormal (called residual in the paper) returns are systematically positive in the months prior to selection) and "loser" (whose risk adjusted abnormal returns are negative in the prior months) portfolios formed "directly and exclusively on the residual return behavior." They do so 
by using the market model to estimate $\alpha$ and $\beta$ for each security over 60 months and then compute abnormal returns by comparing expected and actual returns over the following 12 months. They use these to form the stocks into winner and loser portfolios. Setting the month of portfolio formation as $\mathrm{t}=0$, they compute the risk adjusted abnormal returns for each stock in each portfolio from $t=-19$ to $t=20$ using the market model. The portfolio abnormal return is the equally weighted mean of the excess return of the stocks in the portfolio, implicitly requiring the rebalancing of the portfolio each month. These average abnormal risk adjusted returns are summed to find the Cumulative Average [abnormal] Return (CAR).

Chan (1988) finds that DeBondt and Thaler (1985), whose work is based on the winner/loser portfolios of Beaver and Landsman (1981), fail to account for variation in the systematic risk of the winner and loser stocks. For a variety of reasons (see Chan (1988), page 150), loser stocks naturally tend to become more risky, for example, as stock price falls, if the firm does not rebalance debt, debt becomes a larger part of its capital structure which increases the risk of the firm. At the same time, and for similar reasons, winner stocks tend to become less risky. This failure to account for time varying risk premia as measured by $\beta$ causes their results to overstate the potential returns to contrarian strategies. Chan uses the market model to find winner and loser portfolios but then uses CAPM to test for abnormal returns in the resulting portfolios.

Beaver and Landsman (1981) and DeBondt and Thaler (1985) use $\beta$ estimated during the selection phase of portfolio formation to determine the expected return during the test period, but Chan (1988) argues that the market risk of the firm is likely to change and so estimates $\beta$ during the test period, assuming that the $\beta$ measured over that period is the mean of the actual time varying $\beta$ during the period. He calculates a self-financing arbitrage portfolio (loser - winner) 
which consists of long positions in the losers and short positions in the winners (since he assumed reversion to the mean). Chan finds that losers are less risky (smaller $\beta$ ) than winners during the rank period but become more risky than winners after portfolio formation, ie in the test period.

Chopra, Lakonishok and Ritter (1992) find that loser stocks tend to have lower capitalizations than winner stocks, and since Banz (1981) found that smaller stocks have higher risk adjusted returns, Chopra et al (1992) adjust for both size and time varying beta and still find an economically-important overreaction effect.

Kothari, Shanken, and Sloan (1995) and Kothari and Shanken (1999) find that size and beta are necessary to explain returns, but while statistically significant, size provides little economic benefit. They also find that book to market as used by Fama and French $(1992,1993)$ has little explanatory power and its seeming explanatory power came from selection bias, data mining and is period specific to the Fama French data. Jegadeesh and Titman (2001) revisit their 1993 work using both CAPM and the Fama French three factor model to adjust returns for risk and find that the Fama French model returns slightly higher risk adjusted returns in momentum portfolios.

\subsection{Two-Factor Model}

Merton (1973) believes that the CAPM is used, despite its proven theoretical and empirical flaws, because it is easy to understand and does explain much of the variation in asset returns. He proposes an extension of the CAPM, the Intertemporal CAPM which shows that investors are rewarded for bearing market risk and the risk of unfavorable shifts in the investment opportunity set, which is associated with, and therefore can be proxied by, changes in the interest rate. Stone (1974) takes a more direct approach and proposes a two factor model with 
the usual stock market index and a well diversified bond index for interest rate risk. Lloyd and Shick (1977) provide some support for Stone's 2-factor model, though they use a different, unmanaged, bond index and use a different correction for multicollinearity (though they found correcting for multicolinearity does not affect the results of their study). However, Chance (1979) shows that Lloyd and Shick probably use bad data and bad statistical methods. He finds no support for Stone's 2-factor model in his study.

Lynge and Zumwalt (1980) revisit Stone's 2-factor model using a different data set, different bond index, and different correction for multicollinearity between the stock and bond indexes and find that the addition of the bond index provides greater explanatory power than a 1factor equity model (CAPM). Fogler, John and Tipton (1981) propose a 3 factor model with two bond indexes, one of 3-month U.S. Government bonds and the other of corporate bonds. They argue that the usual correction for multicolinearity, orthogonalization, does not add to the explanatory power of the model and the choice of variables to be orthogonalized is arbitrary, and so they do not orthogonalize any of the indexes. They find that most of the variation in stock returns is explained by the market variable with some additional influence by the government bond index, but that the corporate bond index does not provide any additional explanation of the stock returns.

Flannery and James (1984) test Stone's 2 factor model using 1-year Treasury Bills, 7year Treasury Bonds, and 8\% Government National Mortgage Association (GNMA) bonds. They use only US government or government agency issued bonds to insure that only interest rate risk is being captured by the bond data, and not changes in risk premia. Supporting Fogler et al (1981), they find no significant value in orthogonalizing the data series. In addition, they examine the effect of anticipated changes in interest rates by replacing the raw bond returns with 
the residuals from an $\mathrm{AR}(3)$ autoregressive model. They find that the returns on bank stocks are highly correlated with interest rate changes, supporting Stone's 2-factor model, and that using unanticipated interest rate changes, as opposed to raw interest rate data, does not produce superior results. Like Flannery and James (1984), Kane and Unal (1988) find that using unorthogonalized, unadjusted (ie not estimated) holding-period returns for long-term government bonds provides the greatest explanatory power when used in Stone's 2-factor model. They also find that the betas for both the market and bond indexes change over time, suggesting the need to re-estimate them over time.

Subsequent researchers either try to improve on Stone's basic 2-factor model or to identify the underlying factors that make the return on bank stocks dependant on interest rates. Kwan (1991) tests the hypothesis that bank stocks are sensitive to interest rate changes due to the mismatch between the duration of their assets and liabilities. He finds that this is so for a bond index using short term government bonds, but when a long-term government bond index is used, bank stock returns are affected only by the stock market index and the bond index, not the gap between asset and liability duration. Kwan finds no advantage to orthorgonalizing the indexes, but does use an $\mathrm{AR}(3)$ model to estimate the impact of unanticipated changes in interest rates. Dinenis and Staikouras (1998) find that the choice of bond duration does not matter, but that the affect is greater during periods of high interest rate volatility. They do orthogonalize their indexes and use the change in rates, but do not check to see if this affects their results. Fraser, Madura and Weigand (2002) orthogonalize the market index and estimate the unexpected component of the change in interest rates. They find that the magnitude of a bank stocks' reaction to interest rate changes is stable and independent of the size of the bank. In summarizing the research in this area, Staikouras $(2003,2006)$ finds that four factors seem to explain the 
sensitivity of bank stock returns to changes in interest rates: “(a) the intermediary's balance sheet mix, (b) the direction of interest rates, (c) the volatility of interest rates, and (d) inappropriate/non-existent off-balance sheet hedging platforms."

\subsection{The Contribution of this Dissertation to the Literature}

This research adds to the literature in six important ways. First, statistical models that attempt to identify problematic banks span the range of statistical methods from simple factor analysis to complex, nonparametric techniques requiring intricate programming and sophisticated data manipulation. Each model claims the power to identify problematic banks, and a few of the studies attempt to demonstrate that their new method is an improvement over some previous methods. However, none of the researchers compare their models to a universal objective standard, such as the power of markets to discern which banks are most likely to fail. This dissertation is the first research comparing archetypical bank failure models to a universal objective standard: the power of markets to discern which banks are most likely to fail.

Second, using this universal objective standard allows us to determine which models work best and if newer, more complex models perform better than their simpler predecessors. I examine model performance using two measures: their ability to correctly predict the three publicly traded commercial banks that failed during the study period as well as their ability to form portfolios that can outperform a naïve all bank strategy, both adjusted and unadjusted for risk.

Third, this study is the first long term study (24 years, from 1986 through 2009) of these models using a modern dataset. This is especially instructive during the financial crisis of 2008 as this is the first study to examine the use of many of these models during such a chaotic and potentially unpredictable time. 
Fourth, it is necessary to construct a unique dataset for matching failed banks to nonfailed banks for those models that require a priori identification of failed banks and matching them to nonfailed banks because the period under study includes a long period of time when relatively few bank failures occurred. This is done by accumulating data over the entire period (see section 4.2 for more on the matching method used). For this method to work, the parameters used in the studies must be stable over time, that is, if a ratio of 1:5 for net income to total assets is associated with a nonfailed bank while a ratio of $1: 10$ is associated with a failed bank, this ratio must be relatively stable over time for this accumulation method to work. Thus, in the later years of this study, the predictive power of the models is a joint test of the model and this method of applying the model during times of limited numbers of bank failures, as well as a test of the stability of key factors that may predict bank failure, which is the fifth contribution of this research to the literature.

And finally, by testing the power of these models to create trading rules which might be able to beat the market on a risk adjusted basis, this research lends significant support to the efficient market hypothesis after 1994. 


\section{Methodology}

\subsection{Portfolio Formation}

Given the purpose of this research, I decided that the models studied should be mature, that is, they should be regularly used by researchers as tools to study banks rather than the model itself being the focus of research, which would imply that the model is still under development. The models studied include logit analysis as typified by Martin (1977), MDA as typified by Pettway and Sinkey (1980), Cox PHM as typified by Lane et al (1986), trait recognition as typified by Kolari et al (2002), and robust regression as typified by the LOESS regression used by Kimmel et al (2010).

I use the these five statistical models as trading rules to form zero cost portfolios, long winners and short losers, accounting for the effect of dividends on short sales. Portfolio formation lags the end of the quarter by 2 months to allow dissemination of the quarterly reports to investors. The portfolios are adjusted for risk using the CAPM, and as a robustness check, by using Stone's (1974) two-factor model using unorthogonalized, unadjusted holding-period returns for an index of long-term government bonds. Betas are estimated using a rolling 24 month estimation period to avoid parameter shifts. Portfolios are equally weighted so that the focus is on the model's ability to predict poor performance rather than on the market capitalizations of the stocks in each portfolio. Returns are calculated on portfolios that are rebalanced each quarter which eliminates survivor bias. The risk adjusted returns on the arbitrage portfolio and its long and short components are compared to risk adjusted returns on a long portfolio of all banks in the sample. If the models allow investors to "consistently make better 
evaluations of available information than are implicit in market prices" (Fama 1970) we will have shown that markets are inefficient.

\subsection{A Portfolio Formation: logit analysis based on the work of Martin (1977)}

Martin (1977) uses an ex-post empirical model in which banks are grouped into failed and non-failed categories which are used as the dependent variable in a logit regression. Failure is defined as the occurrence of failure, supervisory merger or other emergency measure to resolve an imminent failure situation within two years of the statement year to which the financial ratio data apply. Characteristics (the independent variables of the logit regression) of the failed group one or more years before the failure are compared to the same characteristics of the non-failed group and used to predict future failure by examining these characteristics in future periods. The independent variables are drawn from a set of 25 financial ratios found by earlier studies to be useful as early warning indicators.

The population, $\mathrm{N}$, is defined as all banks which are members of the Federal Reserve (FED) System and the number of failed banks in the estimation period is denoted $\mathrm{n}$. A bank is assigned to the failed bank group if its estimated probability is higher than $\mathrm{n} / \mathrm{N}$, that is if it has a greater than equal probability of failure. The likelihood ratio index (LRI) and Akaike Information Criterion (AIC) are used to select the combination of variables that best fit the given data set. The model works best when using estimates from periods of the business cycle when bank failures are more common. This will tend to overestimate failure during times of low rates of bank failure, but "the relative weights of different characteristics will be based on their objective contribution to risk rather than the subjective weights currently used in rating banks." 
Using 1974 data, Martin (1977) finds that a constant, net income/total assets, gross charge-offs/net operating income, commercial loans/total loans, and gross capital/risk assets provide the best fit (see Table: 1 Martin (1977)).

\subsection{B Portfolio Formation: discriminant analysis based on the work of Pettway and Sinkey (1980)}

Pettway and Sinkey (1980) use a two-variable MDA classification model (the model is described more completely in Sinkey (1979)). A sample of distressed banks (33 large banks that failed between 1970 and 1975) is compared to a paired sample (based on deposit size, number of branches, and location) of healthy banks (note that in his 1979 paper Sinkey recommended using a random sample to match with the failed banks rather than the paired sample he used in the 1980 paper. He offers no reason for this in the 1980 paper). The two variables used are given in Table 2: Pettway \& Sinkey (1980), as are the variables used to match failed banks to healthy banks.

Coefficients are calculated during a classification period and then applied in the test period to calculate the probability that a bank belongs to each group (failed and non-failed). While MDA would theoretically work with banks of any size, Pettway and Sinkey (1980) focus on "giant" banks which they define as having total assets greater than $\$ 1$ billion and "large" banks with assets greater than $\$ 100$ million and only validate their model using 6 of the largest banks ever to have failed as of the date of their research. 


\subsection{Portfolio Formation: Cox proportional hazard model based on the work of Lane et al (1986)}

The PHM used by Lane et al (1986) is a semiparametric model that does not require distributional assumptions for the estimation of the baseline hazard function or probability that an average bank will fail ${ }^{5}$. The model is designed to predict the probability that a bank that was "alive" at time $t$ will fail in the next instant. In this way, the model can not only predict which banks are likely to fail, but it can provide an estimate of the probable time to failure.

The probability that a bank will fail an instant after time $t$ given the state of certain explanatory variables is called the hazard function and is denoted by

$h(t \mid z)=\exp \left(\beta^{\prime} z\right) h_{0}(t)$

Equation 1

where $z$ are the explanatory variables, $\beta$ is a vector of their regression coefficients, and $h_{0}(t)$ is the hazard of an average bank at time $t$.

Like MDA, PHM requires matching samples of failed banks to nonfailed banks, but unlike Pettway and Sinkey (1980) who match one failed bank to one nonfailed bank, Lane et al (1986) match each failed banks with one to ten nonfailed banks resulting in a sample of 130 failed banks and 334 nonfailed banks. The matching is based on geographic location, charter status (state or national), size (total assets, the match must not be more than twice its size), holding company affiliation, and age. A set of 21 ratios are used in the classification phase (see Table 3: Lane et al (1986) for a listing of the variables). Data for each variable is gathered for each bank as of December 31 for one and two years before the sample banks failed, resulting in two data sets. For a nonfailed bank, the censored survival time is defined as the number of

\footnotetext{
${ }^{5}$ The Cox PHM does require a multiplicative relationship between the underlying hazard function and the loglinear function of the covariates (the proportionality assumption). This assumption does not hold for ratio 11 (log total capital/total assets) in our dataset. Lane et al (1986) acknowledge the problem but dismiss it saying, "even if the assumption of constant ratios is not valid for these data, the Cox model based on this assumption still provides useful results."
} 
months from the data reporting date to the end of the year in which its matched bank failed. A stepwise procedure combining forward and backward elimination is used to determine which combination of explanatory variables provides the best fit with the data.

In the test phase, the betas from the classification phase are used to calculate the probability that a particular bank will survive for longer than $t$ months. Betas from the one year before data set are used to predict the likelihood of failure (1 - probability of survival) within 12 months and betas from the two year data set are used to predict the likelihood of failure between 12 and 24 months. If the likelihood of failure is greater than some cutoff value, $\mathrm{C}$, then the bank is classified as likely to fail and "healthy" otherwise. As in the logit procedure of Martin (1977), this value is set as the percentage of failed banks in the sample during the classification phase. The model is validated using a holdout sample of 137 banks.

\subsection{Portfolio Formation: trait recognition ${ }^{6}$ based on the work of Kolari et al (2002)}

Trait recognition is a nonparametric model and so does not rely on statistical or distributional assumptions about the predictor variables. "Building a trait recognition model is a multistep procedure that involves: (1) selecting cutpoints for each of the variables, (2) binary coding of the variables, (3) constructing a trait matrix for each observation, (4) identifying good and bad traits (or distinctive features), and (5) implementing voting matrix classification rules." Cutpoints are set for each independent variable to divide the range of values into thirds based on variance. The middle range or segment is defined by $+/-1$ standard deviation from the

\footnotetext{
${ }^{6}$ Software was provided by Dr. Kolari: TRAITS V7.0

Written by: Matthew B. Butler, modified by: Rajneesh Khanna, modified by: Hwan Shin (classification for original run) Original programs by: Dr. James W. Kolari, Drew L. Wagner

This software is copyrighted. It may not be used in whole or in part for any reason without the express permission of the owners. All copying by electronic medium or hard copy is strictly prohibited by law. All violations are subject to legal action. COPYRIGHT BUTLER/KHANNA/KOLARI/WAGNER 1996 ALL RIGHTS RESERVED

Documentation: User's Manual to Traits V2.0, Written By: Rajneesh Khanna, Modified By: Hwan Shin

Fortran used provided by the Free Software Foundation GNU project with help from Dr. Roumani of York University.
} 
mean with the lower and upper ranges defined accordingly. These segments are coded 00, 01, and 11 respectively for the lower, middle, and upper segments. To capture the interaction between variables, traits are composed of groupings of three variables. Each trait is coded as a vector of 6 digits, two for each variable, that represent the variable and the range (lower, middle, or upper). A search routine is used to cull traits that do not help to discriminate between failed and nonfailed banks. The remaining traits that do help are called features. Features are grouped depending on whether they are associated with failed (unsafe) or nonfailed (safe) banks. The number of safe and unsafe features for each bank is tallied and this tally is used to place it into a voting matrix. Finally, rules for determining which cells in the voting matrix are safe and unsafe, determined by whether each cell is dominated by failed or nonfailed banks, are developed during the classification period and applied during the prediction period.

Kolari et al (2002) validate their model using large banks which they define as having total assets greater than $\$ 250$ million providing a sample of just over 1,000 banks each year during the prediction phase.

\subsection{E Portfolio Formation: robust regression based on the work of Kimmel et al (2010)}

Unlike the other models in this study, the robust regression model used by Kimmel et al (2010) does not require the a priori identification of failed banks and so does not require a classification phase to determine which levels of the predictor variables are associated with failure or nonfailure.

In this nonparametric model, the 46 largest (in terms of total assets) banks are ordered by total assets under the assumption that banks of a similar size should be similar in other respects, specifically in terms of total loans (TL), net income (NOI), net loan losses (NLL), and loan loss provision (LLP). Four models are evaluated using LOESS (Locally Weighted Scatter Plot 
Smooth, a type of Local Regression Smoothing):

Model $1: Y X^{-1 / 2}=\beta_{0} X^{-1 / 2}+\beta_{1} X^{1 / 2}$

Equation 2

Models 2, 3, \& 4: $Y X^{-1}=\beta_{0}$ Case

Equation 3

where Case is the observation number identifying each bank in the original dataset and the variables are as defined in Table 5: .

Kimmel et al (2010) find that a smoothing parameter of 50\% and a first degree polynomial works well in the LOESS regressions. The residuals from the regressions are inspected to determine if the bank is a potential problem. "Bad" is determined in the following manner. For models 1 and 2, problem banks are expected to have negative residuals, indicating they are not utilizing their total assets to earn net income as efficiently as other banks. For models 3 and 4, problem banks are expected to have positive residuals indicating they have high net loan losses (or high loan loss provisions) as a percentage of total loans and high net loan losses (or high loan loss provisions) compared to total assets respectively. In validating their model, Kimmel et al (2010) conclude that the model is successful if the problematic bank is one of the 5 banks with the largest (absolute value) "bad" residuals. Model 1 is the most adept at detecting the problematic banks and is the one used in this study.

\subsection{Model Evaluation}

Three statistics are used to judge the effectiveness of the models. The first is to determine whether the model is able to predict the failure of each of the 3 publicly traded commercial banks that failed during the period, and if so, by how many years before failure the model is able to flag the bank.

The second method used to evaluate the effectiveness of the models is the risk adjusted Cumulative Abnormal Return using both the CAPM and Stone 2-factor models. The normal 
return is defined as the expected return without conditioning on the events taking place. For firm $i$ and date $t$ the abnormal return is

$$
A R_{i \tau}=R_{i \tau}-E\left(R_{i \tau} \mid X_{i \tau}\right)
$$

Equation 4

where $A R_{i \tau}, R_{i \tau}$, and $E\left(A R_{i \tau} \mid X_{i \tau}\right)$ are the abnormal, actual, and expected returns respectively for time period $\tau$.

The CAPM and Stone 2-factor models are econometric models which relate the return of any given security to the return of the market portfolio, and for the Stone 2-factor model, to an index of bond returns. The model's linear specification follows from the assumed joint normality of asset returns. For any security $i$ the market model is

$R_{i \tau}=\alpha_{i}+\beta_{i} R_{m i}+\varepsilon_{i \tau}$ Equation 5 where $E\left(\varepsilon_{i \tau}\right)=0$ and $\operatorname{var}\left(\varepsilon_{i \tau}\right)=\sigma_{\varepsilon_{i}}^{2}$ for the CAPM and $R_{i \tau}=\alpha_{i}+\beta_{m i} R_{m i}+\beta_{b i} R_{b i}+\varepsilon_{i \tau}$ Equation 6 for the Stone 2-factor model where $R_{i \tau}$ and $R_{m \tau}$ and $R_{b i}$ are period $\tau$ returns for security $i$, the market portfolio, and a bond index respectively, and $\varepsilon_{i \tau}$ is the zero mean disturbance term. The Center for Research in Securities Prices (CRSP) NYSE/AMEX/NASDAQ equally-weighted stock index is used for the market portfolio.

To avoid problems with cross correlations due to clustering, the abnormal return observations are aggregated into equally weighted portfolios in order to draw overall inferences for the event of interest (Bernard 1987). The aggregation is along two dimensions - through time and across securities. The return for the portfolio will be

$$
R_{p t}=\frac{1}{N} \sum_{i=1}^{N} R_{i t}
$$


The expected return on the portfolio is determined by regressing the portfolio return on the return for the market and estimating the parameters:

$R_{p t}=\hat{\alpha}+\hat{\beta}\left(R_{m t}\right)+\varepsilon_{t}$

Equation 8

for CAPM and

$R_{p t}=\hat{\alpha}+\widehat{\beta_{m}}\left(R_{m t}\right)+\widehat{\beta_{b}}\left(R_{b t}\right)+\varepsilon_{t}$

Equation 9

for the Stone 2-factor model during the estimation period. The abnormal return compares the return on the portfolio with the expected return given these parameters:

$A R_{p t}=R_{p t}-\hat{\alpha}-\hat{\beta}\left(R_{m t}\right)$

Equation 10

for the CAPM and by

$A R_{p t}=R_{p t}-\hat{\alpha}-\widehat{\beta_{m}}\left(R_{m t}\right)-\widehat{\beta_{b}}\left(R_{b t}\right)$

Equation 11

for the Stone 2-factor model. The Cumulative Abnormal Return for the portfolio is then

$C A R=\sum_{t=1}^{T} A R_{p t}$

Equation 12

To test the hypothesis that the $\mathrm{CAR}=0$ we use the test statistic

$\Phi=C A R /\left[\sigma^{2}\left(A R_{\tau}\right) / T\right]^{1 / 2}$

Equation 13

where $\mathrm{T}$ is the number of months in the period of study. Rejecting the null hypothesis in favor of positive cumulative abnormal returns indicates the model is able to beat the market. In addition, if the portfolios created using the models are able to outperform a naïve strategy of going long all publicly traded commercial bank stocks, it demonstrates that the models have predictive power and can inform markets. The ability of the models to beat the naïve strategy is given by Perf $\mathrm{CAPM}_{\mathrm{C}}$

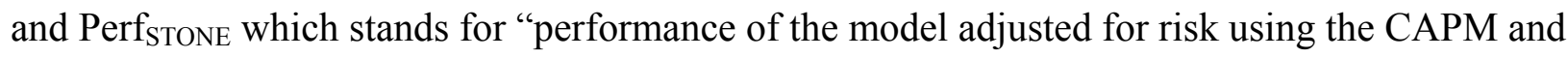
Stone 2-factor model" respectively. Performance is defined as the cumulative abnormal return on the portfolio formed using the model minus the cumulative abnormal return on the naïve all bank 
portfolio. The test statistic used here is

$$
t=\frac{C A R_{p}-C A R_{n}}{\sqrt{\frac{\sigma_{p}^{2}}{N_{p}}+\frac{\sigma_{n}^{2}}{N_{n}}}}
$$

Equation 14

where $C A R_{n}$ and $C A R_{p}$ are the cumulative abnormal returns on the naïve and model determined portfolios respectively and $\sigma^{2}$ is the variance of the returns.

The third method used to evaluate the effectiveness of the models is to compare the total return on a portfolio of all publicly traded commercial banks (the naïve strategy) to the return on winner, loser, and long-short portfolios formed by the models in question. Performance is defined as the total return on the on the portfolio formed using the model minus the total return on the naïve all bank portfolio. If the returns on the portfolios formed by the models are significantly different (greater than) from the naïve strategy, the models must be able to inform markets. The test statistic used here is

$t=\frac{R_{p}-R_{n}}{\sqrt{\frac{\sigma_{p}^{2}}{N_{p}}+\frac{\sigma_{n}^{2}}{N_{n}}}}$

Equation 15

where $R_{n}$ and $R_{p}$ are the returns on the naïve and model determined portfolios respectively and $\sigma^{2}$ is the variance of the returns. 


\section{Data}

\subsection{Data Description}

The Chicago branch of the FED maintains two databases of bank related information, one for commercial banks and the other for bank holding companies. Bank holding companies may own one or more commercial banks as well as nonbank affiliates. The commercial bank database has data from 1976 while holding company data is available beginning with 1986 and does not contain as many variables as the commercial bank database. In order to facilitate research using these databases, the New York branch of the FED maintains a database matching the FED's identification number for each bank or bank holding company to the PERMCO number used by CRSP. The commercial bank database contains information on 86 publicly traded banks, while the holding company database contains information on 800 publicly traded institutions. Unfortunately, not every institution reports on each variable each quarter, so some data is missing, reducing the effective sample size for some of the models. The data used from these databases are specified for each model in Tables 1 though 5. Basic summary statistics for this data is presented in Table 8: Commercial Banks, FED database and Table 9: Bank Holding Companies, FED database.

Only the commercial bank database is used in this research. One of the main goals of this research is the development of a market-based test of the effectiveness of the bank EWS's, and this requires that the accounting data used as inputs into the models reflect the performance of the bank's stock. The publicly traded banks in the commercial database are pureplay banks, while multibank holding companies commonly engage in nonbank activities and "crosssubsidy' policies whereby [they] provide credit support for other members" (Curry et al 2007). 
In addition, since commercial banks are smaller than some of the largest bank holding companies, "Too Big To Fail" policies will not affect the outcome. Finally, the number of BHC that fail between 1986 and 2008 average less than three per year, while for commercial banks, the average is 54 per year during the same period.

Data on bank failures come from the Federal Deposit Insurance Corporation (FDIC) and are summarized in Table 7: FDIC Bank Failures 1986 Through June 2010. Most failures of commercial banks occurred between 1986 and 1992, averaging over 100 per year. The rate of failure then fell off, averaging less than three a year until 2009 when 19 commercial banks failed with another 10 failing in the first half of 2010. For commercial banks affiliated with a BHC, the number of failures remained fairly steady up until 2008, averaging less than three per year between 1986 and 2008, then rising to 18 in 2008, 111 in 2009, and 63 in the first half of 2010. Of special interest are the three publicly traded commercial banks that fail during the study period: the Bank of San Pedro which failed July 15, 1994, the Fairfield Bank which failed July 12, 1996, and the City Bank of Lynnwood which failed April 16, 2010 (see Table 12).

Monthly stock prices and returns, both adjusted and un-adjusted for dividends, are obtained from CRSP. Summary statistics for this data is presented in Table 10: CRSP Data for Commercial Banks. The CRSP index of constant maturity Treasury bonds is used to obtain yields on 20 year government bonds and the CRSP Fama Risk Free database provides risk free rates based on the average prices of 3 month T-bills. Summary statistics for these variables are presented in Table 11: Yields.

\subsection{Matching}

All of the models used in this research, with the exception of the Kimmel et al (2010) LOESS model, require a priori identification of failed banks and matching (except the Martin 
(1977) Logit model which does not require matching) these failed banks to non-failed banks to complete the training phase of the model. Since the goal of this paper is to use the stock market to measure the effectiveness of the models in predicting problematic or underperforming banks, and to ensure that failure is the result of bank related activity or conditions, only publicly traded pure play (not part of a larger holding company that may have non-bank components) commercial banks are used in the classification and prediction phases, however, because of the relatively small number of such banks, especially ones that fail during the study period (see Table 7), all failed commercial banks, whether publicly traded or not, are used in the training phase. Because this sample differs significantly from those used in the original model research, the matching method has to be modified, and is subsequently standardized across all models in this research.

Matching loosely follows Lane et al (1986). Matching is done utilizing fourth quarter, yearend results. Each failed bank is matched with up to 3 non-failed banks based on the highest point score from a formula that gives 70 percent weight to banks of similar total assets (with a maximum 2:1 ratio), 20 percent weight to banks of similar age, and 10 percent weight to banks headquartered in the same state. Banks from prior years are added to the current year for training purposes resulting in an increasing number of banks in the training sample each year, up to 978 failed and 392 non-failed banks. Training of the models is done each year. This aggregation is necessary due to the scarcity of failed banks during most of the period under study, especially during the mid 2000's (see Table 7). Without aggregation, training could not be done every year as there are several years without a single failure, and there are many more when the number of failures is in the single digits. 
The result is a training sample that compares favorably with those used in much of the literature. The sample begins in 1986 with 102 failed banks matched to 34 nonfailed banks, and after aggregation, ends up with 978 failed and 392 non-failed banks in 2008. Meyer and Pifer (1970) use a sample of 30 matched banks, less than 2 failures per year of their study. Sinkey $(1974,1975)$ uses 110 matched banks or an average of 16 failures per year. Pettway and Sinkey (1980) use 66 matched banks for an average of 11 failures per year. Kolari et al (2002) use a sample with 55 bank failures or 14 per year on average. Curry et al (2007) use a database of commercial and savings banks with a combined average rate of 11 failures per year.

\subsection{Merger activity}

It is possible that some of the many mergers that occurred during the study period among non-failed publicly traded commercial banks were in fact on the verge of failure and the merger was forced by the bank's regulator as a less costly alternative to declaring the bank a failure. Such hidden failures would reduce the models' ability to differentiate between failed and nonfailed banks. To see if such hidden failures explain some of the merger activity in the data set used, FDIC records are used to determine if the merger occurred "with assistance" of the regulator and if any enforcement actions had been taken against the bank. In addition, both local and national news articles are checked for stories about the merged banks for a period of 2 years prior and 1 year post merger and negative articles are tabulated. Table 6 shows that of the 89 publicly traded commercial banks that existed at some time during the study period, 61 merge and 28 do not. Only 3 merge with regulator assistance, all of which have FDIC enforcement orders and bad press in advance of the merger. Of the 57 that merge without assistance, only 18 $(32 \%)$ have FDIC enforcement orders and $3(5 \%)$ have bad press in advance of the merger. This compares with 8 (29\%) banks with FDIC enforcement orders that do not merge. Most merged 
banks have no FDIC enforcement orders or bad press reports before their merger, and since the percentage of banks with FDIC enforcement orders is about the same between banks that have and have not merged, it seems unlikely that the "unassisted" mergers were forced by the bank's regulator. A more likely explanation for the high number of mergers is the consolidation going on in the banking industry during the period. For this research, only banks merged with overt FDIC assistance are considered to have failed. 


\section{Empirical Results}

All of the models used in this research require some exercise of judgment on the part of the researcher to "tune" the model to produce acceptable results. This is sometimes a matter of using past experience to determine that the 5 banks with the most negative residuals will be deemed troubled instead of the worst 4 or 6 banks, as with the LOESS model of Kimmel et al (2010). At the other extreme, the trait recognition model of Kolari et al (2002) requires input at several stages of the analysis which can alter not just the number of banks deemed troubled, but also their relative ranking. In every case, I follow the original researchers as far as possible, making changes only when the model failed to produce reasonable results, ie flagging all banks as either troubled or non-troubled. When changes are made, they are made without back tracking. If changes are made using 2001 data to predict 2002 failures, no changes are made based on the success of the model in predicting actual failures in 2002 as an investor in 2001 would not be able to do this. As a result, different judgments on the part of the researcher might produce different results than those obtained here, but these results reasonably reflect what an investor might have done using these models to select a portfolio of bank stocks. In addition, because sample selection for both training and prediction is driven by the scarcity of publicly

traded commercial banks, especially of failed publicly traded commercial banks, the sample used here differs significantly from that used by any of the original researchers in developing their models.

Three statistics are used to judge the effectiveness of the models. The first, given in Table 12: Prediction Success by 1 Year and 2 Year Ahead Models, shows whether the model is able to predict the failure of each of the 3 publicly traded commercial banks that failed during the period, and if so, by how many years before failure it is able to flag the bank. The second is the 
risk adjusted Cumulative Abnormal Return using both the CAPM and Stone 2-factor models. This is compared to both the market as a whole and a naïve strategy of buying all publicly traded commercial bank stocks. The third is to compare the total return (unadjusted for risk) on a portfolio of all publicly traded commercial banks (the naive strategy) to the return on winner, loser, and long-short portfolios formed by the models in question.

\subsection{A Empirical Results: logit analysis based on the work of Martin (1977)}

Table 12 shows that the Martin (1977) Logit model is able to predict the failure of the Bank of San Pedro as early as 1991 using both 1 and 2 year prediction data. The failure of Fairfield Bank is predicted as early as 1990 using both 1 and 2 year prediction data. The failure of the City Bank of Lynnwood is predicted in 2008 by the 2 year model, but missed by the one year model.

Table 13 shows that all of the portfolios, for both the 1 and 2 year prediction models, significantly underperform the market on a risk adjusted basis over the entire period from 1989 through 2009. In addition, the naïve strategy beats every model based portfolio on a risk adjusted basis using both the CAPM (Perf CAPM $_{\text {) }}$ and Stone 2-factor (Perf STONE$)$ models for both 1 and 2 year predictions. However, Figure 1 clearly shows that from 1991 through 1994 the short portfolio does beat both the market and all other portfolios on a risk adjusted basis. Note that while only the figure for the 1 year prediction model using CAPM is shown, the figures of the 2 year model and the models using the Stone 2-factor model are similar.

Table 13 also shows that over the entire period the returns on all of the model based portfolios are significantly different from the naïve all bank portfolio for both the 1 year and 2 year prediction models. The return on the long portfolio is greater than the return on the all bank portfolio while the returns on the short and long-short portfolios (just labeled "portfolio" in the 
table) are significantly lower. As can be seen from Figure 2, most of this difference comes from the post 1994 period. Note that while only the figure for the 1 year prediction model is shown, the figure of the 2 year model is similar.

Table 19 shows that all of the portfolios beat the market during the financial crisis period (2006 through 2009) on a risk adjusted basis (only CAPM results are shown, but results using the Stone 2-factor model are similar), and that the long portfolio is able to outperform the naïve all bank strategy, though the short and long-short (labeled portfolio in the table) portfolios do not. Similar results are seen in unadjusted total returns.

\subsection{B Empirical Results: discriminant analysis based on the work of Pettway and Sinkey (1980)}

Table 12 shows that the MDA model used by Pettway and Sinkey (1980) is one of only 2 models that are able to predict every failure during the study period using both the 1 and 2 year prediction models, and it is able to predict their failure earlier than the other models in almost every case. It is able to predict the failure of the Bank of San Pedro as early as 1988 using 2 year prediction data. The failure of Fairfield Bank is predicted as early as 1990 using both 1 and 2 year prediction data. The failure of the City Bank of Lynnwood is predicted as early as 1994 by the 1 year model and in 2007 by the 2 year model.

Table 14 shows that all of the portfolios, for both the 1 and 2 year prediction models, significantly underperform the market on a risk adjusted basis over the entire period from 1989 through 2009. However, unlike with the Martin (1977) Logit model, figures of the cumulative abnormal return, represented here by Figure 3, the 1 year ahead CAPM CAR, fails to show any period of time where the model is able to beat the market on a risk adjusted basis. In addition, the 
naïve strategy beat every model based portfolio on a risk adjusted basis using both the CAPM $\left(\right.$ Perf $\left._{\mathrm{CAPM}}\right)$ and Stone 2-factor $\left(\operatorname{Perf}_{\mathrm{STONE}}\right)$ models for both 1 and 2 year predictions.

Table 14 also shows that over the entire period the returns on all of the model based portfolios are significantly different from the naïve all bank portfolio for both the 1 year and 2 year prediction models. The return on the long portfolio is greater than the return on the all bank portfolio while the returns on the short and long-short portfolios (just labeled "portfolio" in the table) are significantly lower. As can be seen from Figure 4, most of this difference comes from the post 1994 period. Note that while only the figure for the 1 year prediction model is shown, the figure of the 2 year model is similar

Table 19 shows that all of the portfolios, except the Short portfolio, beat the market during the financial crisis period (2006 through 2009) on a risk adjusted basis (only CAPM results are shown, but results using the Stone 2-factor model are similar), though none of the portfolios are able to outperform the naïve all bank strategy. Similar results are seen in unadjusted total returns.

\subsection{Empirical Results: Cox Proportional Hazard Model based on the work of Lane et al (1986)}

Table 12 shows that the Cox PHM used by Lane et al (1986) is one of only 2 models that completely fail to predict the failure of the City Bank of Lynnwood using both the 1 and 2 year models. It is able to predict the failure of the Bank of San Pedro as early as 1991 using 2 year prediction data. The failure of Fairfield Bank is predicted as early as 1991 using both 1 and 2 year prediction data.

Table 15 shows that all of the portfolios, for both the 1 and 2 year prediction models, significantly underperform the market on a risk adjusted basis over the entire period from 1989 
through 2009. Like the Pettway and Sinkey (1980) MDA model, figures of the cumulative abnormal return, represented here by Figure 5, the 1 year ahead CAPM CAR, fails to show any period of time where the model is able to beat the market on a risk adjusted basis. In addition, the naïve strategy beat every model based portfolio on a risk adjusted basis using both the CAPM $\left(\right.$ Perf $\left._{\mathrm{CAPM}}\right)$ and Stone 2-factor $\left(\operatorname{Perf}_{\mathrm{STONE}}\right)$ models for both 1 and 2 year predictions.

Table 15 shows that over the entire period the returns on all of the model based portfolios are significantly different from the naïve all bank portfolio for both the 1 year prediction models while only the short and long-short portfolios (just labeled "portfolio" in the table) are significant in the 2 year prediction models. The returns on all of the model based portfolios are less than (or the difference is insignificant) that of the naïve all bank portfolio except for the short portfolio using the 2 year ahead prediction model, which earns a slightly higher return (when shorted it produces a negative return). As can be seen from Figure 6, most of this difference comes from the post 1994 period. Note that while only the figure for the 1 year prediction model is shown, the figure of the 2 year model is similar.

Table 19 shows that all of the portfolios, except the Short portfolio, beat the market during the financial crisis period (2006 through 2009) on a risk adjusted basis (only CAPM results are shown, but results using the Stone 2-factor model are similar), and that the long portfolio is able to outperform the naïve all bank strategy, though the short and long-short (labeled portfolio in the table) portfolios do not. Similar results are seen in unadjusted total returns.

\subsection{Empirical Results: Trait Analysis based on the work of Kolari et al (2000)}

Table 12 shows that the Kolari et al (2000) Trait Analysis is one of only 2 models that completely fail to predict the failure of the City Bank of Lynnwood using both the 1 and 2 year 
prediction models. It is able to predict the failure of the Bank of San Pedro as early as 1991 using 1 year prediction data and 1990 using 2 year prediction data. The failure of Fairfield Bank is predicted as early as 1987 and 1986 using 1 and 2 year prediction data respectively.

Table 16 shows that all of the portfolios, for both the 1 and 2 year prediction models, significantly underperform the market on a risk adjusted basis over the entire period from 1989 through 2009. Like the MDA and PHM models, figures of the cumulative abnormal return, represented here by Figure 7, the 1 year ahead CAPM CAR, fails to show any period of time where the model is able to beat the market on a risk adjusted basis. However, the long only portfolio is able to outperform the naïve strategy in the 1 year prediction using both the CAPM

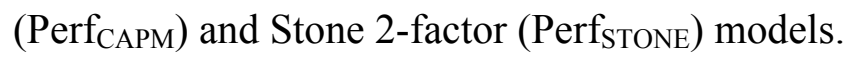

Table 16 shows that over the entire period the returns on all of the model based portfolios are significantly different from the naïve all bank portfolio for both the 1 year and 2 year prediction models. The return on the long portfolio is greater than the return on the all bank portfolio while the returns on the short and long-short portfolios (just labeled "portfolio" in the table) are significantly lower. As can be seen from Figure 8, most of this difference comes from the post 1994 period. Note that while only the figure for the 1 year prediction model is shown, the figure of the 2 year model is similar.

Table 19 shows that all of the portfolios, except the Short portfolio, beat the market during the financial crisis period (2006 through 2009) on a risk adjusted basis (only CAPM results are shown, but results using the Stone 2-factor model are similar), and that the long portfolio is able to outperform the naïve all bank strategy, though the short and long-short (labeled portfolio in the table) portfolios do not. Similar results are seen in unadjusted total returns. 


\subsection{E Empirical Results: LOESS based on the work of Kimmel et al (2010)}

Table 12 shows that the LOESS as used by Kimmel et al (2010) is one of only 2 models that are able to predict every failure during the study period using both the 1 and 2 year ahead prediction models. It is able to predict the failure of the Bank of San Pedro as early as 1991 using 1 year prediction data and 1990 using 2 year prediction data. The failure of Fairfield Bank is predicted as early as 1990 and 1989 using 1 and 2 year prediction data respectively, while the failure of the City Bank of Lynnwood is predicted in 2008 and 2007 respectively.

Table 17 shows that all of the portfolios, for both the 1 and 2 year prediction models, significantly underperform the market on a risk adjusted basis over the entire period from 1989 through 2009. Like the logit model, figures of the cumulative abnormal return, represented here by Figure 9, the 1 year ahead CAPM CAR, clearly shows that from 1991 through 1994 the short portfolio beats both the market and all other portfolios on a risk adjusted basis. In addition, the long-short portfolio (labeled just "Portfolio" in the tables) beats the naïve strategy on a risk adjusted basis using both the CAPM (Perf $\mathrm{CAPM}_{\text {) }}$ and Stone 2-factor models (Perf $\left.\mathrm{PTONE}_{\mathrm{STO}}\right)$ for the 1 year ahead prediction (the long portfolio does as well for the CAPM model, but not for the Stone 2-factor model).

Table 17 shows that over the entire period the returns on all of the model based portfolios are significantly different from the naïve all bank portfolio for both the 1 year and 2 year prediction models. The return on the long portfolio (and the long-short portfolio, just labeled "portfolio" in the table, for the 1 year prediction) is greater than the return on the all bank portfolio while the returns on the short and long-short portfolios (for the 2 year prediction) are significantly lower. As can be seen from Figure 10, most of this difference comes from the post 
1994 period. Note that while only the figure for the 1 year prediction model is shown, the figure of the 2 year model is similar.

Table 19 shows that all of the portfolios beat the market during the financial crisis period (2006 through 2009) on a risk adjusted basis (only CAPM results are shown, but results using the Stone 2-factor model are similar), but that none of the portfolios are able to outperform the naïve all bank strategy. Similar results are seen in unadjusted total returns, except the long portfolio is able to beat the naïve all bank strategy.

\subsection{Robustness}

I conduct two robustness checks to ensure that my results are not an artifact of the methodology employed in this research. In the first analysis, I check to ensure that the matching method does not affect the results by rerunning the analysis for the 19961 year ahead prediction using data for all nonfailed publicly traded commercial banks instead of a matched sample. Table 20 compares the predictions of problematic banks made by each model in the primary research with the prediction made using the "No Matching" sample and the results are summarized in Table 21. The additional data provided by the "No Matching" sample reduces the number of banks flagged as potential problems, but in every case, every bank flagged by the "No Matching" sample is also flagged by the models using a matched sample. In addition, all of the models were able to flag Fairfield Bank, PERMCO 7807, the bank that actually failed in 1996.

In the second robustness check, I seek to determine if the variables originally specified for the models drive the results or if it is the statistical method utilized. I examine the models to find a set of common significant variables. Results from the logit and Cox PHM are examined to determine which variables are consistently statistically significant in the models as originally specified and the results summarized in Table 22. Since MDA and LOESS, as originally 
specified, only use two and one variable respectively, all three variables are utilized in this analysis. It is difficult to isolate significant variables in Trait Analysis because of the complex interaction between variables, so no variables unique to the Kolari et al (2002) specification of Trait Analysis were included in this analysis. The five numbered variables in Table 22 are used in place of the original variables in each model and the analysis for the 19961 year ahead prediction rerun.

The results are shown in Table 20, Table 22, and Table 23. Table 22, in the column labeled "Common", shows which variables, from among the five common ones discussed in the paragraph above, are statistically significant in the Logit and Cox PHM using these five common variables. Surprising, none of the variables used by Lane et al (1986) in their specification of the Cox PHM were significant when combined with the other three common variables, while both significant variables from the Martin (1077) logit model remained significant when combined with the other three common variables.

Table 23 shows that all of the statistical methods, except LOESS, are able to predict the failure of Fairfield Bank. LOESS also has the lowest overlap between the banks predicted to fail using the original specification used by Kimmel et at (2010) and those predicted to fail when all five common variables are used. This is not surprising as earlier research by this researcher has shown the model works best when examining variables one at a time. The other statistical methods were all able to predict the fail of Fairfield Bank and all, except MDA, had a high degree of overlap. Table 20 shows that the relatively poor overlap between the results using original Pettway and Sinkey (1980) specification and the common variables is due to a significant decrease in the number of banks predicted to fail when the five common variables are 
used, but over half of the problematic banks flagged using the common variables are also flagged using the original specification.

Table 20 also shows that there is a high degree of agreement among the statistical methods about which banks are most likely to fail. Using the original specifications, nine banks are flagged as likely to fail by at least three of the models, five banks by four of the models, and three by all five of the models. Using the common variables, ten banks are flagged by at least three of the statistical methods, five banks by four of the methods, and only one bank by all five methods. Results without matching, but using the original variable specifications, produces results similar to the original models with matching.

Table 20 shows that all of the models/statistical techniques using original specifications, common variables, and no matching are able to agree that certain banks are very unlikely to fail with five, five, and 12 banks not receiving a single flag from any of the models/statistical techniques respectively. In between are the majority of banks which are flagged by a model/statistical technique or two. This is most probably noise or type I errors which might be filtered out by using multiple models/statistical techniques. 


\section{Summary}

All of the models do a good job predicting bank failure even though the models are not "back-tuned" and the sampling procedures used in this study differ significantly from those of the original researchers (see sections 4.2 Matching and 5: Empirical Results). Three of the 5 models predict 2 of the 3 failures among the publicly traded commercial banks in the study, while 2 of the models are able to predict all 3 (see Table 12.)

On a risk adjusted basis, the short portfolio is able to outperform the market and all other portfolios during the period from 1991 through 1994 when formed using the Martin (1977) Logit and Kimmel et al (2010) LOESS models for both 1 and 2 year predictions. Over the entire study period, the Kolari et al (2002) Trait Analysis model is able to form a long portfolio that beat the all bank naïve strategy using the 1 year ahead prediction, while the Kimmel et al (2010) LOESS model is able to form a long-short strategy (labeled "Portfolio" in the tables) that beats the naïve strategy using 1 year ahead predictions.

All of the models, with the exception of the Lane et al (1986) Cox PHM, are able to form long portfolios that beat the naïve strategy in terms of absolute total returns for both the 1 and 2 year predictions. In addition, the Kimmel et al (2010) LOESS model is able to form a short portfolio that beats the naïve strategy in terms of absolute total returns using the 1 year prediction.

Table 19 makes it clear that all of the models are able to continue performing during the financial crisis of 2008. The fact that all of the portfolios of all of the models (except the short portfolios of three of the models) are able to beat the market on a risk adjusted basis is probably more a reflection of changes in beta lagging the market because of its rolling 24 month estimation period than a demonstration of predictive power of the models themselves. More 
significant is the ability of the Martin (1977), Lane et all (1986), and Kolari et al (2002) models to beat the naïve all bank strategy with their long portfolios, demonstrating their power to filter out underperforming bank stocks even during this volatile period. The long portfolios of the Martin (1977), Lane et all (1986), Kolari et al (2002) and Kimmel et al (2010) models are also able to beat the naïve all bank strategy on an absolute return basis during the period. This strong showing is somewhat tempered by the failure of the Lane et all (1986) and Kolari et al (2002) models to forecast the failure of the City Bank of Lynwood in 2010. It is interesting to note that during this period, marked by the financial crisis, the stocks of publicly traded commercial banks are able to outperform the market and return 51.8 percent over the period versus a loss of 22 percent for the market (as measured by the CRSP equally weighted index).

From this research, it is clear that all of the models do a good job of predicting bank failure. It is also clear that all of the models, except the Lane et al (1986) Cox PHM, are able to improve the performance of the long portfolio by identifying and filtering out some underperforming stocks (see Figure 12). The returns on the problematic banks, which are formed into the short portfolios, clearly underperform the long and all bank naïve strategy portfolios, though they do not lose value over the study period and so following a strategy of shorting these stocks fails. After adjusting for increases in risk, results are not as favorable (see Figure 11). Only the Kolari et al (2002) Trait Analysis and Kimmel et al (2010) LOESS models are able to produce portfolios that performed better than the naïve strategy over the study period, though the Martin (1977) Logit and Kimmel et al (2010) LOESS models are able to produce short portfolios that beat the market and the naïve strategy on a risk adjusted basis for a 3 year period from 1991 to 1994 . 
These results seem to indicate that the market for publicly traded commercial bank stocks became more efficient after 1994, though even after, the market is not perfectly efficient. This conclusion cannot be explained by the sampling method used in this research as the pattern of returns, both unadjusted and adjusted for risk, is virtually the same for all of the models, even the Kimmel et al (2010) LOESS model, which does not use a training cycle or require matching failed and nonfailed banks and does not depend on the a priori identification of failed banks, and so uses data only from 1 or 2 years prior to the year of prediction.

There is no evidence, under the sampling method used in this research, that more complex or newer models outperform the simpler and/or older models in terms of failure prediction, In terms of identifying underperforming bank stocks, the performance of the Kolari et al (2002) and Kimmel et al (2010) models provide some evidence that newer models outperform older models, but not that more complex models outperform simpler models. Despite significant differences in the composition of the portfolios formed by the various models, the pattern of returns for all of them are remarkably consistent, as shown by Figure 11and Figure 12.The failure of some of the models to predict the failure of the City Bank of Lynnwood in April 2010 could be due to changes in the relative importance of some of the variables used by those models over the period of the study as these are kept constant throughout the study, or it could be caused by the lack of failures among commercial banks during the later years of the study which diminished the sample size for training the models. However, the fact that some of the models are able to predict this failure using the same sampling method and using unchanged variables suggests that these are not significant factors, or that some models are more sensitive to these factors than others. Models which were best able to predict bank failure were not always the best 
able to discern which bank stocks will underperform the market (whether defined as the stock market as a whole or the market for commercial bank stocks). 


\section{Conclusions and Implications}

Using markets as a universal standard to evaluate bank EWS shows that all of the models evaluated in this study produce similar results despite their varying statistical models and wide range of financial variables. It would seem that the use of financial variables influences the results more than the model used. The complexity of the model and the data requirements don't seem to produce consistently better results. The financial indicators used by these models seem to be quite stable over long time periods, allowing the models to work even when there are long periods of time when few bank failures occur. The market for publicly traded commercial banks is quite efficient, though the use of these models can be used to improve an investor's return by filtering out problematic banks, but at the cost of adding risk to the portfolio.

The change in apparent market efficiency identified by the Martin (1977) Logit and Kimmel et al (2010) LOESS models which occurs in 1994 is problematic with several possible explanations. It is possible that some exogenous change in bank regulation or the widespread adoption of bank EWS by analysts' or regulators actually improved the efficiency of the market.

It is possible that the risk adjusted abnormal returns detected by these two models are just a random occurrence of the method and variables used by the models, a kind of data snooping, and not a repeatable finding. Finally, it is possible that the efficiency of these models is tied to the number of bank failures during a given period. When the number of bank failures is high, as they are prior to 1994, they can identify both the extreme outliers which fail and the less extreme outliers which underperform in the stock market but ultimately do not fail. When the number of bank failures is low, the models can only identify the extreme outliers, the ones that actually fail, with any degree of precision. 
Investors should not rely on any of these models as the sole means of picking stocks, but may wish to use any of them as a means to identify potentially underperforming stocks for further investigation. Sophisticated investors with access to computational resources and data may wish to utilize more than one model, but less sophisticated investors should be assured that the simplest of them can improve the performance of their portfolios.

Regulators, who's primary concern is the identification of banks likely to fail, should consider using a combination of parametric (MDA, for example) and non-parametric models, especially one like the Kimmel et al (2010) LOESS model that does not require the a priori identification of failed banks. Regulators should also recognize the limitations of these models and the similarity of their results. Models that use factors other than the financial variables utilized by these models should be incorporated into their screening process.

Researchers can be assured that any of these models can be used to predict bank failure, so the choice of model should rest on the number and type of variables being studied. They can be assured that the predictive powers of these financial variables are stable over relatively long periods of time, which allows for the aggregation of data over long periods of time, allowing the study of the properties of banks during times when few failures are occurring. 


\section{Works Cited}

Alexander, Sidney S. 1961. Price Movements in Speculative Markets; Trends or Random Walks. Industrial Management Review 2, no. 2: 7-28.

Arora, S., B. Barak, M. Brunnermeier, and R. Ge. 2010. Computational complexity and information asymmetry in financial products. In Proceedings of the First Symposium on Innovations in Computer Science (ICS).

Banz, R. W. 1981. The relationship between return and market value of common stocks. Journal of financial economics 9 , no. 1: 3-18.

Barrell, R., E. P Davis, D. Karim, and I. Liadze. 2010. "Bank regulation, property prices and early warning systems for banking crises in OECD countries." Journal of Banking \& Finance 34 (9): 2255-2264.

Beaver, William H., and Wane R. Landsman. 1981. Note on the Behavior of Residual Security Returns for Winner and Loser Portfolios. Journal of Accounting and Economics 3: P. 233-241.

Berkowitz, Stephen A., Dennis E. Logue, and Eugene A. Noser, Jr. 1988. The Total Cost of Transactions on the NYSE. The Journal of Finance 43, no. 1 (March): 97-112.

Bernard, V. L. 1987. Cross-Sectional Dependence and Problems in Inference in Market-Based Accounting Research. Journal of Accounting Research, Vol. 25, No. 1, pp. 1-48.

Booth, D. E. 1980. The identification of problem banks - An application of robust regression, Paper presented at the Eighth Annual Conference, Statistics, sponsored by the Miami University Department of Mathematics and Statistics. Oxford, Ohio. 
- 1982. The analysis of outlying data points using robust regression: a multivariate problem-bank identification model, Decision Sciences, Vol. 12, no. 1, pp.71-81.

Caporale, G. M, R. Matousek, and C. Stewart. 2009. Rating Assignments: Lessons from International Banks. CESifo, Center for Economic Studies \& Ifo Institute for economic research.

Chan, K. C. 1988. On the contrarian investment strategy. Journal of Business: 147-163.

Chance, D. M. 1979. Comment: A test of Stone's two-index model of returns. Journal of Financial and Quantitative Analysis 14, no. 3: 641-644.

Chopra, Navin, Josef Lakonishok, and Jay R. Ritter. 1992. Measuring abnormal performance: Do stocks overreact? Journal of Financial Economics 31: 235-268.

Cole, R. A, and L. J White. 2010. "Déjà vu all over again: The causes of US commercial bank failures this time around." MPRA Paper.

Cole, R. A, and Q. Wu. 2009. Predicting bank failures using a simple dynamic hazard model. In CFR Seminar Series Library-2009.

_ 2010. "Is hazard or probit more accurate in predicting financial distress? Evidence from US bank failures.” MPRA Paper.

Curry, T. J, P. J Elmer, and G. S Fissel. 2007. "Equity market data, bank failures and market efficiency." Journal of Economics and Business 59 (6): 536-559.

Davis, E. P, and D. Karim. 2008. "Could early warning systems have helped to predict the subprime crisis?" National Institute Economic Review 206 (1): 35.

DeBondt, Werner F. M., and Richard Thaler. 1985. Does the Stock Market Overreact? The Journal of Finance 40, no. 3 (July): 793-805. 
Demyanyk, Y., and O. Van Hemert. 2009. "Understanding the subprime mortgage crisis." Review of Financial Studies 22.

Dinenis, E., and S. K. Staikouras. 1998. Interest rate changes and common stock returns of financial institutions: evidence from the UK. The European Journal of Finance 4, no. 2: $113-127$.

Fama, E. F, and K. R French. 1992. The cross-section of expected stock returns. Journal of finance 47 , no. 2: 427-465.

- 1993. Common risk factors in the returns on stocks and bonds* 1 . Journal of financial economics 33, no. 1: 3-56.

Fama, E. F. 1970. Efficient Capital Markets: A Review of Theory and Empirical Work. The Journal of Finance 25, no. 2 (May): 383-417.

—. 1991. Efficient capital markets: II. The Journal of Finance 46, no. 5: 1575-1617.

Fama, E. F., and M. E. Blume. 1966. Filter rules and stock-market trading. Journal of Business 39, no. 1, Part 2: Supplement on Security Prices: 226-241.

Flannery, M. J, and C. M James. 1984. The effect of interest rate changes on the common stock returns of financial institutions. Journal of Finance 39, no. 4: 1141-1153.

Fogler, H. R, K. John, and J. Tipton. 1981. Three factors, interest rate differentials and stock groups. Journal of Finance 36, no. 2: 323-335.

Fraser, D. R., J. Madura, and R. A. Weigand. 2002. Sources of Bank Interest Rate Risk. The Financial Review 37: 351-368.

Fukushima, K. 1975. “Cognitron: A self-organizing multilayered neural network.” Biological Cybernetics 20 (3): 121-136. 
Güvenir, H. A, and M. Çakir. 2010. "Voting features based classifier with feature construction and its application to predicting financial distress.” Expert Systems with Applications 37 (2): 1713-1718.

Jegadeesh, N., and S. Titman. 1993. Returns to buying winners and selling losers: Implications for stock market efficiency. Journal of finance: 65-91.

- 2001. Profitability of momentum strategies: An evaluation of alternative explanations. Journal of Finance 56, no. 2: 699-720.

Jensen, M. C. 1978. Some anomalous evidence regarding market efficiency. Journal of Financial Economics 6, no. 2/3: 95-101.

Jordan, D J., D. Rice, J. Sanchez, C. Walker, and D.H. Wort. 2010. "Predicting Bank Failures: Evidence from 2007 to 2010.” Available at SSRN: http://ssrn.com/abstract=1652924

Kane, E. J, and H. Unal. 1988. Change in market assessments of deposit-institution riskiness. Journal of Financial Services Research 1, no. 3: 207-229.

Kimmel, R., Booth, D.E., and Booth, S. 2010. The analysis of outlying data points by robust LOESS: a model for the identification of problem banks, Int. J. Operational Research, Vol. 7, No. 1, pp. 1-15.

King, B. F. 1966. Market and industry factors in stock price behavior. Journal of Business: 139190.

Kolari, J., Glennon, D., Shin, H. and Caputo, M. 2002. Predicting large US commercial bank failures, Journal of Economics and Business, Vol. 54, No. 4, pp.361-387.

Kothari, S. P., and J. A Shanken. 1999. Beta and Book-to-Market: Is the Glass Half Full or Half Empty? The Bradley Policy Research Center Financial Research and Policy Working Paper No. FR 97-20: 44-64. 
Kothari, S. P., J. Shanken, and R. G Sloan. 1995. Another look at the cross-section of expected stock returns. Journal of Finance 50, no. 1: 185-224.

Kothari, S.P. and Warner, J. B. 2007. Economics of Event Studies. Handbook of Corporate Finance: Volume 1: Empirical Corporate Finance, B. Espen Eckbo, ed, Elsevier/NorthHolland, p. $3-36$.

Kwan, S. H. 1991. Re-examination of interest rate sensitivity of commercial bank stock returns using a random coefficient model. Journal of Financial Services Research 5, no. 1: 6176.

Lane, W. R, S. W Looney, and J. W Wansley. 1986. An application of the Cox proportional hazards model to bank failure. Journal of Banking \& Finance 10, no. 4: 511-531.

Levy, R. A. 1967. Relative strength as a criterion for investment selection. Journal of Finance: 595-610.

Lloyd, W. P, and R. A Shick. 1977. A test of Stone's two-index model of returns. Journal of Financial and Quantitative Analysis 12, no. 03: 363-376.

Lynge Jr, M. J, and J. K Zumwalt. 1980. An empirical study of the interest rate sensitivity of commercial bank returns: A multi-index approach. Journal of Financial and Quantitative Analysis 15, no. 3: 731-742.

Martin, D. 1977. Early warning of bank failure: A logit regression approach, Journal of Banking and Finance, Vol. 1, pp.249-276.

Maymin, P. 2011. "Markets are efficient if and only if $\mathrm{P}=$ NP." Algorithmic Finance, Forthcoming; NYU Poly Research Paper. Available at SSRN: http://ssrn.com/abstract=1773169. 
Merton, R. C. 1973. An intertemporal capital asset pricing model. Econometrica: Journal of the Econometric Society 41, no. 5: 867-887.

Meyer, P. A. and Pifer, H. W. 1970. Prediction of bank failures, Journal of Finance, Vol. 25, No. 4, pp. $853-868$.

Ng, G. S., C. Quek, and H. Jiang. 2008. "FCMAC-EWS: A bank failure early warning system based on a novel localized pattern learning and semantically associative fuzzy neural network." Expert Systems with Applications 34 (2): 989-1003.

Pettway. R. H., and Sinkey, J. F., Jr. 1980. Establishing on-site bank examination priorities: An early warning system using accounting and market information, Journal of Finance, Vol. 35, pp.137-150.

Poghosyan, T., M. Čihák, and International Monetary Fund. European Dept. 2009. Distress in European Banks: An Analysis Based on a New Data Set. International Monetary Fund.

Ravisankar, P. and V. Ravi. 2010. "Financial distress prediction in banks using Group Method of Data Handling neural network, counter propagation neural network and fuzzy ARTMAP.” Knowledge-Based Systems 23: 823-831.

Secrist, H. 1938. National bank failures and non-failures: An autopsy and diagnosis, The Principia Press, Bloomington, Indiana.

Simon, H. A. 1955. “A behavioral model of rational choice.” The quarterly journal of economics 69 (1): 99.

Sinkey, Jr. J. F. 1974. The Way Problem Banks Perform. Bankers' Magazine, Vol. 57, Issue 4, p. $40-51$. 
-1975. A multivariate statistical analysis of the characteristics of problem banks, Journal of Finance, Vol. 30, No. 1, pp. 21 - 36.

- 1977. Identifying large problem/failed banks: the case of Franklin National Bank of New York, Journal of Financial \& Quantitative Analysis, Vol. 12, No. 5, pp. 779 - 800.

_. 1978. Identifying "problem" banks, Journal of Money, Credit \& Banking, Vol. 10, No. 2, pp. $184-193$.

. 1979. Problem and failed institutions in the commercial banking industry, JAI press, Greenwich, Conn.

Staikouras, S. K. 2003. The interest rate risk exposure of financial intermediaries: A review of the theory and empirical evidence. Financial Markets Institutions and Instruments 12, no. 4: $257-289$.

- 2006. Financial intermediaries and interest rate risk: II. Financial Markets, Institutions \& Instruments 15, no. 5: 225-272.

Stone, B. K. 1974. Systematic Interest-Rate Risk in A Two-Index Model of Returns. Journal of Financial and Quantitative Analysis 9, no. 5: 709 - 721.

Tam, K.Y., Kiang, M.Y., 1992. Managerial applications of neural networks: The case of bank failure predictions, Management Science, Vol. 38, No. 7, pp. 926 - 947.

Tung, W.L., Quek, C., and Cheng, P. 2004. GenSo-EWS: a novel neural-fuzzy based early warning system for predicting bank failures, Neural Networks, Vol. 17, pp.567-587.

Wheelock, D.C., and Wilson, P.W. 2000. Why do banks disappear? The determinants of U.S. bank failures and acquisitions, The Review of Economics and Statistics, Vol. 82, No. 1, pp. $127-138$. 
Yeh, Q. 1996. The Application of data envelopment analysis in conjunction with financial ratios for bank performance evaluation, The Journal of the Operational Research Society, Vol. 47, No. 8, pp.980-988. 

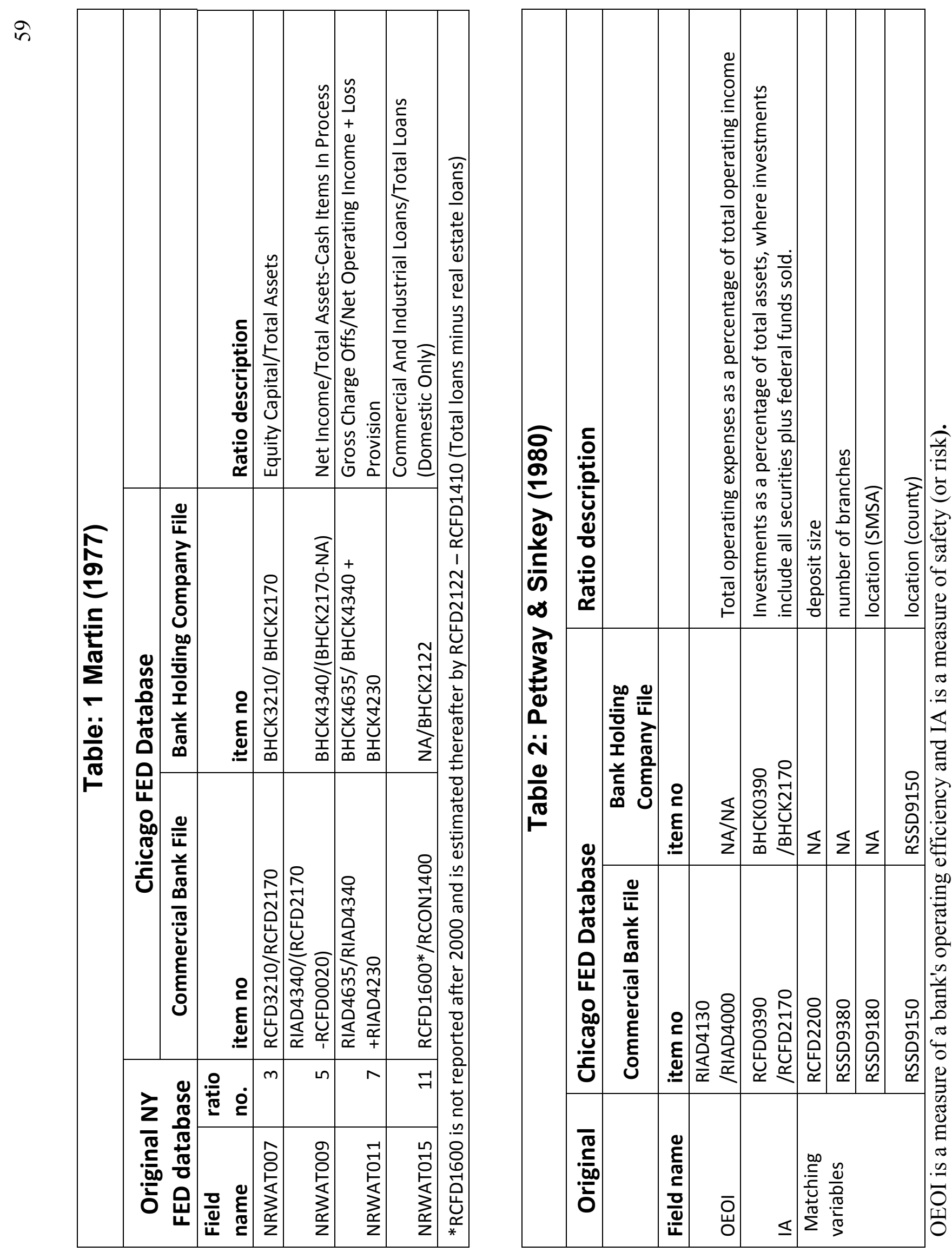


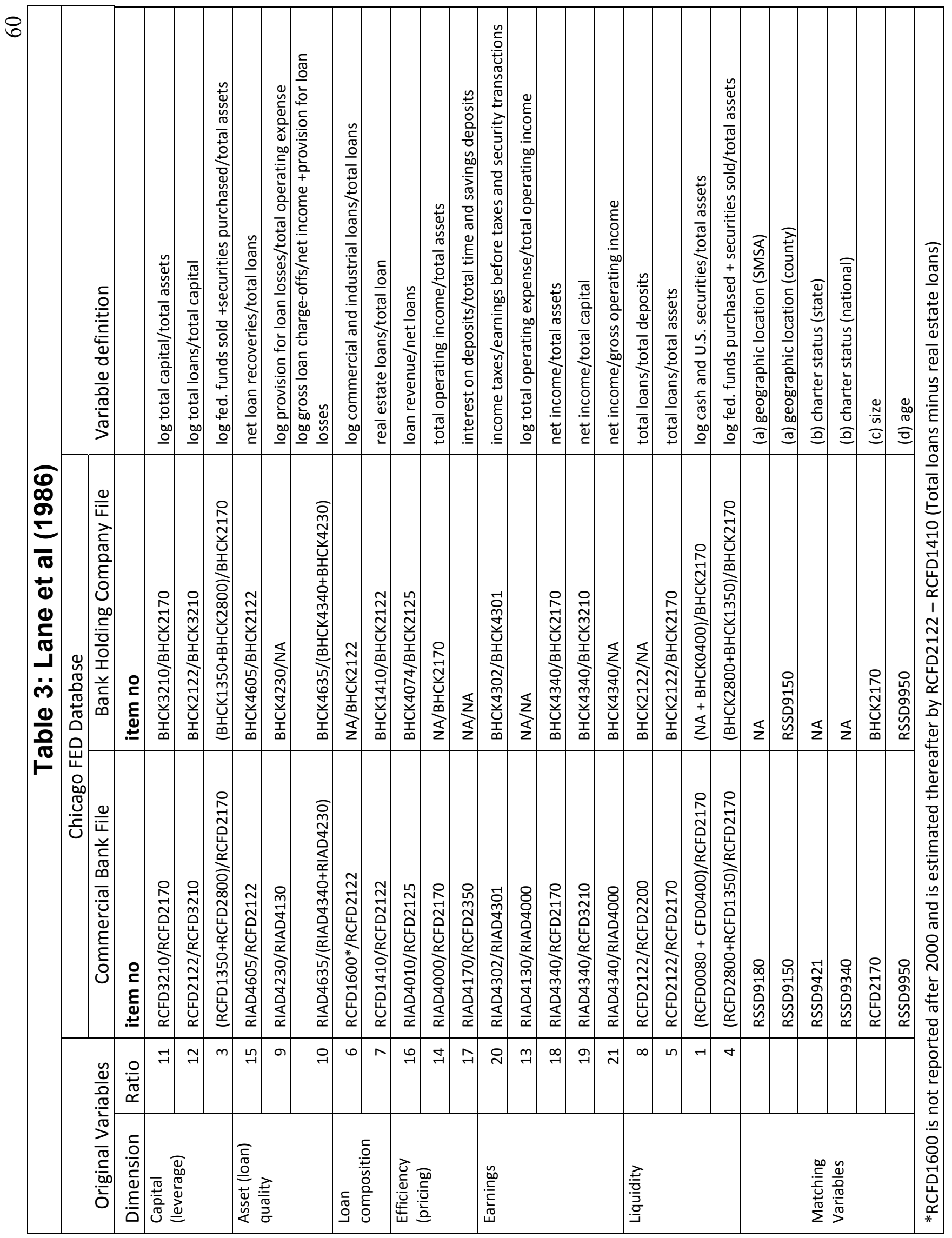




\begin{tabular}{|c|c|c|c|}
\hline \multicolumn{4}{|c|}{ Table 4: Kolari et al (2000) } \\
\hline & \multicolumn{2}{|c|}{ Chicago FED Database } & \multirow[b]{2}{*}{ variable description } \\
\hline $\mathbf{X j}$ & Commercial Bank File & $\begin{array}{l}\text { Bank Holding } \\
\text { Company File }\end{array}$ & \\
\hline 1 & RCFD2170 & NA & Total assets (millions) \\
\hline 2 & NA & BHCK2170 & Bank holding co. (BHC) total assets (millions) \\
\hline 3 & & & Maximum change in $\mathrm{X} 1 /$ mean $\mathrm{X} 1$ \\
\hline 4 & & & Maximum change in $\mathrm{X} 1$ /mean change $\mathrm{X} 1$ \\
\hline 5 & RIAD4074/RCFD2170 & BHCK4074/BHCK2170 & Net interest income/total assets \\
\hline 6 & & & Max change in X5/mean X5 \\
\hline 7 & RIAD4340/RCFD2170 & BHCK4340/BHCK2170 & Net income after taxes/total assets \\
\hline 8 & & & Maximum change in $X 7 /$ mean $X 7$ \\
\hline 9 & RCFD3210/RCFD2170 & BHCK3210/BHCK2170 & Total equity/total assets \\
\hline 10 & & & Maximum change in $\mathrm{X} 9 /$ mean $\mathrm{X} 9$ \\
\hline 11 & RCFD3123/ RCFD2170 & BHCK3123/ BHCK2170 & Allowance for loan losses/total assets \\
\hline 12 & & & Max change in X11/mean X11 \\
\hline 13 & RIAD4230/RCFD2170 & BHCK4230/BHCK2170 & Provision for loan losses/total assets \\
\hline 14 & & & Maximum change in $\mathrm{X} 13 /$ mean $\mathrm{X} 13$ \\
\hline 15 & $\begin{array}{l}\text { (RIAD4635- } \\
\text { RIAD4605)/RCFD2170 }\end{array}$ & $\begin{array}{l}\text { (BHCK4635- } \\
\text { BHCK4605)/BHCK2170 }\end{array}$ & Net loan charge-offs/total assets \\
\hline 16 & & & Maximum change in X15/mean X15 \\
\hline 17 & RCFD1407 & BHCK1407 & $\begin{array}{l}\text { Maximum change in loans past due at least } 90 \\
\text { days/mean of numerator }\end{array}$ \\
\hline 18 & RCFD0390*/RCFD2170 & BHCK0390/BHCK2170 & Total securities/total assets \\
\hline 19 & & & Maximum change in $\mathrm{X} 18 /$ mean $\mathrm{X} 18$ \\
\hline 20 & $\begin{array}{l}\text { (RCFD2948 - RCFD2200)/ } \\
\text { RCFD2948 }\end{array}$ & $\begin{array}{l}(\mathrm{BHCK} 2948-\mathrm{NA}) / \\
\text { BHCK2948 }\end{array}$ & Nondeposit liabilities/total liabilities \\
\hline 21 & & & Maximum change in $\mathrm{X} 20 /$ mean $\mathrm{X} 20$ \\
\hline 22 & RCFD2215/RCFD2200 & NA/NA & Certificates of deposit/total deposits \\
\hline 23 & & & Maximum change in $\mathrm{X} 22 /$ mean $\mathrm{X} 22$ \\
\hline 24 & RCFD1400/RCFD2170 & BHCK2122/BHCK2170 & Total loans and leases/total assets \\
\hline 25 & & & Maximum change in X24/mean X24 \\
\hline
\end{tabular}




\begin{tabular}{|c|c|c|c|c|}
\hline \multicolumn{5}{|c|}{ Table 5: Kimmel et al (2010) } \\
\hline Model & \multicolumn{3}{|c|}{$\mathrm{Y}$} & $\mathrm{x}$ \\
\hline $1 \& 2$ & \multicolumn{3}{|c|}{ Net Income (NI) } & Total Assets (TA) \\
\hline 3 & \multicolumn{3}{|c|}{ Net Loan Losses (NLL) or Loan Loss Provision (LLP) } & Total Loans (TL) \\
\hline 4 & \multicolumn{3}{|c|}{ Net Loan Losses (NLL) or Loan Loss Provision (LLP) } & Total Assets (TA) \\
\hline \multicolumn{5}{|c|}{ Chicago FED Database } \\
\hline \multicolumn{2}{|c|}{ variable } & Commercial Bank File & \multicolumn{2}{|c|}{ Bank Holding Company File } \\
\hline \multicolumn{2}{|c|}{ Net Income } & RIAD4340 & \multicolumn{2}{|r|}{ BHCK4340 } \\
\hline \multicolumn{2}{|c|}{ Total Assets } & RCFD2170 & \multicolumn{2}{|r|}{ BHCK2170 } \\
\hline
\end{tabular}




\begin{tabular}{|c|c|c|c|c|c|c|}
\hline \multicolumn{7}{|c|}{ Table 6: Analysis of Merger Activity } \\
\hline Date Of Merger & \begin{tabular}{|l|} 
With \\
Assistance
\end{tabular} & $\begin{array}{l}\text { Without } \\
\text { Assistance }\end{array}$ & & & & \\
\hline & & Number & \multicolumn{2}{|c|}{ Bad Press } & \multicolumn{2}{|c|}{$\begin{array}{l}\text { FDIC Enforcement } \\
\text { Orders }\end{array}$} \\
\hline & & & Number & Percent & Number & Percent \\
\hline 1988 & & 1 & & & & \\
\hline 1992 & & 1 & & & & \\
\hline 1994 & 1 & 0 & & & & \\
\hline 1995 & & 1 & & & & \\
\hline 1996 & 1 & 7 & & & & \\
\hline 1997 & & 2 & & & & \\
\hline 1998 & & 9 & & & 4 & $44 \%$ \\
\hline 1999 & & 6 & & & 1 & $17 \%$ \\
\hline 2000 & & 6 & 1 & $17 \%$ & 2 & $33 \%$ \\
\hline 2001 & & 6 & 1 & $17 \%$ & 2 & $33 \%$ \\
\hline 2002 & & 2 & & & 1 & $50 \%$ \\
\hline 2003 & & 0 & & & & \\
\hline 2004 & & 5 & 1 & $20 \%$ & 4 & $80 \%$ \\
\hline 2005 & & 2 & & & 1 & $50 \%$ \\
\hline 2006 & & 3 & & & 1 & $33 \%$ \\
\hline 2007 & & 3 & & & 1 & $33 \%$ \\
\hline 2008 & & 1 & & & & $0 \%$ \\
\hline 2009 & & 0 & & & & \\
\hline 2010 & 1 & 2 & & & 1 & $50 \%$ \\
\hline total merged & 3 & 57 & 3 & $5 \%$ & 18 & $32 \%$ \\
\hline did not merge & & 28 & & & 8 & $29 \%$ \\
\hline & & 89 & & & & \\
\hline
\end{tabular}

note: I do not look for bad press among firms that do not merge 


\begin{tabular}{|c|c|c|c|c|c|}
\hline \multicolumn{6}{|c|}{ Table 7: FDIC Bank Failures 1986 Through June 2010} \\
\hline Year & $\begin{array}{c}\text { Commercial } \\
\text { Banks not } \\
\text { Affiliated w/ BHC }\end{array}$ & $\begin{array}{c}\text { Commercial } \\
\text { Banks Affiliated } \\
\text { w/ BHC }\end{array}$ & $\begin{array}{c}\text { Publicly Traded } \\
\text { Commercial } \\
\text { Bank }\end{array}$ & $\begin{array}{l}\text { Publicly } \\
\text { Traded } \\
\text { BHC }\end{array}$ & $\begin{array}{l}\text { Publicly Traded } \\
\text { Commercial Bank } \\
\text { Affiliated w/BHC }\end{array}$ \\
\hline 1986 & 105 & 1 & & 1 & \\
\hline 1987 & 198 & 3 & & & \\
\hline 1988 & 269 & 11 & & 5 & \\
\hline 1989 & 207 & & & & \\
\hline 1990 & 166 & 1 & & & \\
\hline 1991 & 121 & 3 & & & \\
\hline 1992 & 118 & 1 & & & \\
\hline 1993 & 23 & 20 & & & \\
\hline 1994 & 7 & 6 & 1 & 1 & \\
\hline 1995 & 5 & 1 & & 1 & \\
\hline 1996 & 3 & 2 & 1 & & \\
\hline 1997 & 1 & & & & \\
\hline 1998 & 1 & 2 & & & \\
\hline 1999 & 5 & 2 & & & \\
\hline 2000 & 1 & 5 & & & \\
\hline 2001 & 3 & & & & \\
\hline 2002 & 5 & 5 & & 1 & \\
\hline 2003 & 2 & 1 & & & \\
\hline 2004 & & 3 & & & \\
\hline 2007 & 2 & & & & \\
\hline 2008 & 8 & 18 & & 5 & \\
\hline 2009 & 19 & 110 & & 20 & 1 \\
\hline 2010 & 10 & 63 & 1 & 10 & \\
\hline $\begin{array}{l}\text { Grand } \\
\text { Total }\end{array}$ & 1279 & 258 & 3 & 44 & 1 \\
\hline
\end{tabular}




\begin{tabular}{|c|c|c|c|c|c|c|c|c|c|}
\hline Variable & $\max$ & $\frac{\text { able 8: }}{\min }$ & mean & $\frac{\text { Clal B }}{\text { median }}$ & $\begin{array}{c}\text { רKS, FE } \\
\text { std dev }\end{array}$ & $\begin{array}{c}\text { datab } \\
\text { skewness }\end{array}$ & $\begin{array}{l}\text { ISE } \\
\text { kurtosis }\end{array}$ & count & missing \\
\hline PERMCO & 43,694 & 841 & 14,310 & 11,698 & & & & 4675 & 0 \\
\hline RCFD0020 & $1,706,108$ & 0 & 41880 & 4782 & $197,734.61$ & 6.34 & 40.43 & 2892 & 1783 \\
\hline RCFD0080 & 842,571 & 0 & 11835 & 1195 & $61,571.72$ & 7.91 & 69.22 & 4171 & 504 \\
\hline RCFD0390 & $1,353,717$ & 0 & 68377 & 15365 & $157,764.88$ & 4.80 & 27.63 & 1783 & 2892 \\
\hline RCFD0400 & $1,244,528$ & 0 & 27238 & 2478 & $83,938.51$ & 6.74 & 63.03 & 1696 & 2979 \\
\hline RCFD1000 & 31,988 & 0 & 3372 & 0 & $7,546.88$ & 2.74 & 7.15 & 48 & 4627 \\
\hline RCFD1350 & $1,614,012$ & 0 & 24970 & 6439 & $83,554.27$ & 9.66 & 125.20 & 3604 & 1071 \\
\hline RCFD1400 & $49,161,663$ & 0 & 745015 & 136026 & $3,296,869.74$ & 8.49 & 82.37 & 4675 & 0 \\
\hline RCFD1407 & 174,720 & 0 & 1900 & 136 & $8,881.79$ & 11.22 & 158.59 & 4675 & 0 \\
\hline RCFD1410 & $30,439,399$ & 0 & 431335 & 85788 & $1,817,843.10$ & 9.96 & 119.98 & 4675 & 0 \\
\hline RCFD1600 & $13,203,055$ & 0 & 158126 & 23113 & $924,645.94$ & 10.14 & 114.15 & 3408 & 1267 \\
\hline RCFD2122 & $49,161,663$ & 0 & 742251 & 135015 & $3,289,062.62$ & 8.52 & 82.89 & 4675 & 0 \\
\hline RCFD2125 & $25,427,098$ & 0 & 466623 & 103040 & $2,079,733.01$ & 8.64 & 82.57 & 3408 & 1267 \\
\hline RCFD2170 & $69,736,605$ & 3,752 & 1106725 & 207462 & $4,773,564.43$ & 8.31 & 77.81 & 4675 & 0 \\
\hline RCFD2200 & $47,391,300$ & 6 & 900012 & 180038 & $3,898,771.61$ & 8.39 & 77.54 & 4675 & 0 \\
\hline RCFD2350 & $6,776,480$ & 371 & 261282 & 84081 & $718,547.69$ & 6.03 & 43.03 & 770 & 3905 \\
\hline RCFD2800 & $1,709,686$ & 0 & 22980 & 0 & $128,272.99$ & 8.66 & 84.51 & 3604 & 1071 \\
\hline RCFD2948 & $62,348,899$ & 8 & 1005087 & 189676 & $4,337,777.53$ & 8.34 & 78.44 & 4675 & 0 \\
\hline RCFD3123 & 724,654 & 0 & 12838 & 1862 & $58,595.31$ & 7.51 & 60.16 & 4675 & 0 \\
\hline RCFD3210 & $7,387,706$ & (375) & 101384 & 17214 & $447,318.93$ & 8.10 & 73.07 & 4675 & 0 \\
\hline RCFD8639 & $6,325,775$ & 0 & 144131 & 8613 & $637,313.26$ & 7.08 & 53.91 & 2892 & 1783 \\
\hline RCFD8641 & $12,227,614$ & 0 & 277376 & 44847 & $1,070,328.79$ & 7.10 & 56.51 & 2892 & 1783 \\
\hline RCFDA223 & $62,025,971$ & 2,062 & 1345373 & 241155 & $5,686,357.66$ & 6.94 & 51.76 & 2366 & 2309 \\
\hline RCFDB558 & $5,759,567$ & 0 & 129413 & 17462 & $535,073.01$ & 6.73 & 49.58 & 1267 & 3408 \\
\hline RCON1400 & $48,307,292$ & 0 & 728912 & 134700 & $3,193,981.11$ & 8.52 & 83.75 & 4675 & 0 \\
\hline RCON1430 & $19,373,838$ & 0 & 181726 & 25822 & $1,085,555.38$ & 11.63 & 154.87 & 4675 & 0 \\
\hline RCON2215 & $10,261,675$ & 0 & 192445 & 45828 & $852,021.97$ & 7.91 & 65.87 & 4675 & 0 \\
\hline RIAD3123 & 724,654 & 0 & 15765 & 2700 & $63,676.60$ & 6.79 & 49.57 & 3237 & 1438 \\
\hline RIAD4000 & $3,787,694$ & 0 & 51306 & 9774 & $232,053.35$ & 9.51 & 105.32 & 4675 & 0 \\
\hline RIAD4010 & $2,534,870$ & 0 & 34384 & 6783 & $150,715.93$ & 9.41 & 104.83 & 4675 & 0 \\
\hline RIAD4074 & $2,045,651$ & 0 & 26462 & 5003 & $122,646.38$ & 9.68 & 108.37 & 4675 & 0 \\
\hline RIAD4130 & $2,894,600$ & 0 & 38514 & 8021 & $165,409.82$ & 9.42 & 106.00 & 4675 & 0 \\
\hline RIAD4170 & $1,078,212$ & 0 & 13748 & 3024 & $52,380.20$ & 9.50 & 115.86 & 4675 & 0 \\
\hline RIAD4230 & 511,190 & $(60,776)$ & 2447 & 270 & $16,508.76$ & 16.45 & 371.27 & 4675 & 0 \\
\hline RIAD4301 & $1,108,275$ & $(212,006)$ & 10509 & 1213 & $61,305.02$ & 10.69 & 133.55 & 4675 & 0 \\
\hline RIAD4302 & 406,528 & $(73,087)$ & 3654 & 379 & $20,680.37$ & 10.56 & 132.71 & 4675 & 0 \\
\hline RIAD4340 & 842,217 & $(138,919)$ & 6890 & 852 & $41,162.25$ & 11.15 & 148.58 & 4675 & 0 \\
\hline RIAD4605 & 58,370 & 0 & 628 & 32 & $3,665.20$ & 9.82 & 109.07 & 4675 & 0 \\
\hline RIAD4635 & 322,469 & 0 & 2610 & 152 & $15,542.19$ & 11.64 & 164.19 & 4675 & 0 \\
\hline RIADA220 & 63,984 & $(24,418)$ & 632 & 0 & $4,765.39$ & 7.88 & 74.62 & 1709 & 2966 \\
\hline RSSD9001 & $3,153,288$ & 31,303 & 1033512 & 775214 & $823,006.20$ & 1.12 & 0.34 & 4675 & 0 \\
\hline RSSD9010 & 0 & 0 & & & & & & 4675 & 0 \\
\hline RSSD9017 & 0 & 0 & & & & & & 889 & 3786 \\
\hline RSSD9047 & 6 & 1 & & & & & & 4675 & 0 \\
\hline RSSD9048 & 300 & 200 & & & & & & 4675 & 0 \\
\hline RSSD9050 & 57,487 & 114 & & & & & & 4675 & 0 \\
\hline RSSD 9052 & 20010409 & 0 & & & & & & 889 & 3786 \\
\hline RSSD9053 & 99991231 & 20050422 & 99541687 & 99991231 & & & & 889 & 3786 \\
\hline RSSD9130 & 0 & 0 & & & & & & 4675 & 0 \\
\hline RSSD9150 & 810 & 1 & & & & & & 4675 & 0 \\
\hline RSSD9180 & 9,200 & 240 & & & & & & 3488 & 1187 \\
\hline RSSD9181 & 97 & 0 & & & & & & 3488 & 1187 \\
\hline RSSD9200 & 0 & 0 & & & & & & 4675 & 0 \\
\hline RSSD9210 & 53 & 6 & & & & & & 4675 & 0 \\
\hline RSSD9220 & 97204-2012 & $00000-0000$ & & & & & & 4675 & 0 \\
\hline RSSD9331 & 10 & 1 & & & & & & 4675 & 0 \\
\hline RSSD9348 & $3,811,467$ & 0 & 566,441 & 0 & & & & 4663 & 12 \\
\hline RSSD9421 & 2 & 1 & & & & & & 4675 & 0 \\
\hline RSSD9424 & 7 & 1 & & & & & & 4675 & 0 \\
\hline RSSD9950 & 20030127 & 18760415 & 19757948 & 19830307 & & & & 4675 & 0 \\
\hline RSSD9999 & 20081231 & 19860331 & 19962132 & 19960331 & & & & 4675 & 0 \\
\hline
\end{tabular}




\begin{tabular}{|c|c|c|c|c|c|c|c|c|c|}
\hline Variable & $\frac{\text { Tabl }}{\max }$ & $\frac{\min }{\min }$ & mean & median & $\begin{array}{c}\text { anies, } \\
\text { std dev }\end{array}$ & $\begin{array}{l}\text { ED Ca } \\
\text { skewness }\end{array}$ & $\begin{array}{c}\text { abas } \\
\text { kurtosis }\end{array}$ & count & missing \\
\hline BHCK0390 & $29,053,918$ & 932 & 852,753 & 134,655 & $2,251,641$ & 5.64 & 40.68 & 13,097 & 29,391 \\
\hline BHCK0400 & $23,584,911$ & - & 240,297 & 37,468 & 783,412 & 14.73 & 345.69 & 13,096 & 29,392 \\
\hline BHCK1350 & $138,668,000$ & - & 542,141 & 10,461 & $5,534,442$ & 17.04 & 328.35 & 12,400 & 30,088 \\
\hline BHCK1407 & 971,000 & - & 11,582 & 1,702 & 49,208 & 11.69 & 174.19 & 6,521 & 35,967 \\
\hline BHCK1410 & $547,830,645$ & - & $3,007,371$ & 340,670 & $16,612,180$ & 15.72 & 328.16 & 39,889 & 2,599 \\
\hline BHCK2122 & $967,736,912$ & 9,509 & $6,394,106$ & 543,238 & $35,636,146$ & 14.00 & 248.45 & 39,889 & 2,599 \\
\hline BHCK2125 & $400,522,000$ & 9,403 & $4,050,829$ & 381,596 & $16,907,745$ & 10.85 & 165.29 & 26,803 & 15,685 \\
\hline BHCK2170 & $2,358,266,000$ & 31,150 & $11,848,444$ & 843,504 & $77,225,723$ & 16.40 & 335.34 & 39,890 & 2,598 \\
\hline BHCK2800 & $181,775,000$ & - & 908,892 & 16,441 & $6,554,957$ & 15.25 & 283.18 & 12,391 & 30,097 \\
\hline BHCK2948 & $2,225,254,000$ & 26,583 & $10,881,457$ & 770,381 & $71,171,423$ & 16.52 & 342.17 & 39,890 & 2,598 \\
\hline BHCK3123 & $29,616,000$ & - & 120,213 & 7,510 & 714,262 & 15.52 & 349.12 & 39,890 & 2,598 \\
\hline BHCK3210 & $177,051,777$ & $(254,123)$ & 940,396 & 71,520 & $6,003,911$ & 15.85 & 304.95 & 39,890 & 2,598 \\
\hline BHCK4074 & $54,086,000$ & 142 & 224,315 & 18,742 & $1,422,355$ & 17.51 & 403.58 & 39,890 & 2,598 \\
\hline BHCK4230 & $33,674,000$ & $(175,136)$ & 38,402 & 975 & 426,468 & 37.61 & $2,048.23$ & 39,879 & 2,609 \\
\hline BHCK4301 & $32,007,503$ & $(53,055,000)$ & 113,130 & 6,488 & 919,892 & 7.23 & 676.59 & 39,890 & 2,598 \\
\hline BHCK4302 & $10,839,974$ & $(20,612,000)$ & 37,473 & 1,900 & 301,276 & 4.13 & 869.47 & 39,882 & 2,606 \\
\hline BHCK4340 & $24,589,000$ & $(33,277,000)$ & 75,694 & 4,550 & 625,744 & 9.01 & 664.31 & 39,890 & 2,598 \\
\hline BHCK4605 & $2,555,000$ & - & 7,811 & 235 & 61,116 & 19.85 & 526.11 & 39,873 & 2,615 \\
\hline BHCK4635 & $20,770,000$ & - & 40,625 & 923 & 363,888 & 24.08 & 815.45 & 39,872 & 2,616 \\
\hline BHCK9802 & 3 & - & 1 & 1 & 0 & 3.13 & 22.28 & 34,413 & 8,075 \\
\hline BHCKA220 & $8,986,000$ & $(26,158,000)$ & 18,122 & - & 353,406 & $(20.12)$ & $1,722.54$ & 22,815 & 19,673 \\
\hline BHCKA223 & $1,377,059,500$ & - & $12,271,506$ & 743,942 & $68,430,354$ & 11.26 & 153.66 & 22,655 & 19,833 \\
\hline PERMCO & 45,567 & 25 & 14,726 & 12,139 & 11,504 & 1.30 & 0.91 & 42,488 & - \\
\hline RSSD9001 & 3347292 & 1020331 & & & & & & 42,488 & - \\
\hline RSSD9010 & 0 & 0 & & & & & & 19,641 & 22,847 \\
\hline RSSD9017 & 0 & 0 & & & & & & 42,488 & - \\
\hline RSSD9047 & 11 & 1 & & & & & & 19,641 & 22,847 \\
\hline RSSD9048 & 720 & 500 & & & & & & 19,641 & 22,847 \\
\hline RSSD9050 & 0 & 0 & & & & & & 19,641 & 22,847 \\
\hline RSSD9052 & 20040826 & 0 & & & & & & 42,488 & - \\
\hline RSSD9053 & 99991231 & 19881230 & & & & & & 42,488 & - \\
\hline RSSD9130 & 0 & 0 & & & & & & 42,488 & - \\
\hline RSSD9150 & 840 & 1 & & & & & & 42,488 & - \\
\hline RSSD9200 & 0 & 0 & & & & & & 42,488 & - \\
\hline RSSD9210 & 72 & 1 & & & & & & 42,488 & - \\
\hline RSSD9220 & 995100000 & 680 & & & & & & 42,488 & - \\
\hline RSSD9331 & 28 & 28 & & & & & & 19,641 & 22,847 \\
\hline RSSD9347 & 13903 & 0 & & & & & & 22,847 & 19,641 \\
\hline RSSD9348 & 3811467 & 0 & & & & & & 42,488 & - \\
\hline RSSD9350 & 13905 & 0 & & & & & & 22,847 & 19,641 \\
\hline RSSD9421 & 0 & 0 & & & & & & 19,641 & 22,847 \\
\hline RSSD9955 & 0 & 0 & & & & & & 19,641 & 22,847 \\
\hline RSSD9999 & 20081231 & 19860630 & 19969275 & 19970331 & & & & 42,488 & - \\
\hline
\end{tabular}




\begin{tabular}{|c|c|c|c|c|c|c|c|c|c|}
\hline Variable & $\max$ & $\begin{array}{l}\text { min } 10 \\
\text { min }\end{array}$ & $\begin{array}{l}\text { CRSP } \\
\text { mean }\end{array}$ & $\begin{array}{l}\text { Data for } \\
\text { median }\end{array}$ & $\begin{array}{l}\text { Comme } \\
\text { std dev }\end{array}$ & $\begin{array}{l}\text { cial Bz } \\
\text { skewness }\end{array}$ & $\begin{array}{l}\text { nKS } \\
\text { kurtosis } \\
\end{array}$ & count & missing \\
\hline DATE & 20091231 & 19830131 & 19980140.7 & 19980731 & & & & 7806 & 0 \\
\hline COMNAM & & & & & & & & 7729 & 77 \\
\hline CUSIP & $98,431,410$ & $1,268,410$ & $52,456,703$ & $54,266,910$ & & & & 7806 & 0 \\
\hline DCLRDT & 20091124 & 19821228 & 19973278.8 & 19971170.5 & & & & 1330 & 6476 \\
\hline DLAMT & 74 & 0 & 18 & 17 & 16.53 & 0.77 & 0.33 & 91 & 7715 \\
\hline DLSTCD & 585 & 100 & 223 & 231 & 108.36 & 1.82 & 4.56 & 91 & 7715 \\
\hline NEXTDT & 20091218 & 19940117 & 19995606.8 & 19955527.5 & & & & 6 & 7800 \\
\hline PAYDT & 20100115 & 19830201 & 19974899.6 & 19980218.5 & & & & 1420 & 6386 \\
\hline RCRDDT & 20091231 & 19830113 & 19974101.8 & 19980166.5 & & & & 1420 & 6386 \\
\hline TICKER & & & & & & & & 7729 & 77 \\
\hline PERMNO & 93,060 & 10,037 & 67,335 & 80,808 & & & & 7806 & 0 \\
\hline NAMEENDT & 20091231 & 19851103 & 20008513.3 & 20020919 & & & & 218 & 7588 \\
\hline SICCD & 6,710 & 0 & 6,022 & 6,020 & & & & 7729 & 77 \\
\hline NAICS & 551,111 & 522,110 & 526,218 & 522,110 & & & & 1822 & 5984 \\
\hline PRIMEXCH & 0 & 0 & & & & & & 7729 & 77 \\
\hline TRDSTAT & 0 & 0 & & & & & & 7729 & 77 \\
\hline SECSTAT & 0 & 0 & & & & & & 7729 & 77 \\
\hline PERMCO & 45,996 & 841 & 17,028 & 12,203 & $13,772.73$ & 1.22 & $(0.01)$ & 7806 & 0 \\
\hline DISTCD & 6,581 & 1,212 & 1,875 & 1,232 & $1,501.30$ & 1.98 & 2.07 & 1420 & 6386 \\
\hline DIVAMT & 73.50 & 0.00 & 0.78 & 0.10 & 4.56 & 8.65 & 89.90 & 1420 & 6386 \\
\hline FACPR & 3 & -1 & 0.00453346 & 0 & 0.25 & 2.24 & 40.50 & 1420 & 6386 \\
\hline FACSHR & 20.806 & -1 & 0.0249159 & 0 & 0.62 & 26.82 & 885.02 & 1420 & 6386 \\
\hline ACPERM & 90,490 & 10,932 & 59,469 & 65,939 & & & & 26 & 7780 \\
\hline ACCOMP & 44,891 & 582 & 10,291 & 10,694 & & & & 34 & 7772 \\
\hline NWPERM & 92,555 & 0 & 29,754 & 0 & & & & 91 & 7715 \\
\hline DLRETX & 0.30 & $(0.85)$ & 0.00 & 0.02 & 0.14 & $(4.05)$ & 23.61 & 91 & 7715 \\
\hline DLPRC & 5.10 & $(0.81)$ & 0.05 & 0.00 & 0.55 & 8.74 & 81.39 & 91 & 7715 \\
\hline DLRET & 0.30 & $(0.85)$ & 0.01 & 0.02 & 0.14 & $(4.05)$ & 23.57 & 91 & 7715 \\
\hline SHROUT & 175,260 & 273 & 7,620 & 3,005 & $19,400.21$ & 6.56 & 45.82 & 7729 & 77 \\
\hline PRC & 125 & & & & & & & 7645 & 161 \\
\hline VOL & $1,024,325$ & 0 & 3,803 & 477 & $20,238.85$ & 25.94 & $1,087.46$ & 7694 & 112 \\
\hline RET & 3 & -0.8125 & 0.01092925 & 0.0019685 & 0.12 & 3.67 & 71.11 & 7645 & 161 \\
\hline CFACPR & 16 & 0 & 1.58234478 & 1 & 1.84 & 5.43 & 35.22 & 7729 & 77 \\
\hline CFACSHR & 16 & 0 & 1.58208321 & 1 & 1.84 & 5.43 & 35.21 & 7729 & 77 \\
\hline RETX & 3 & -0.8125 & 0.00973408 & 0 & 0.12 & 3.69 & 71.53 & 7645 & 161 \\
\hline vwretd & 0.128496 & -0.225363 & 0.00907616 & 0.01452 & 0.04 & $(0.97)$ & 2.67 & 7806 & 0 \\
\hline vwretx & 0.126924 & -0.227344 & 0.00719152 & 0.012441 & 0.04 & $(0.97)$ & 2.68 & 7806 & 0 \\
\hline ewretd & 0.225012 & -0.272248 & 0.01111127 & 0.015778 & 0.05 & $(0.46)$ & 3.30 & 7806 & 0 \\
\hline ewretx & 0.224061 & -0.273085 & 0.00966383 & 0.014571 & 0.05 & $(0.46)$ & 3.30 & 7806 & 0 \\
\hline
\end{tabular}




\begin{tabular}{|c|c|c|c|c|c|c|c|c|c|}
\hline \multicolumn{10}{|c|}{ Table 11: Yields } \\
\hline Variable & $\max$ & $\min$ & mean & median & std dev & skewness & kurtosis & count & missing \\
\hline caldt & 20091231 & 19830131 & 19960680 & 19960680 & & & & 324 & 0 \\
\hline b20ret & 0.14 & $(0.11)$ & 0.01 & 0.01 & 0.03 & 0.17 & 2.20 & 324 & 0 \\
\hline ave_3 & 10.90 & 0.03 & 4.81 & 5.04 & 2.48 & 0.01 & $(0.51)$ & 324 & 0 \\
\hline $\begin{array}{l}\text { b20ret } \\
\text { ave_3 }\end{array}$ & \multicolumn{9}{|c|}{$\begin{array}{l}\text { CRSP constant maturity } 20 \text { year government bond } \\
\text { Fama Risk Free Rate }\end{array}$} \\
\hline
\end{tabular}




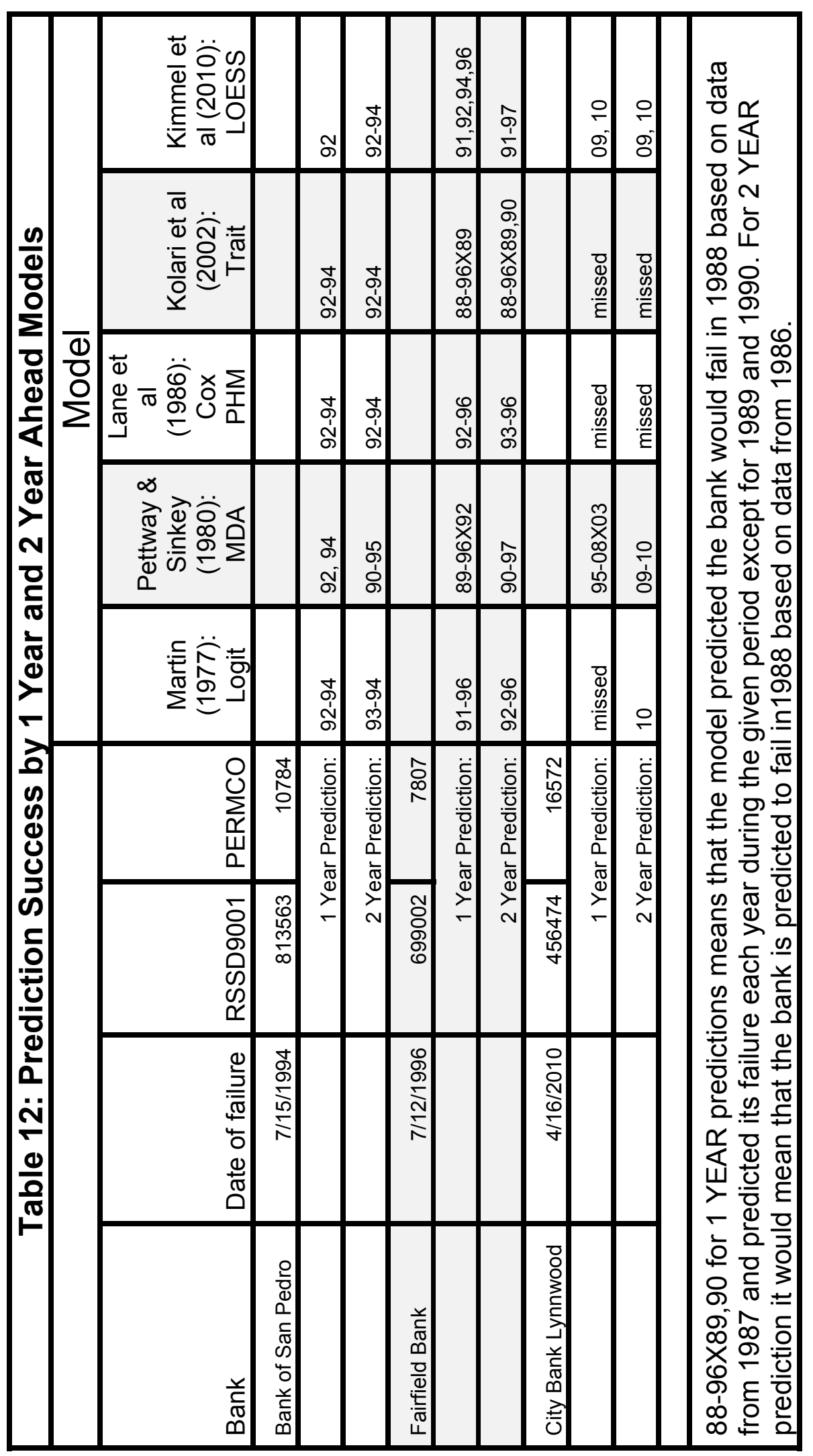




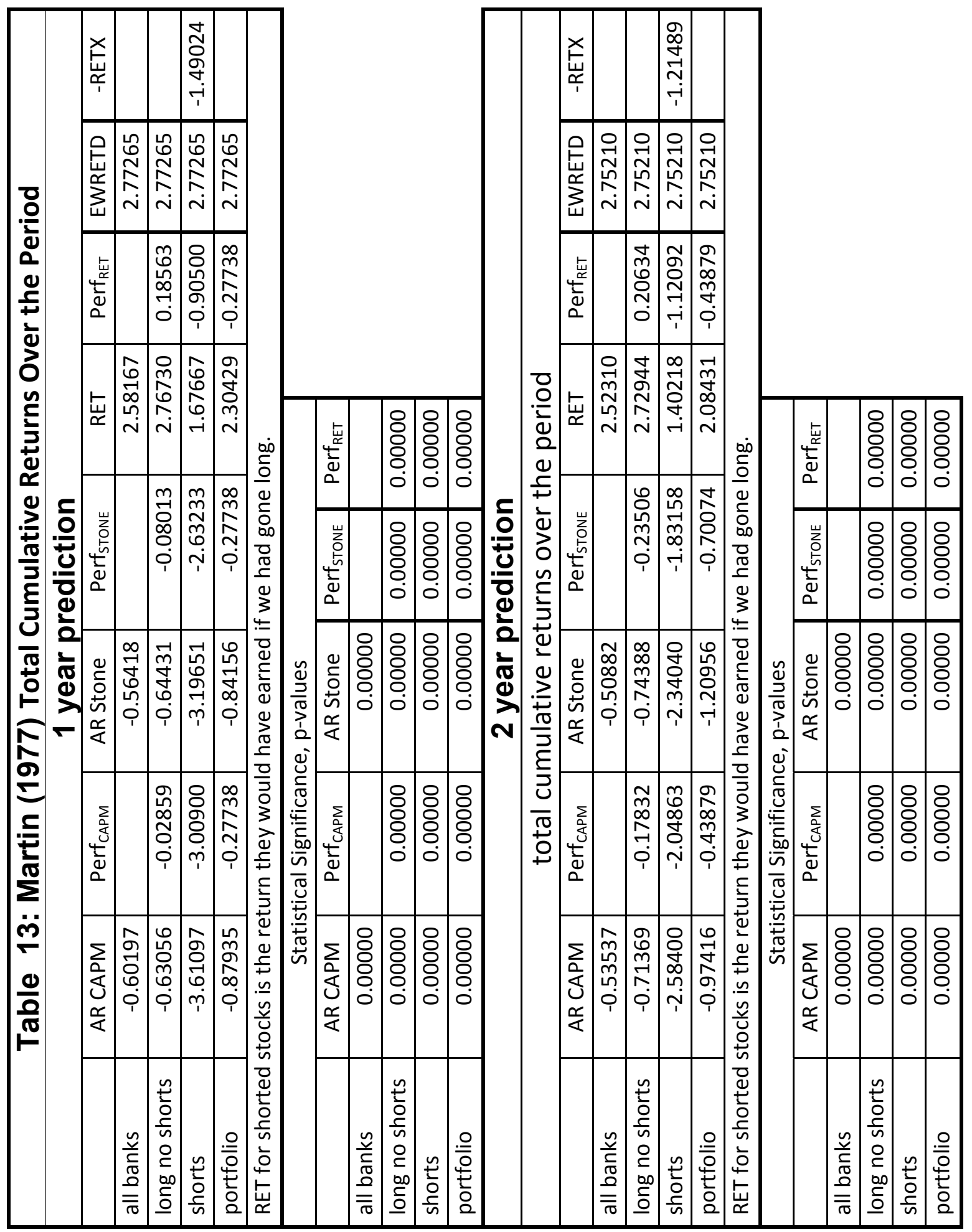




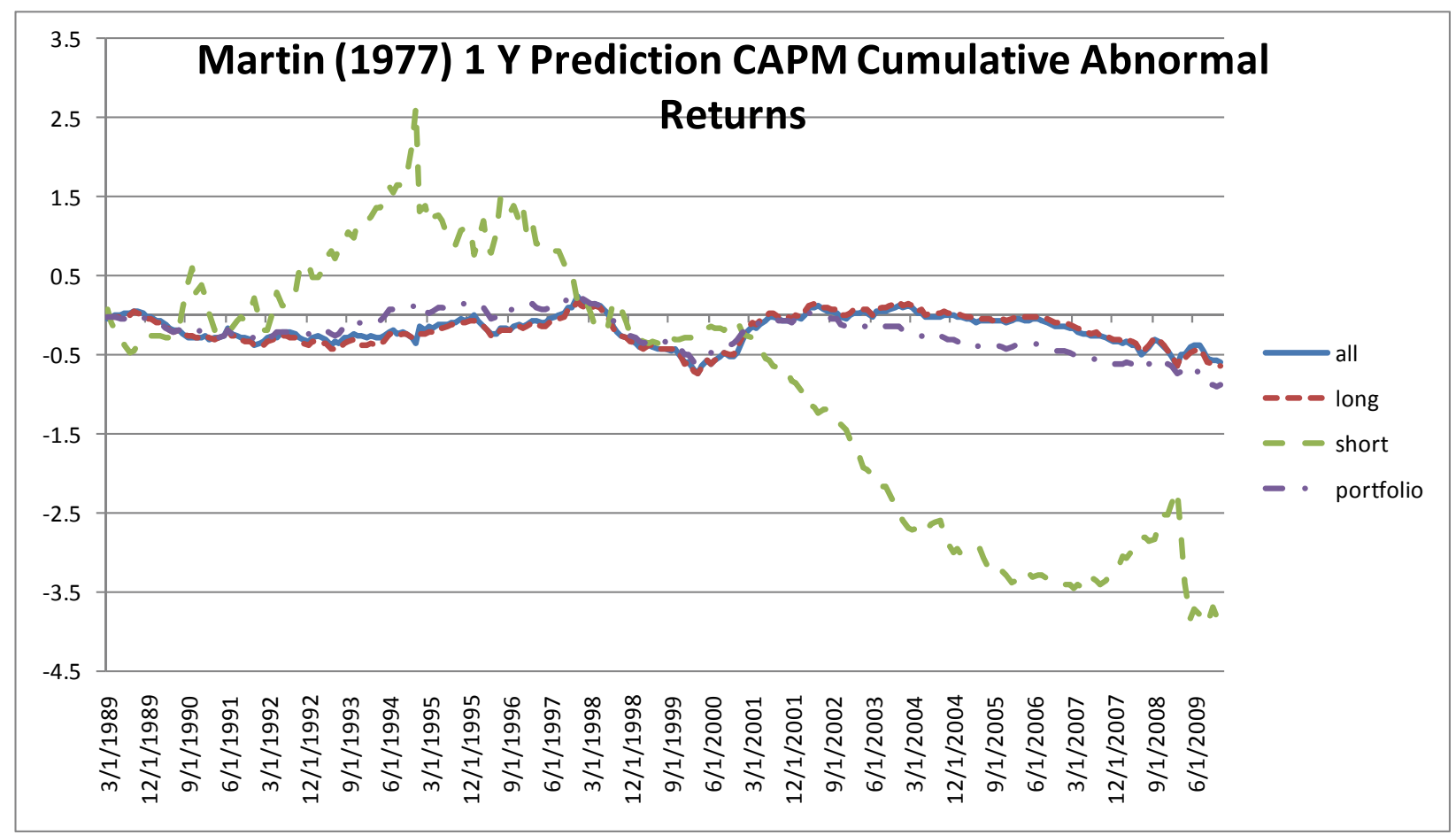

Figure 1

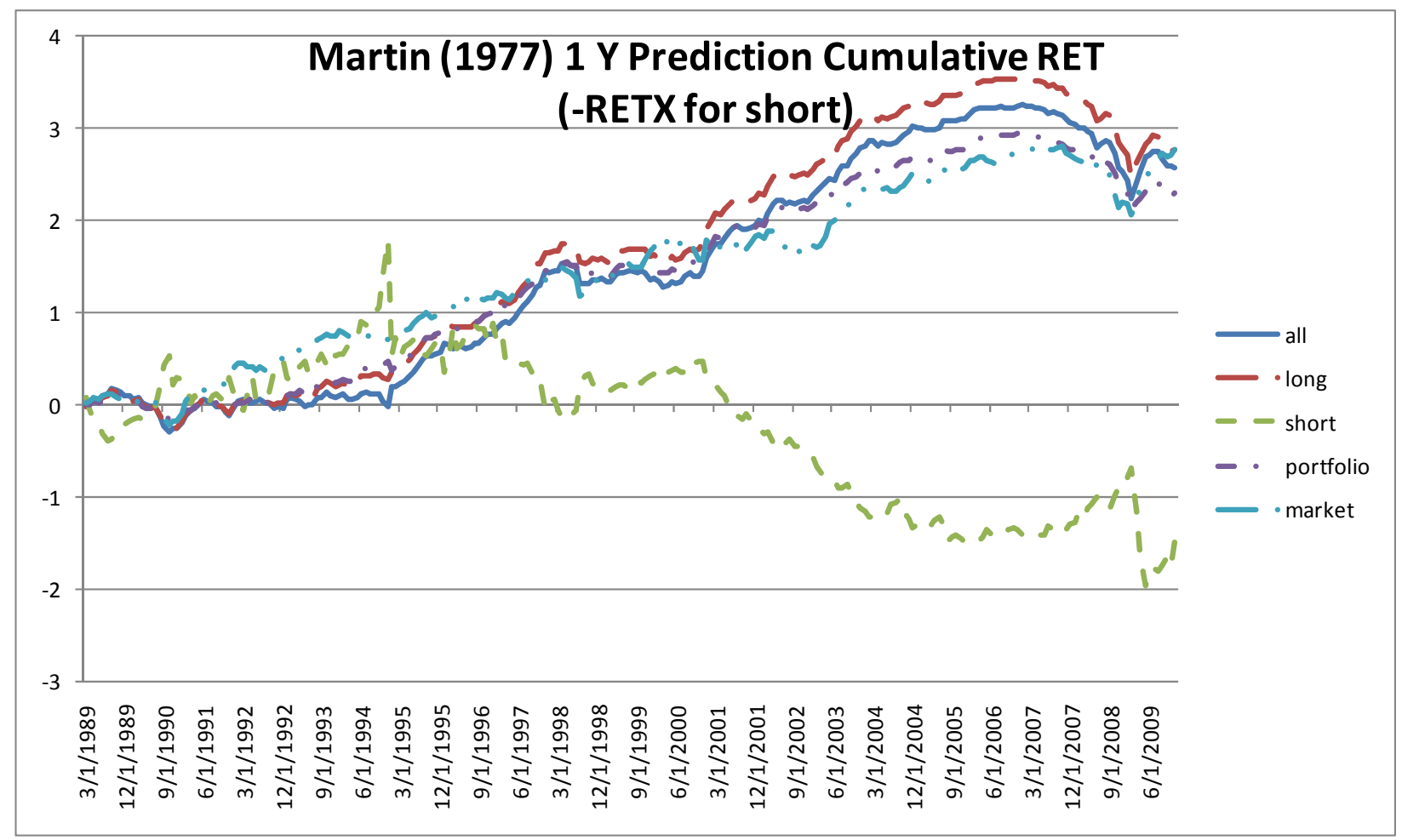

Figure 2 


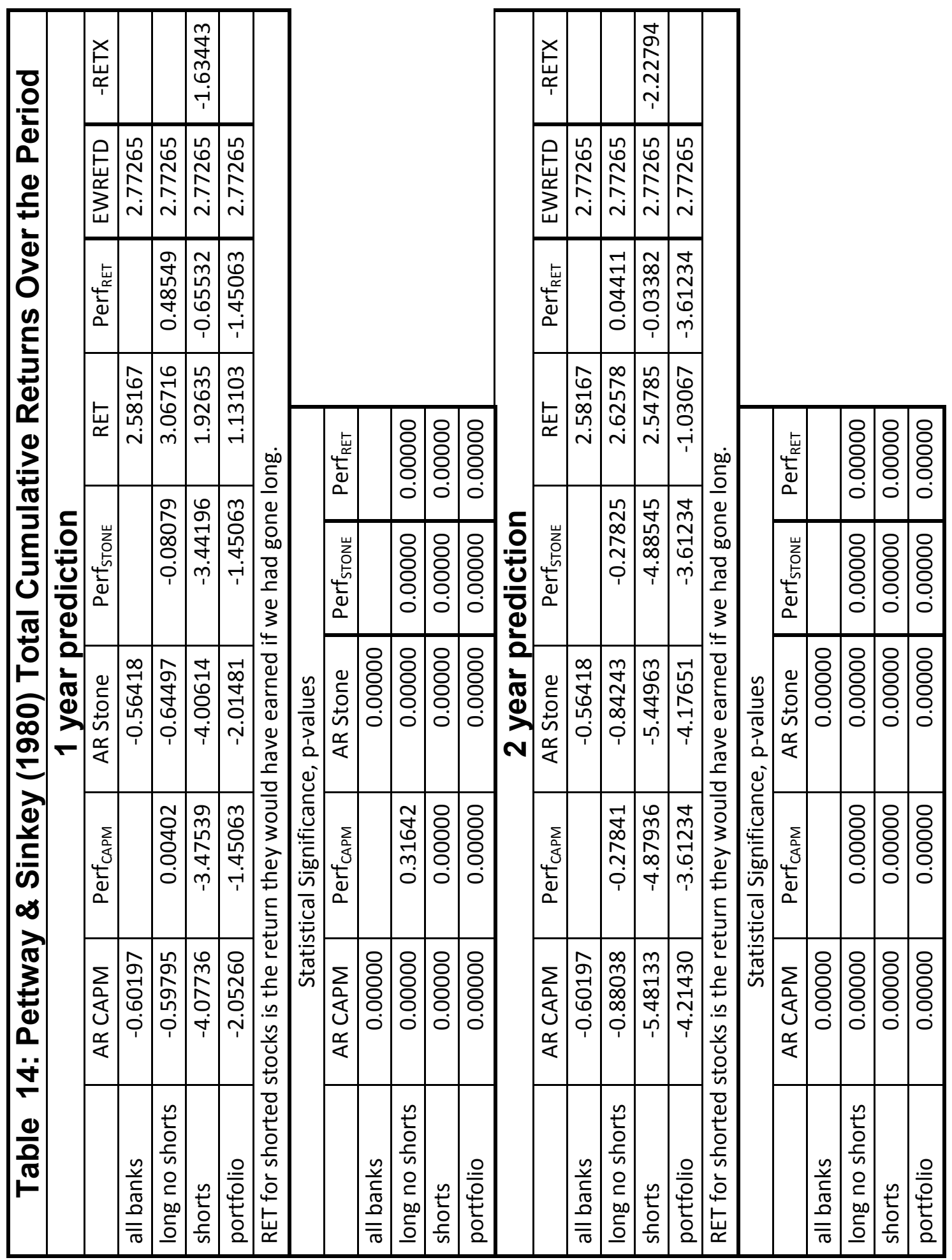




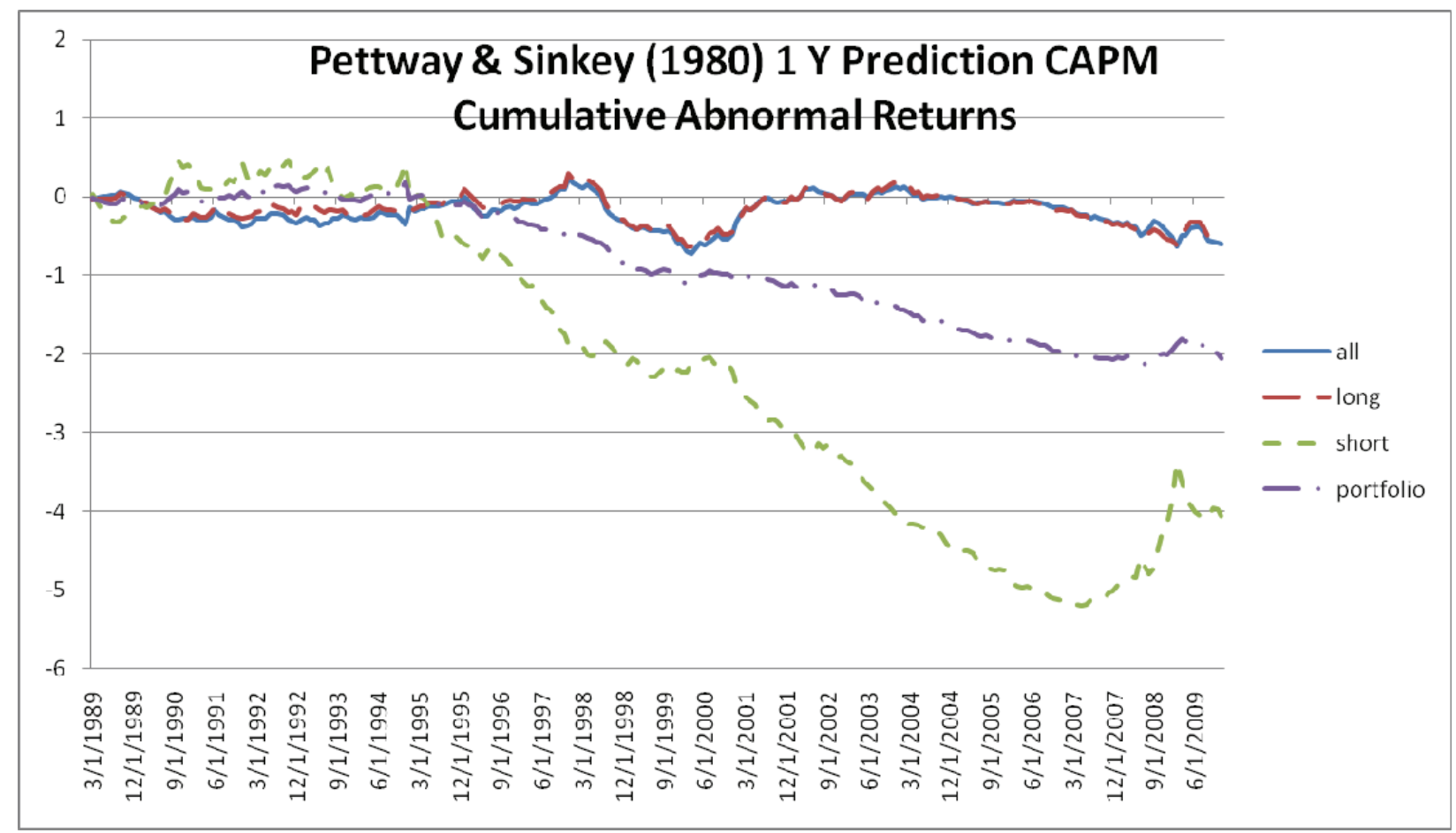

Figure 3

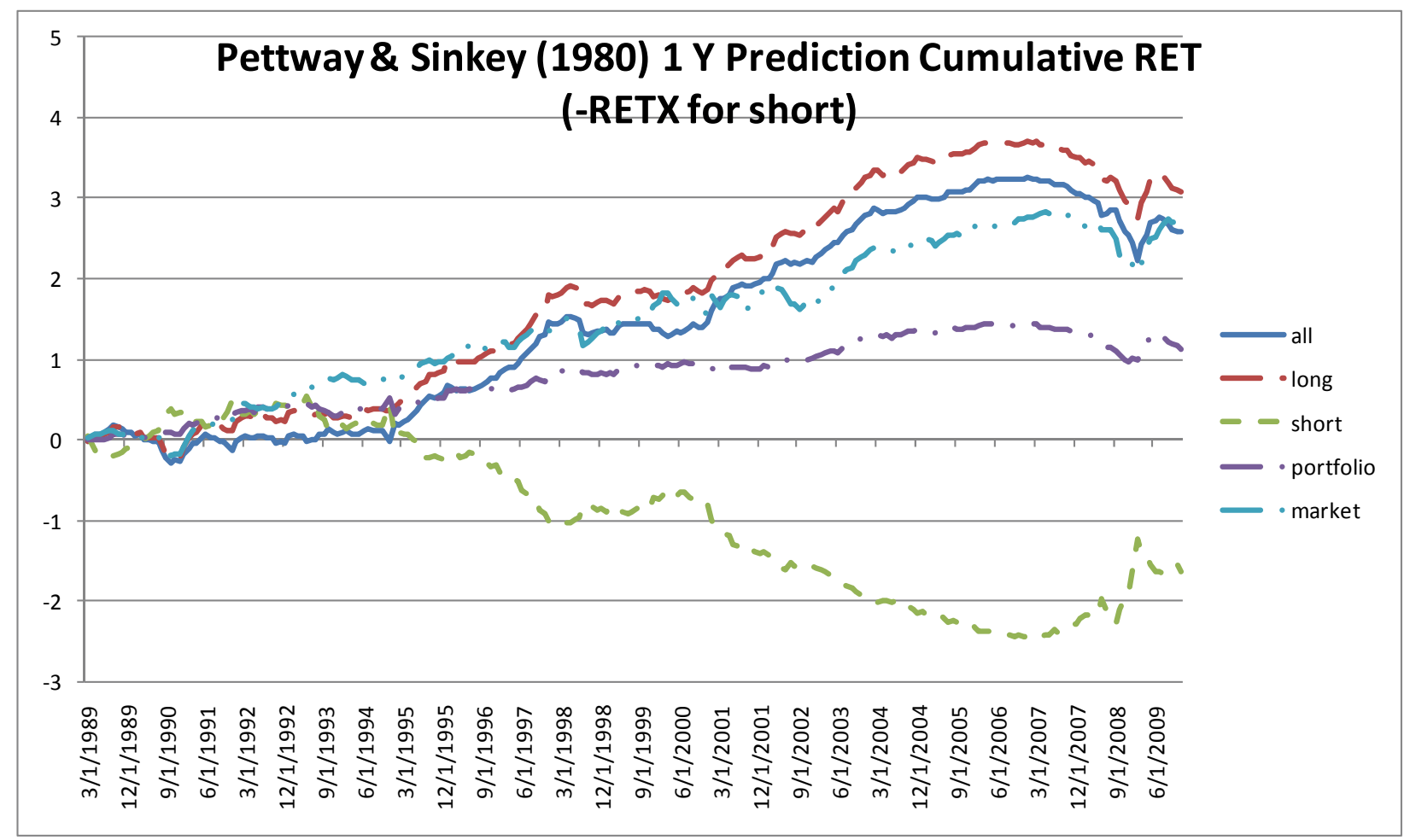

Figure 4 
i

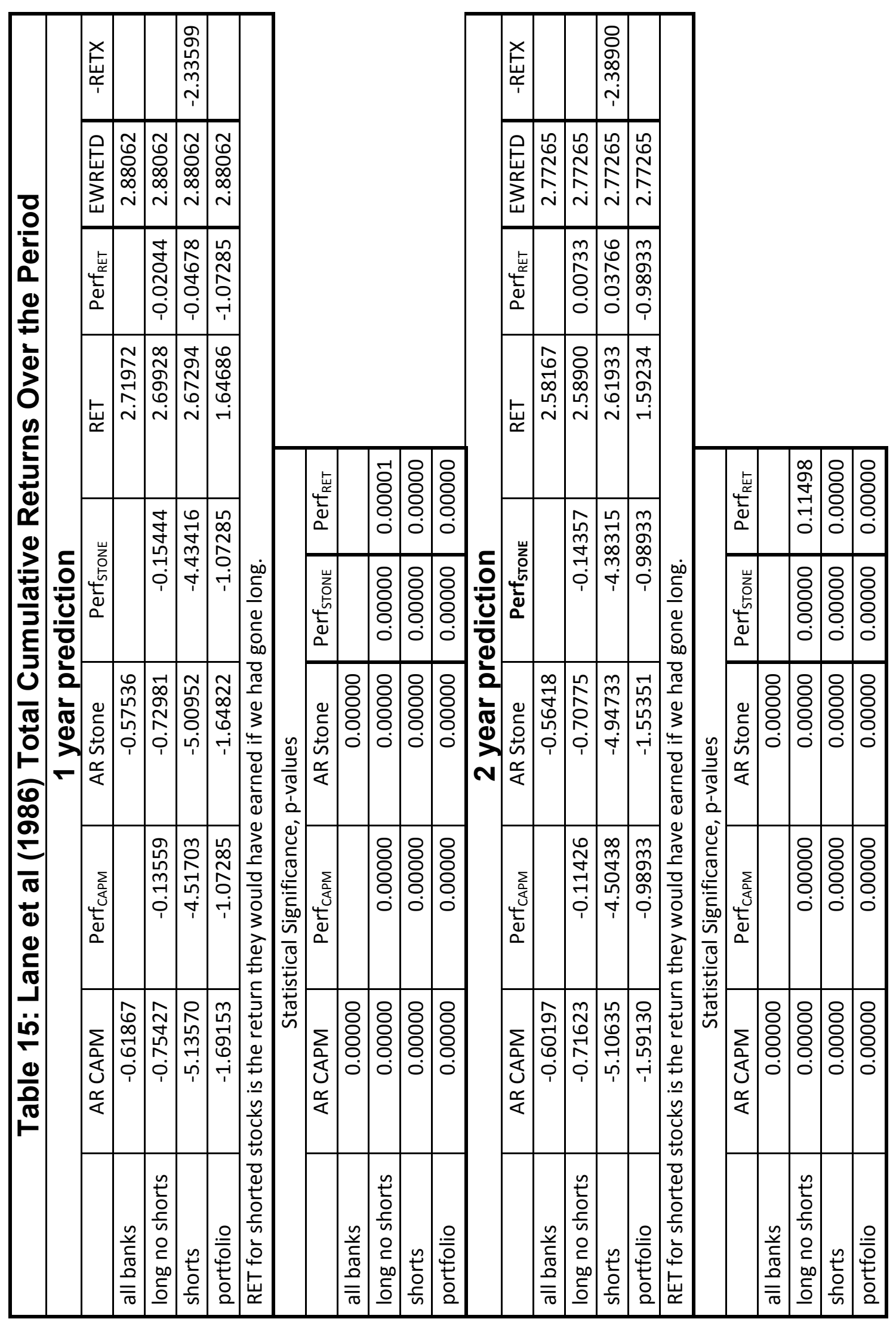




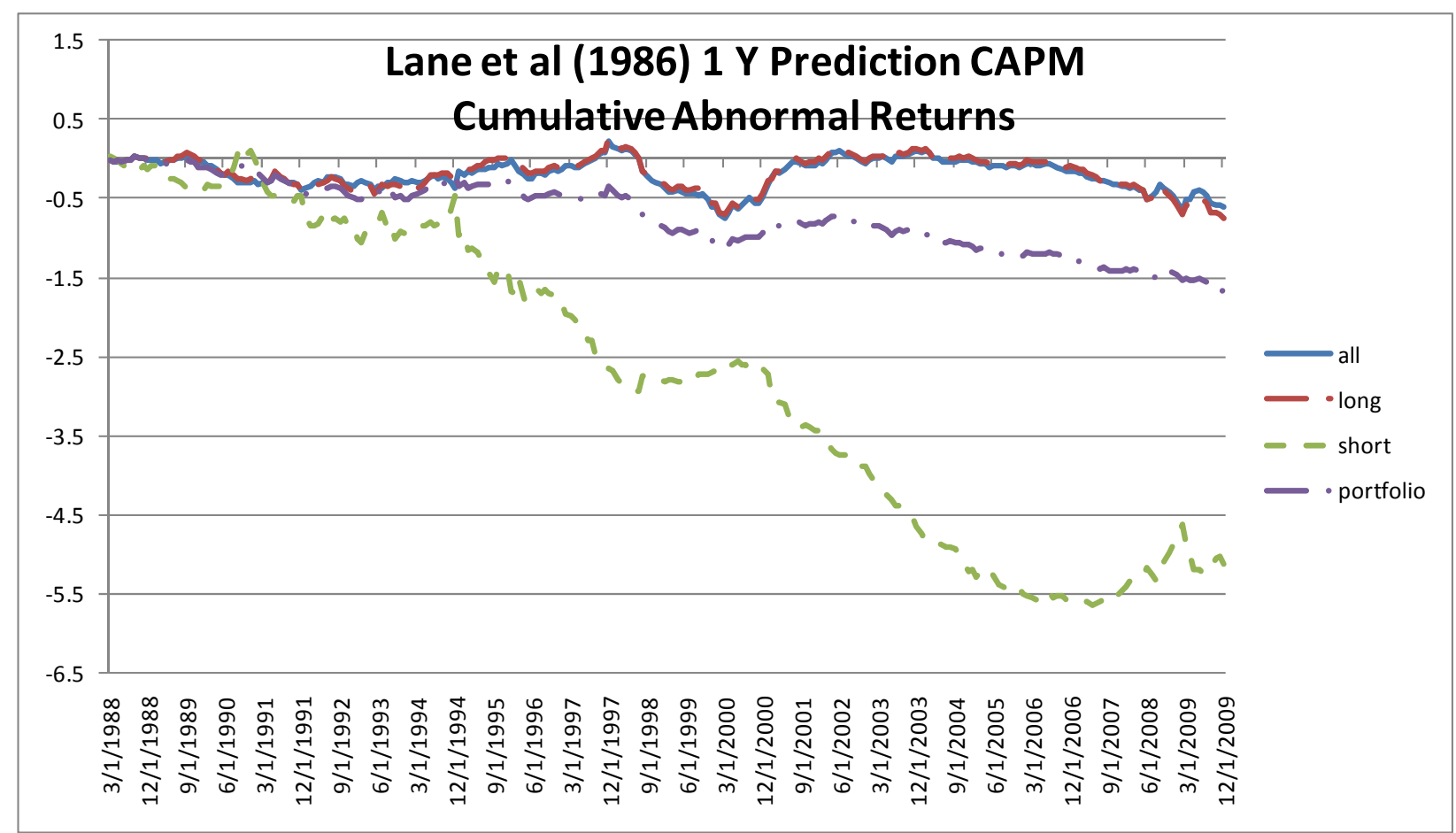

Figure 5

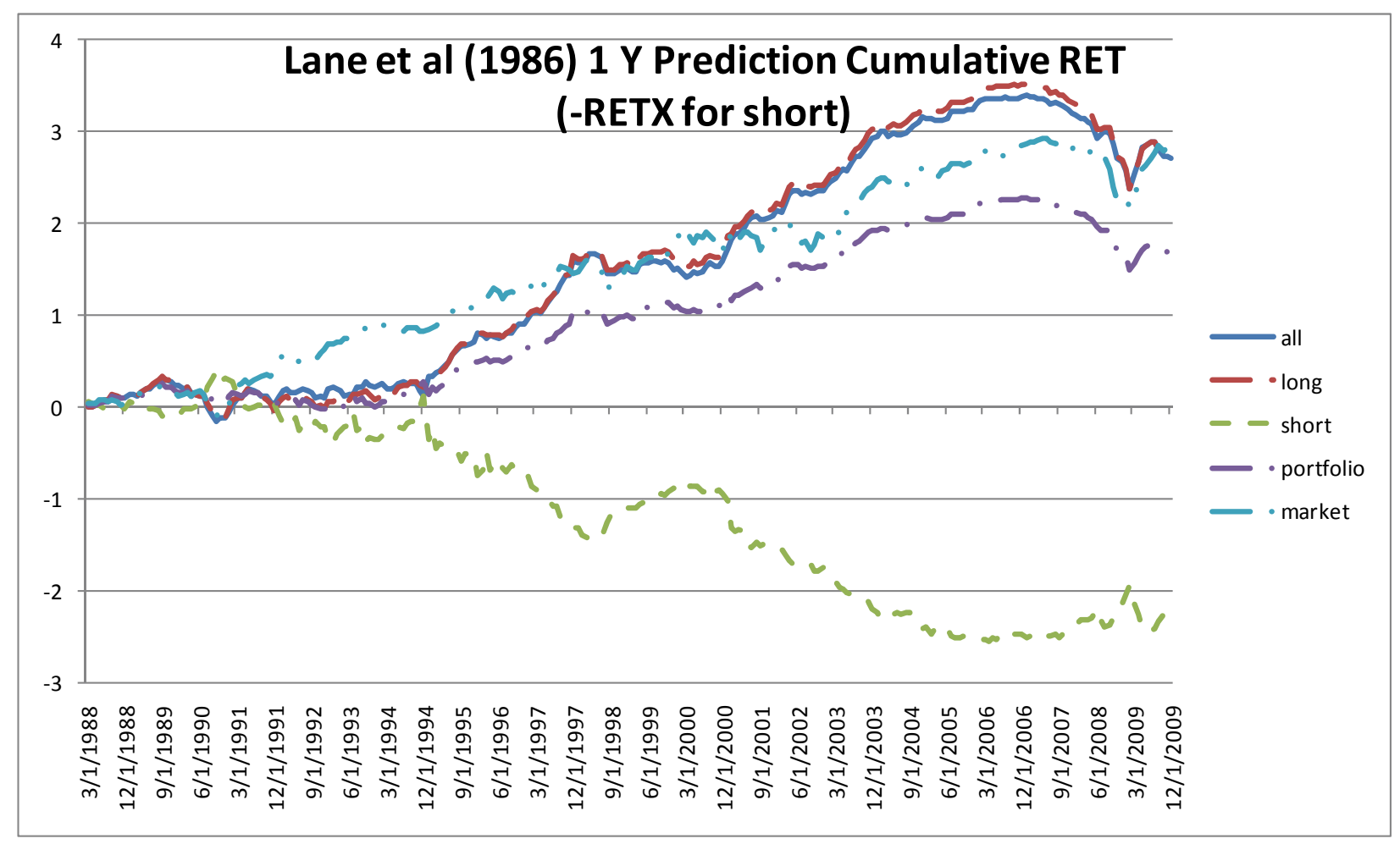

Figure 6 


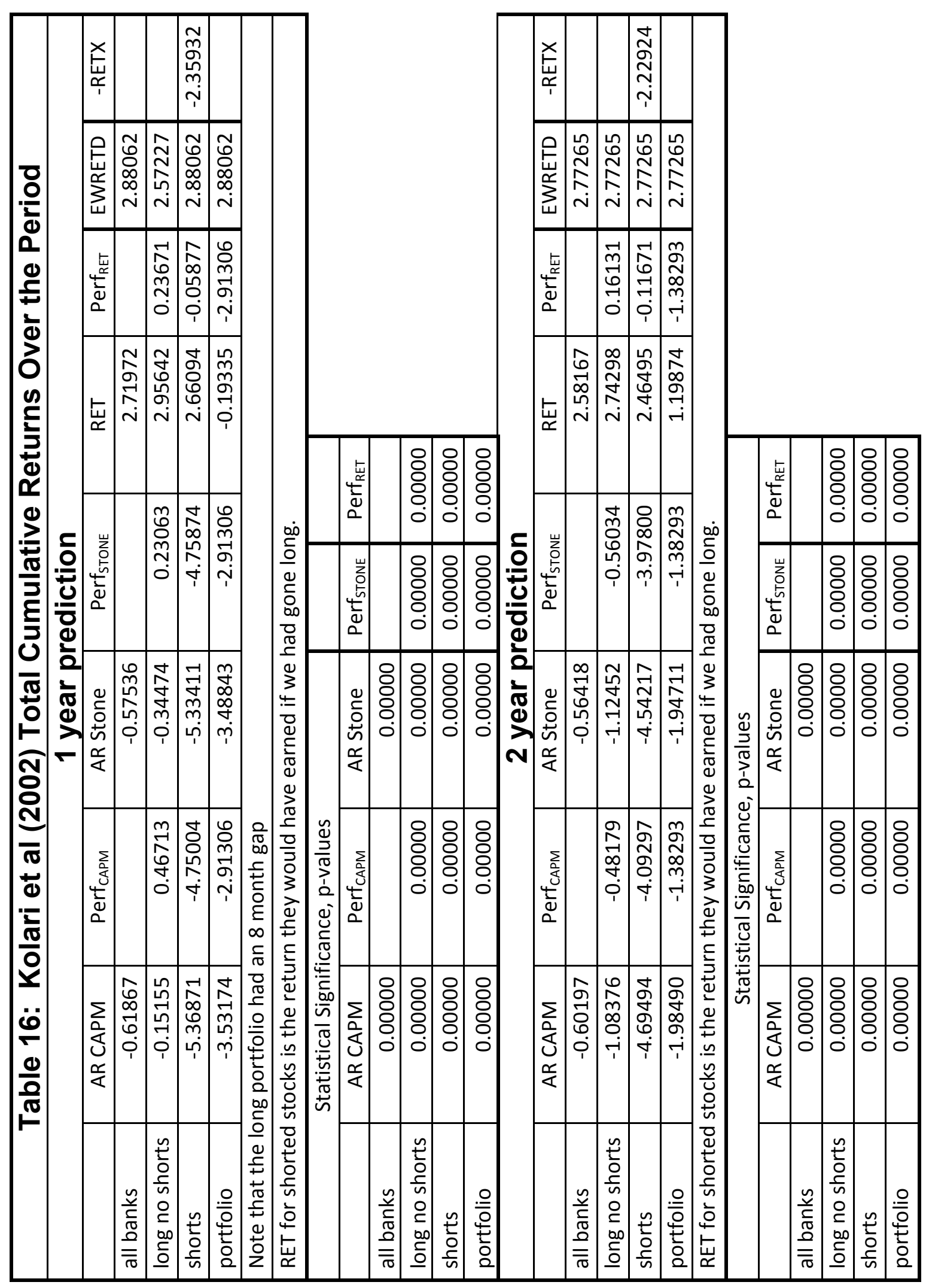




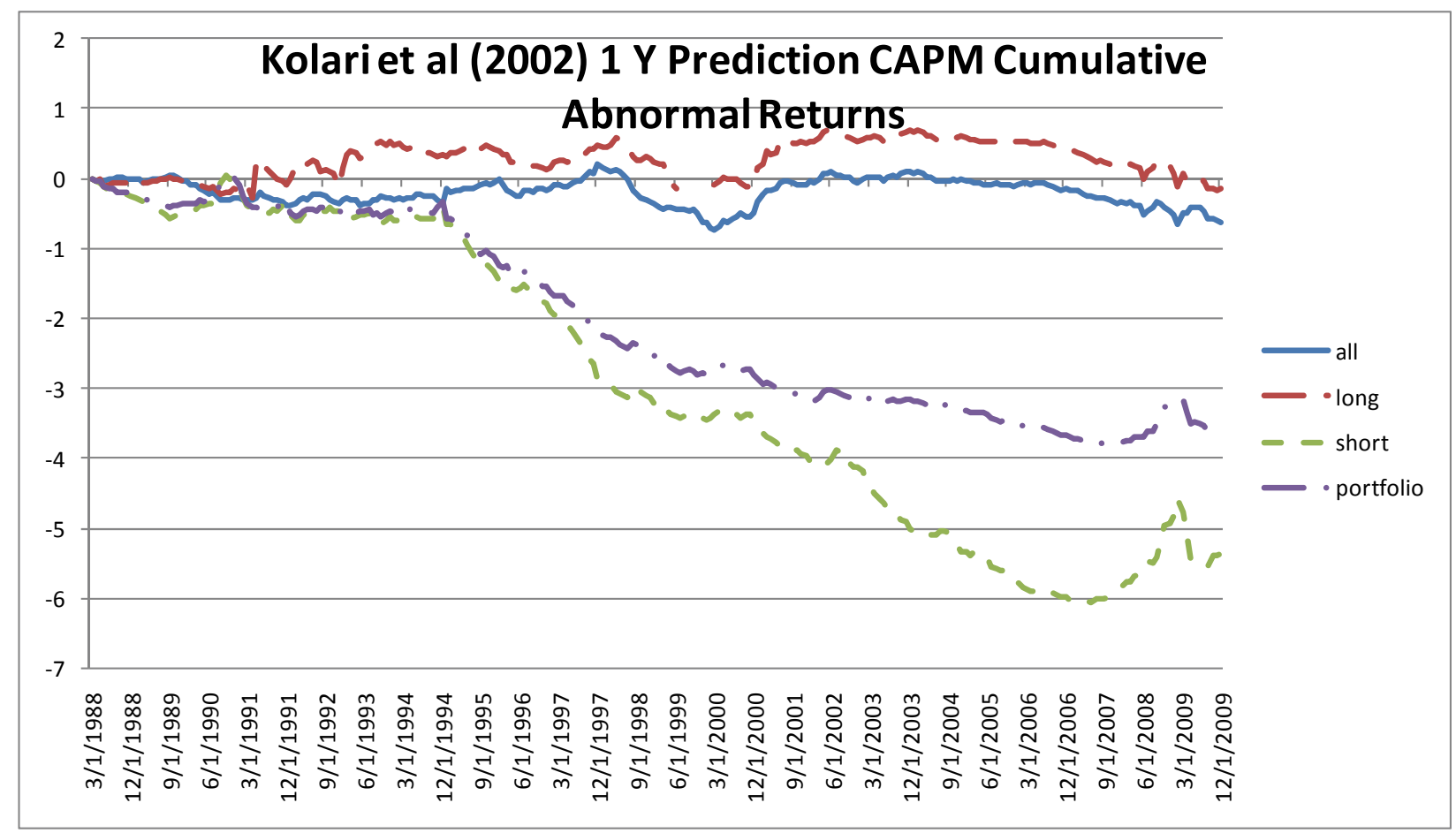

Figure 7

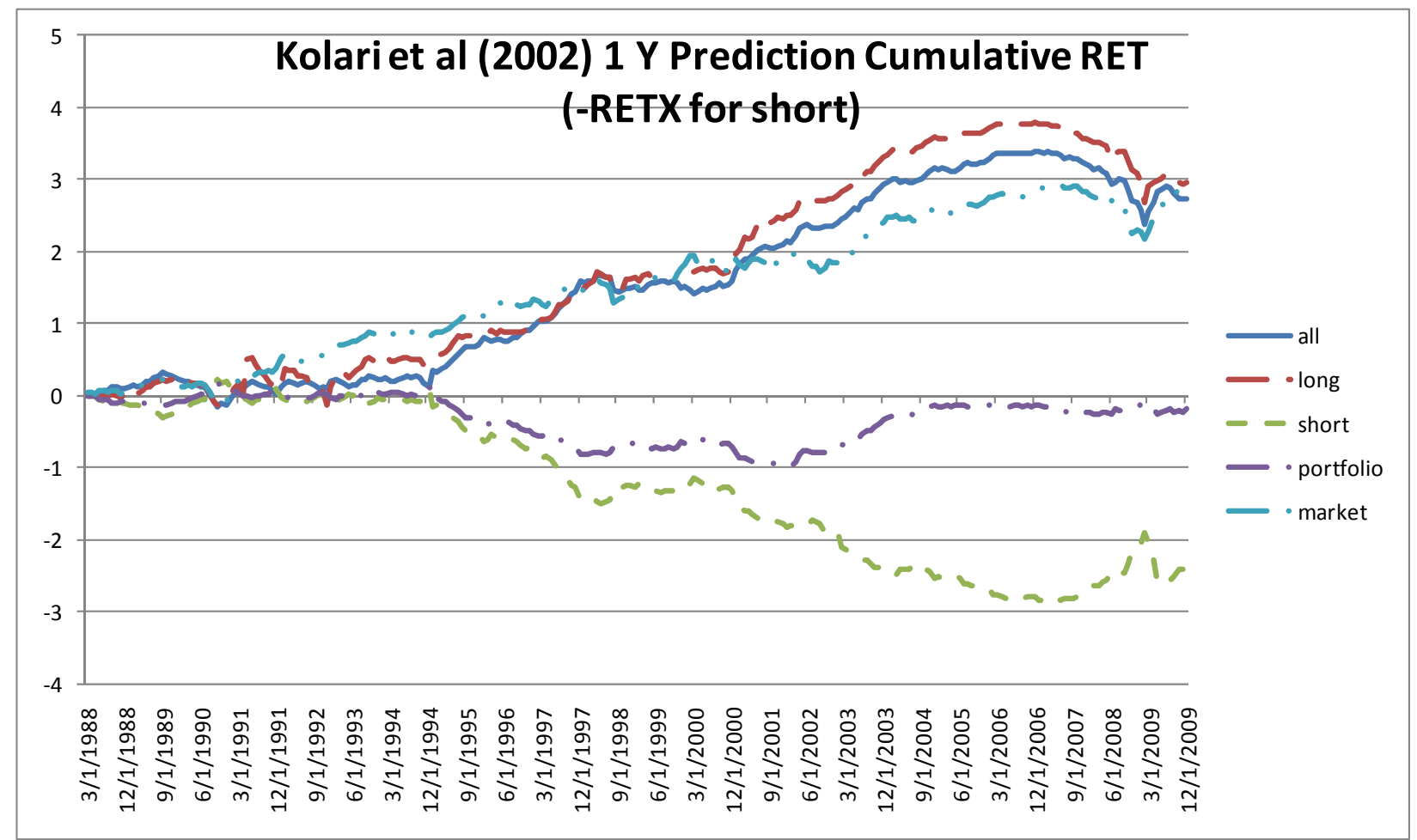

Figure 8 


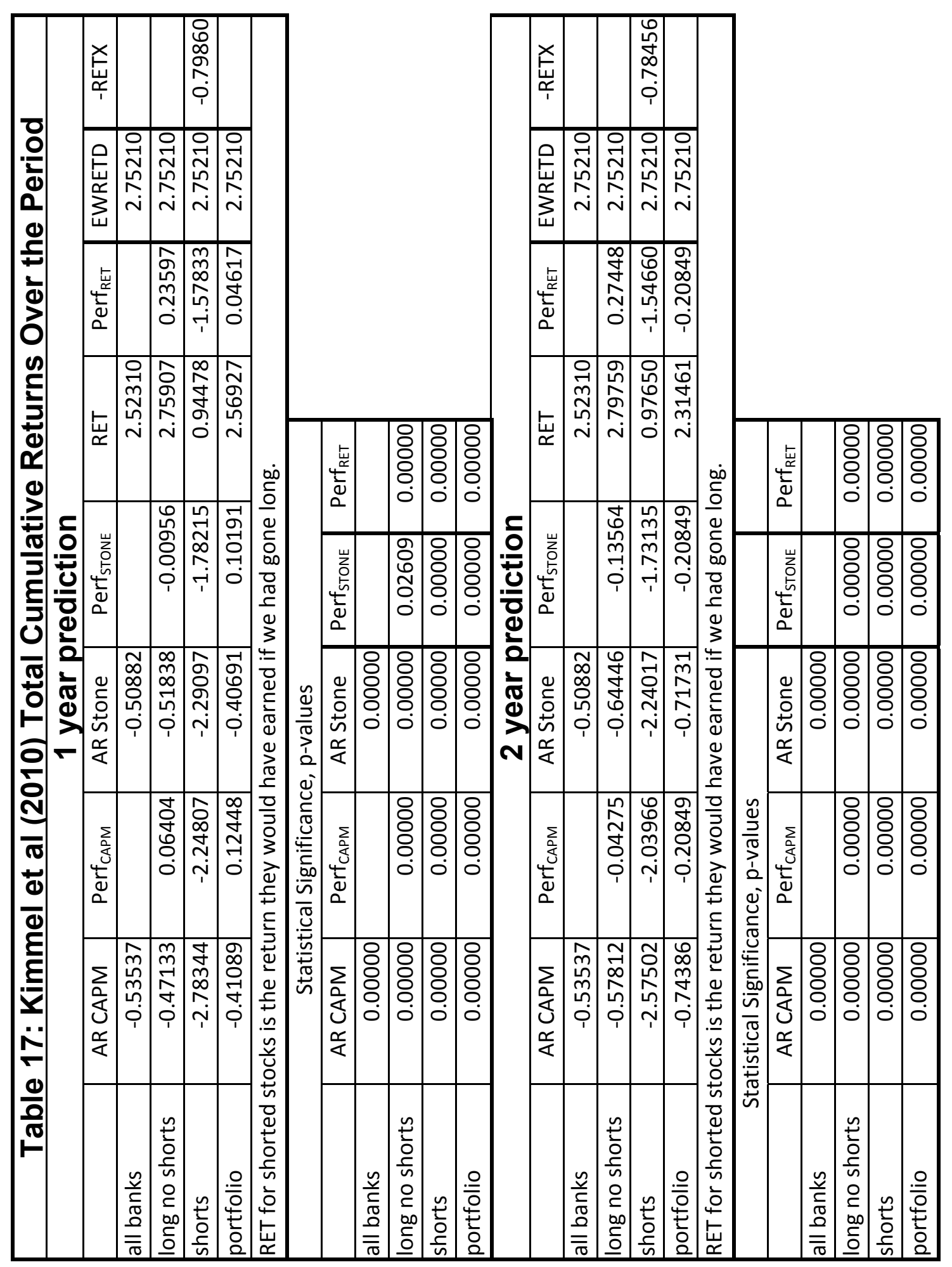




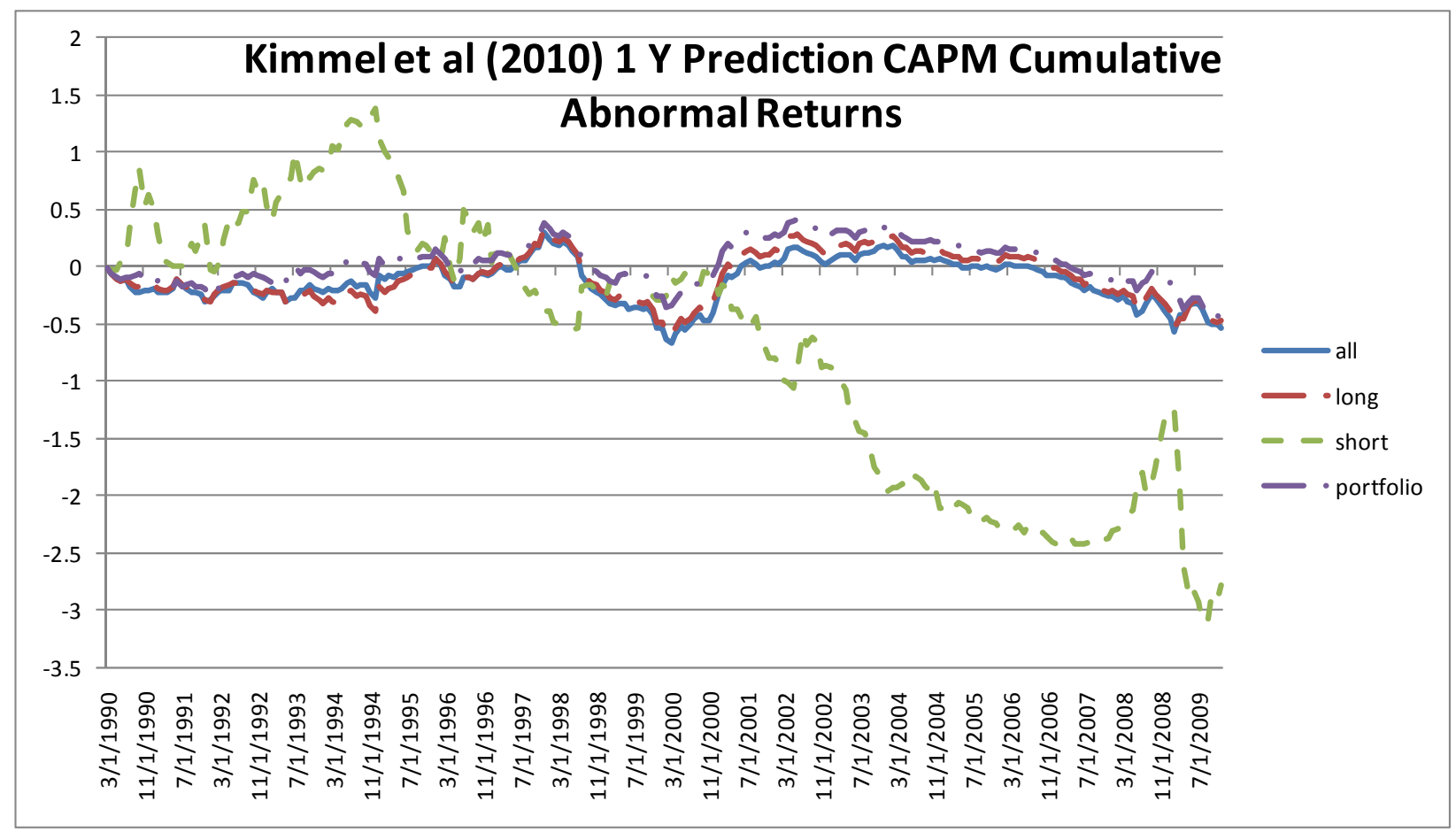

Figure 9

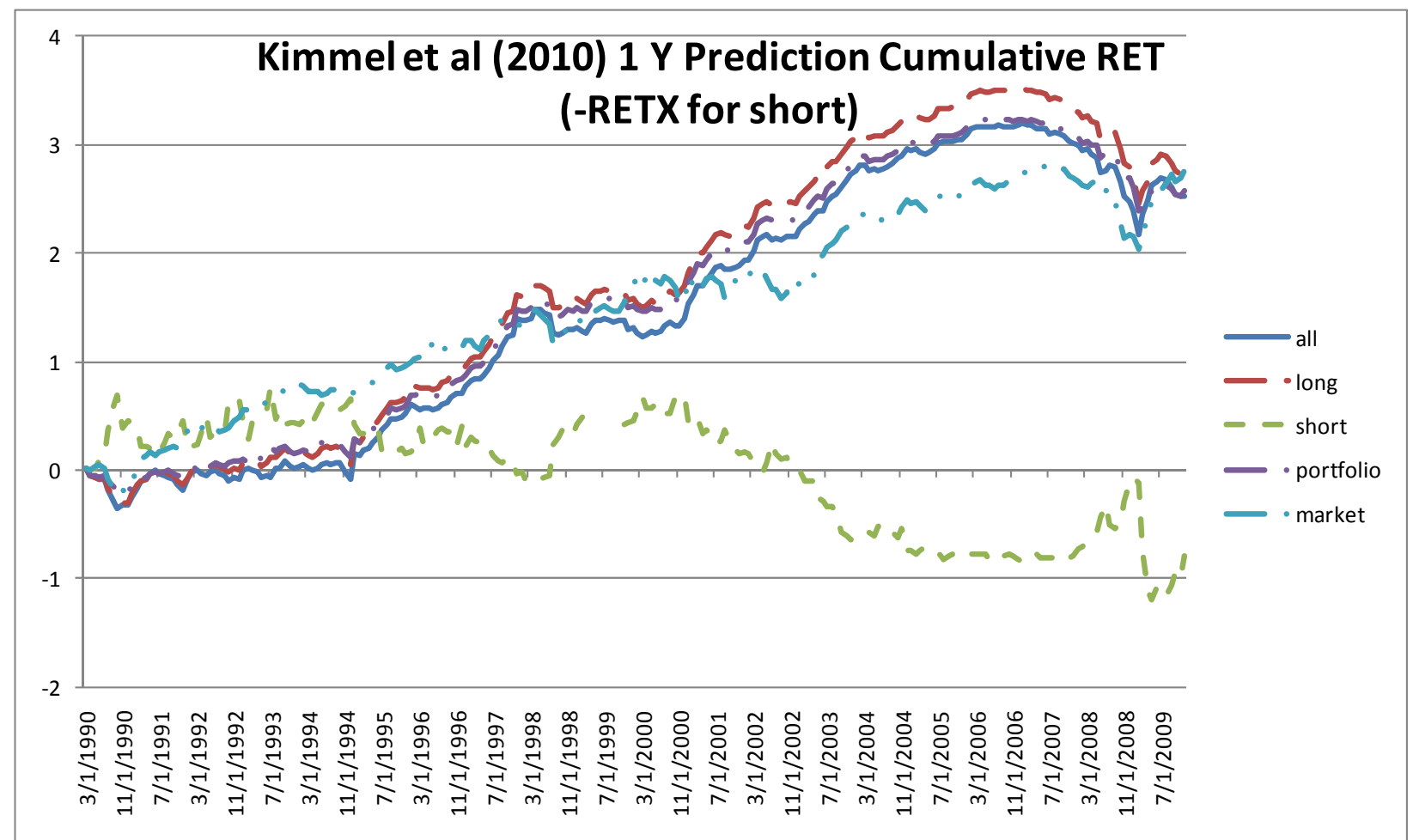

Figure 10 


\begin{tabular}{|c|c|c|c|c|}
\hline \multicolumn{5}{|c|}{ Table 18: Summary } \\
\hline Model & Prediction & $\begin{array}{c}\text { Prediction } \\
\text { Success } \\
\text { (Table 12) }\end{array}$ & $\begin{array}{c}\text { Risk Adjusted Returns (Table } 13 \text { - } \\
\text { Table 17) }\end{array}$ & $\begin{array}{c}\text { Total Returns } \\
\text { (Table } 13- \\
\text { Table } 17 \text { ) }\end{array}$ \\
\hline \multirow{2}{*}{$\begin{array}{c}\text { Martin } \\
\text { (1977): Logit }\end{array}$} & 1 Year Ahead & $67 \%$ & $\mathrm{CAR}_{\mathrm{SHORT}}>\mathrm{CAR}_{\mathrm{MKT}} 91-94$ & LONG>NAÏVE \\
\hline & 2 Year Ahead & $100 \%$ & $\mathrm{CAR}_{\text {SHORT }}>\mathrm{CAR}_{\mathrm{MKT}} 91-94$ & LONG> NAÏVE \\
\hline \multirow{2}{*}{$\begin{array}{c}\text { Pettway \& } \\
\text { Sinkey } \\
\text { (1980): MDA }\end{array}$} & 1 Year Ahead & $100 \%$ & & LONG> NAÏVE \\
\hline & 2 Year Ahead & $100 \%$ & & LONG> NAÏVE \\
\hline \multirow{2}{*}{$\begin{array}{c}\text { Lane et al } \\
\text { (1986): Cox } \\
\text { PHM }\end{array}$} & 1 Year Ahead & $67 \%$ & & \\
\hline & 2 Year Ahead & $67 \%$ & & \\
\hline \multirow{2}{*}{$\begin{array}{c}\text { Kolari et al } \\
\text { (2002): Trait } \\
\text { Analysis }\end{array}$} & 1 Year Ahead & $67 \%$ & $\mathrm{CAR}_{\text {LONG }}>\mathrm{CAR}_{\text {NAIVE }}$ & LONG> NAÏVE \\
\hline & 2 Year Ahead & $67 \%$ & & LONG> NAÏVE \\
\hline \multirow[t]{2}{*}{$\begin{array}{l}\text { Kimmel et al } \\
\text { (2010): LOESS }\end{array}$} & 1 Year Ahead & $100 \%$ & $\begin{array}{l}\text { CAR }_{\text {SHORT }}>C_{\text {CAR }} \text { MKT } \\
\text { CA1-94, } \\
\text { CARORTFOLIO }_{\text {PCAR }} \text { NAIIVE }\end{array}$ & $\begin{array}{l}\text { LONG, SHORT> } \\
\text { NAIIVE }\end{array}$ \\
\hline & 2 Year Ahead & $100 \%$ & $\mathrm{CAR}_{\mathrm{SHORT}}>\mathrm{CAR}_{\mathrm{MKT}}$ 91-94, & LONG> NAÏVE \\
\hline
\end{tabular}




\begin{tabular}{|c|c|c|c|c|c|}
\hline \multicolumn{6}{|c|}{ Table 19: Summary Financial Crisis (2006 - 2009) } \\
\hline \multicolumn{6}{|c|}{$\begin{array}{l}\text { statistically significant total cumulative returns over the period using } 1 \text { year } \\
\text { ahead prediction models }\end{array}$} \\
\hline Model & Portfolio & $\begin{array}{l}\text { CAPM } \\
\text { Risk } \\
\text { Adjusted } \\
\text { return }\end{array}$ & PERF & $\begin{array}{l}\text { Total } \\
\text { Return } \\
\text { (Market } \\
\text { return } \\
=-0.220 \text { ) }\end{array}$ & PERF $_{\text {RET }}$ \\
\hline \multirow{4}{*}{$\begin{array}{l}\text { Martin } \\
(1977)\end{array}$} & All (Naïve) & 0.525 & & 0.518 & \\
\hline & Long & 0.575 & 0.050 & 0.613 & 0.094 \\
\hline & Short & 0.369 & -0.156 & 0.029 & -0.490 \\
\hline & Portfolio & 0.475 & -0.050 & 0.468 & -0.050 \\
\hline \multirow{4}{*}{$\begin{array}{c}\text { Pettway \& } \\
\text { Sinkey } \\
(1980)\end{array}$} & All (Naïve) & 0.525 & & 0.518 & \\
\hline & Long & 0.527 & & 0.505 & \\
\hline & Short & -0.660 & -1.184 & -0.601 & -1.120 \\
\hline & Portfolio & 0.276 & -0.249 & 0.270 & -0.249 \\
\hline \multirow{4}{*}{$\begin{array}{l}\text { Lane et al } \\
(1986)\end{array}$} & All (Naïve) & 0.525 & & 0.518 & \\
\hline & Long & 0.685 & 0.160 & 0.647 & 0.128 \\
\hline & Short & -0.294 & -0.819 & -0.170 & -0.689 \\
\hline & Portfolio & 0.482 & -0.043 & 0.476 & -0.043 \\
\hline \multirow{4}{*}{$\begin{array}{c}\text { Kolari et al } \\
(2002)\end{array}$} & All (Naïve) & 0.525 & & 0.518 & \\
\hline & Long & 0.665 & 0.140 & 0.694 & 0.176 \\
\hline & Short & -0.279 & -0.804 & -0.286 & -0.804 \\
\hline & Portfolio & 0.048 & -0.476 & 0.042 & -0.476 \\
\hline \multirow{4}{*}{$\begin{array}{l}\text { Kimmel et } \\
\text { al (2010) }\end{array}$} & All (Naïve) & 0.525 & & 0.518 & \\
\hline & Long & 0.527 & & 0.602 & 0.083 \\
\hline & Short & 0.567 & & 0.022 & -0.497 \\
\hline & Portfolio & 0.541 & & 0.535 & \\
\hline
\end{tabular}




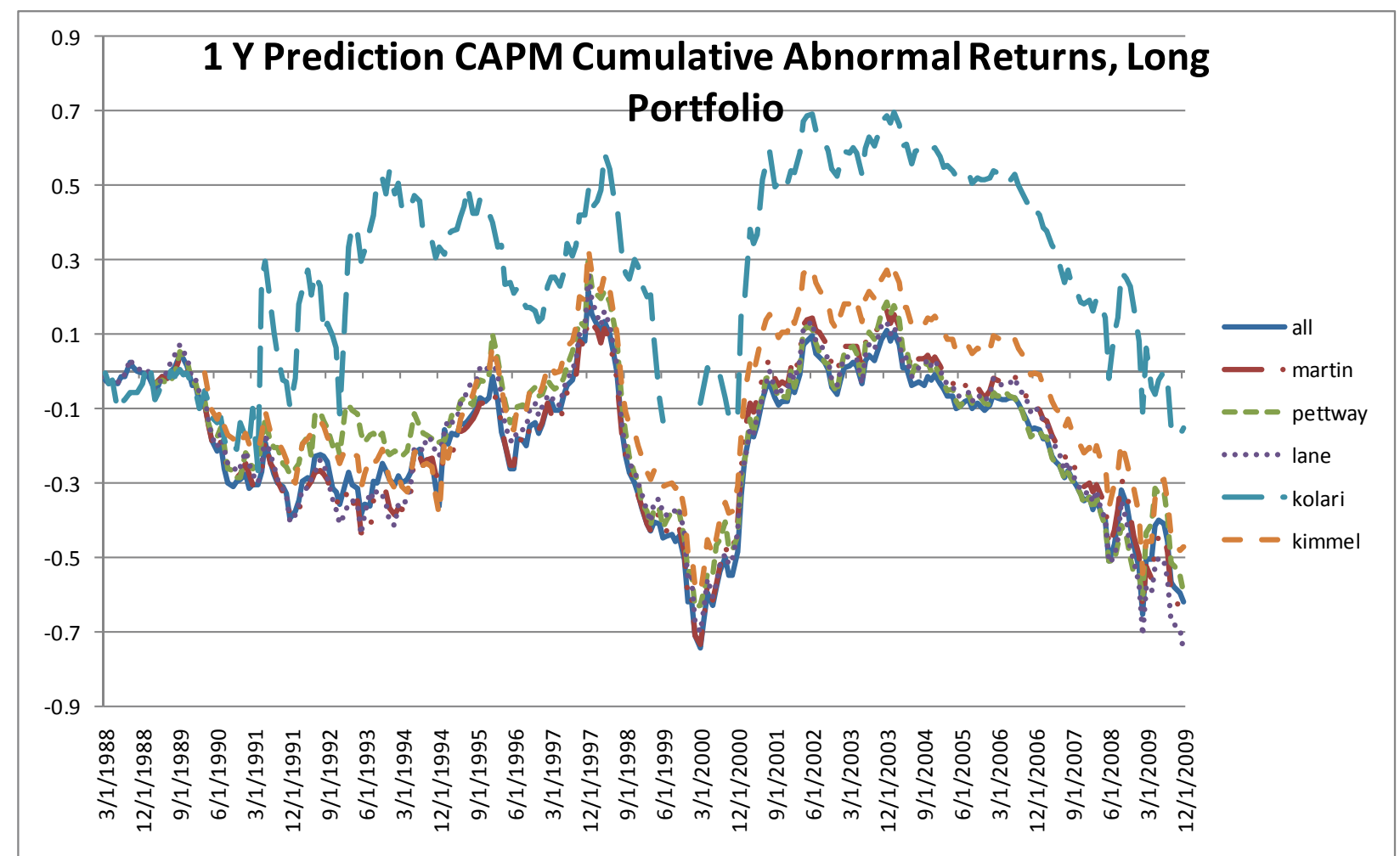

\section{Figure 11}

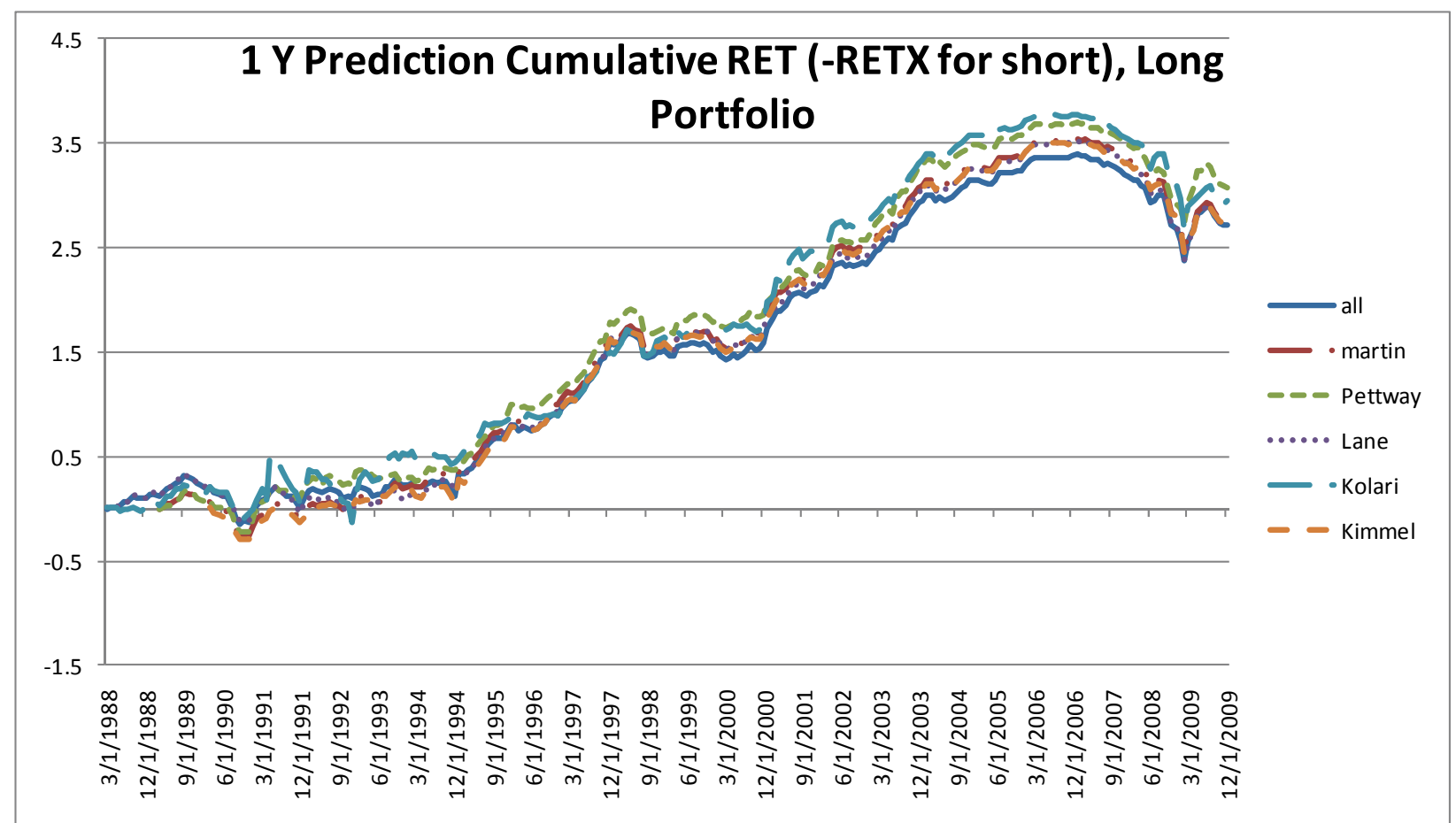

Figure 12 


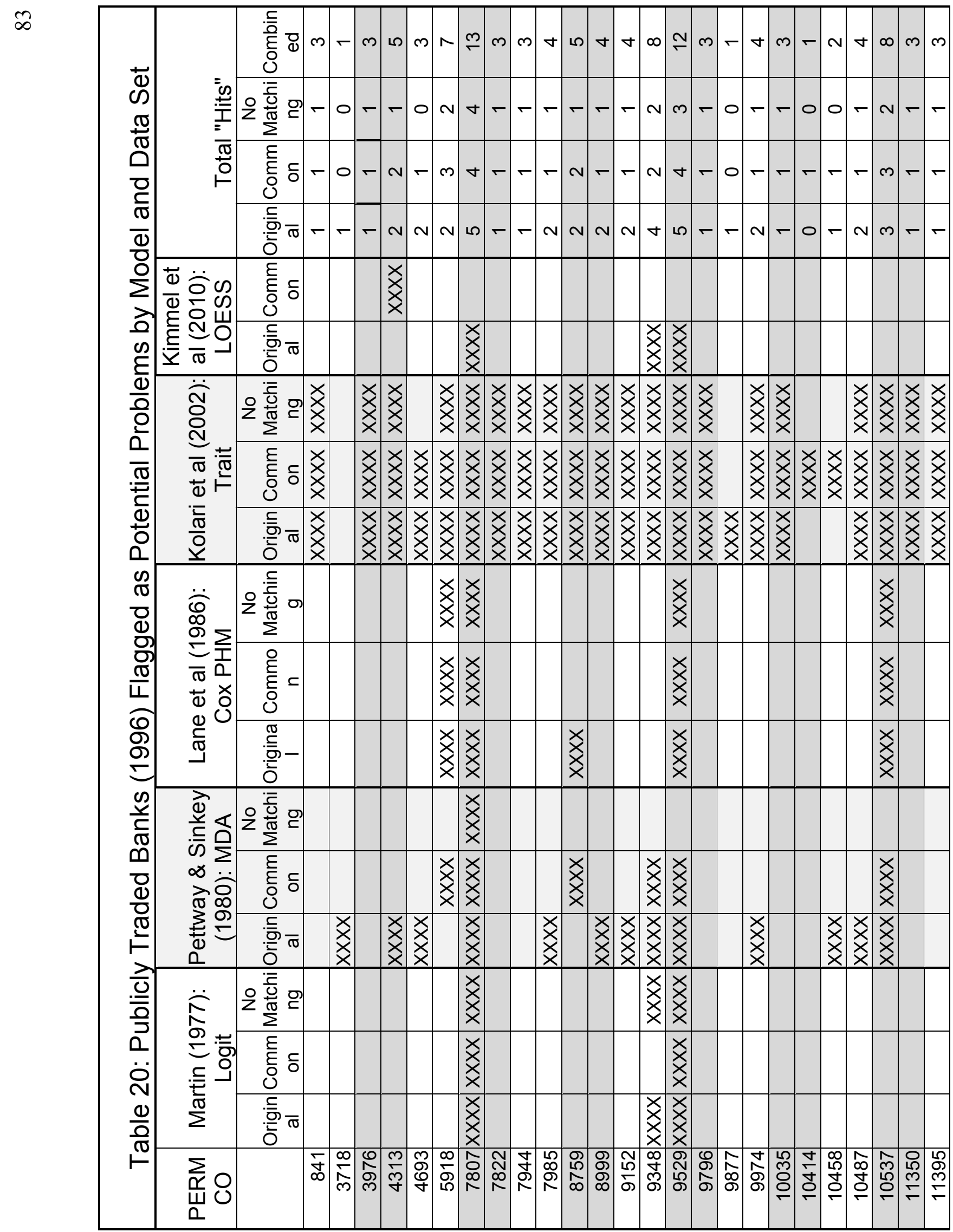


\$

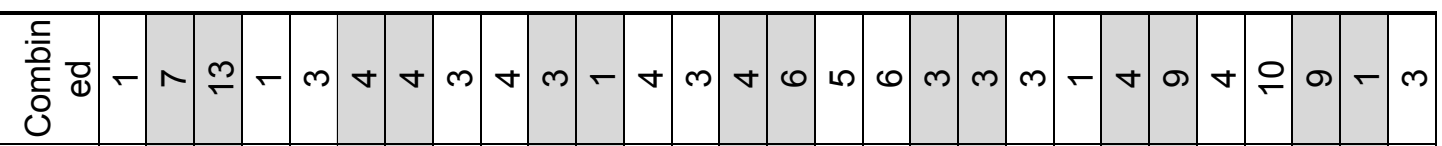

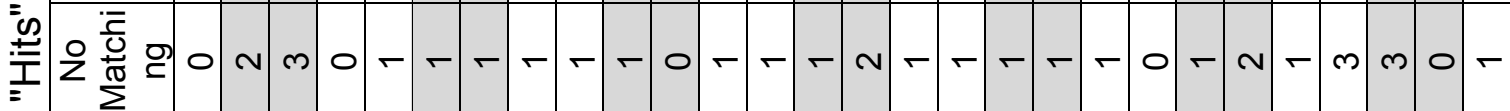
$\frac{0}{0}$
$\bar{\pi}$

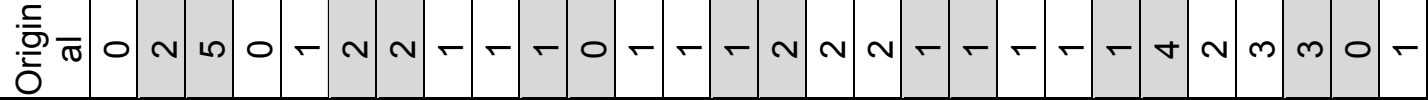

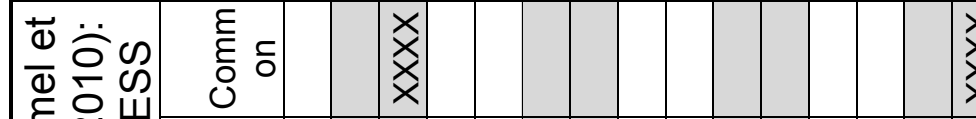

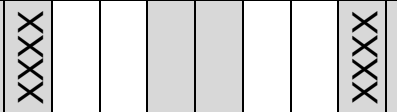

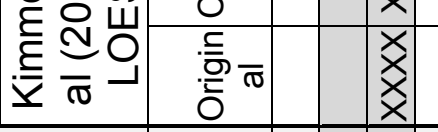

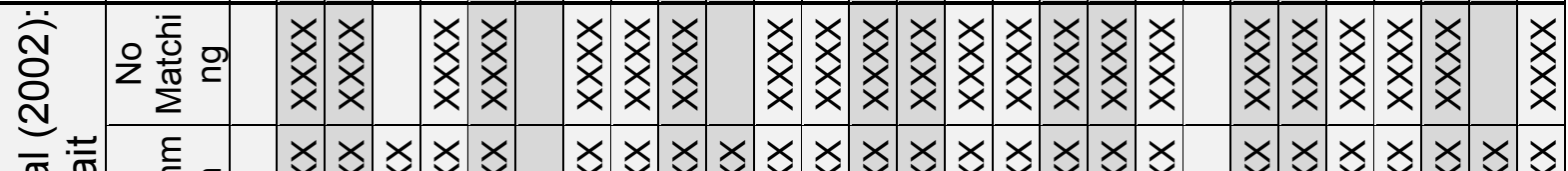

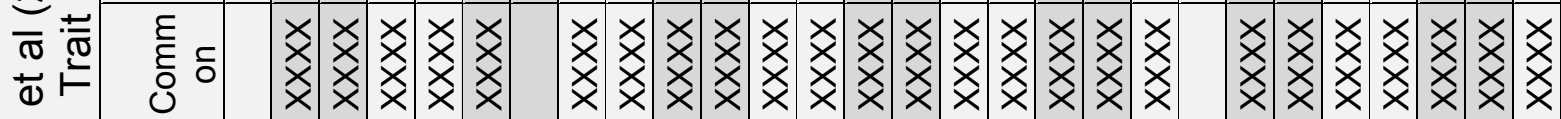

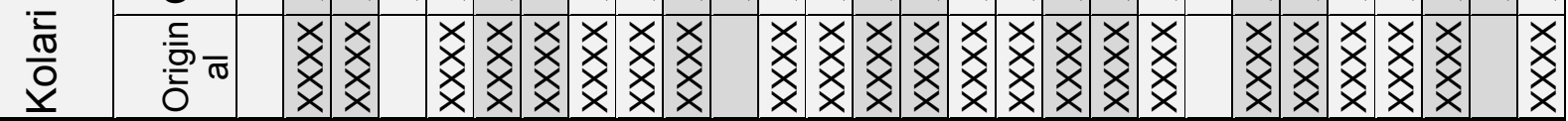

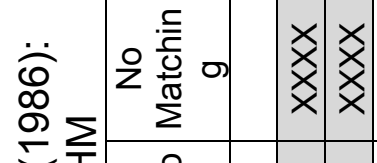

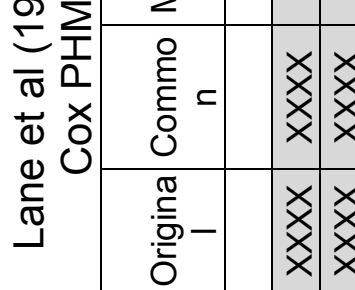

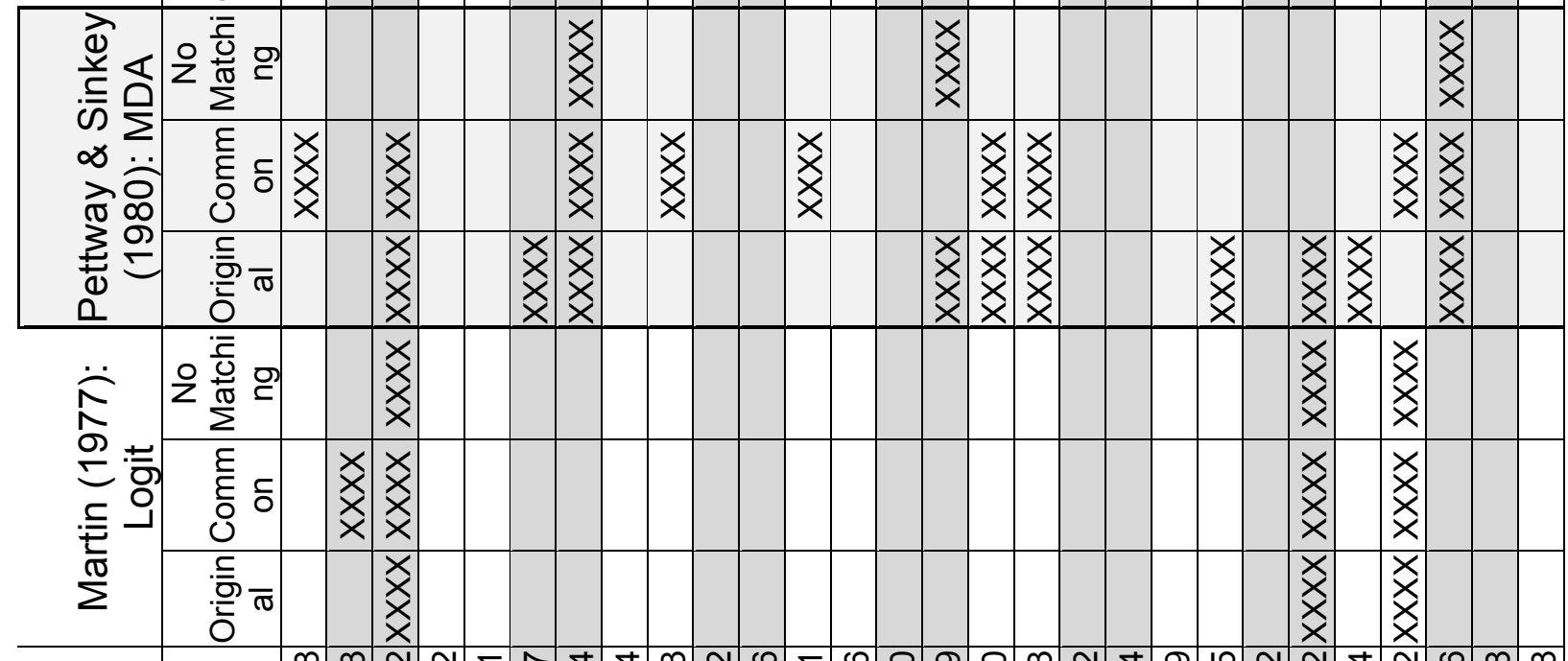
蛋 0 
$\infty$

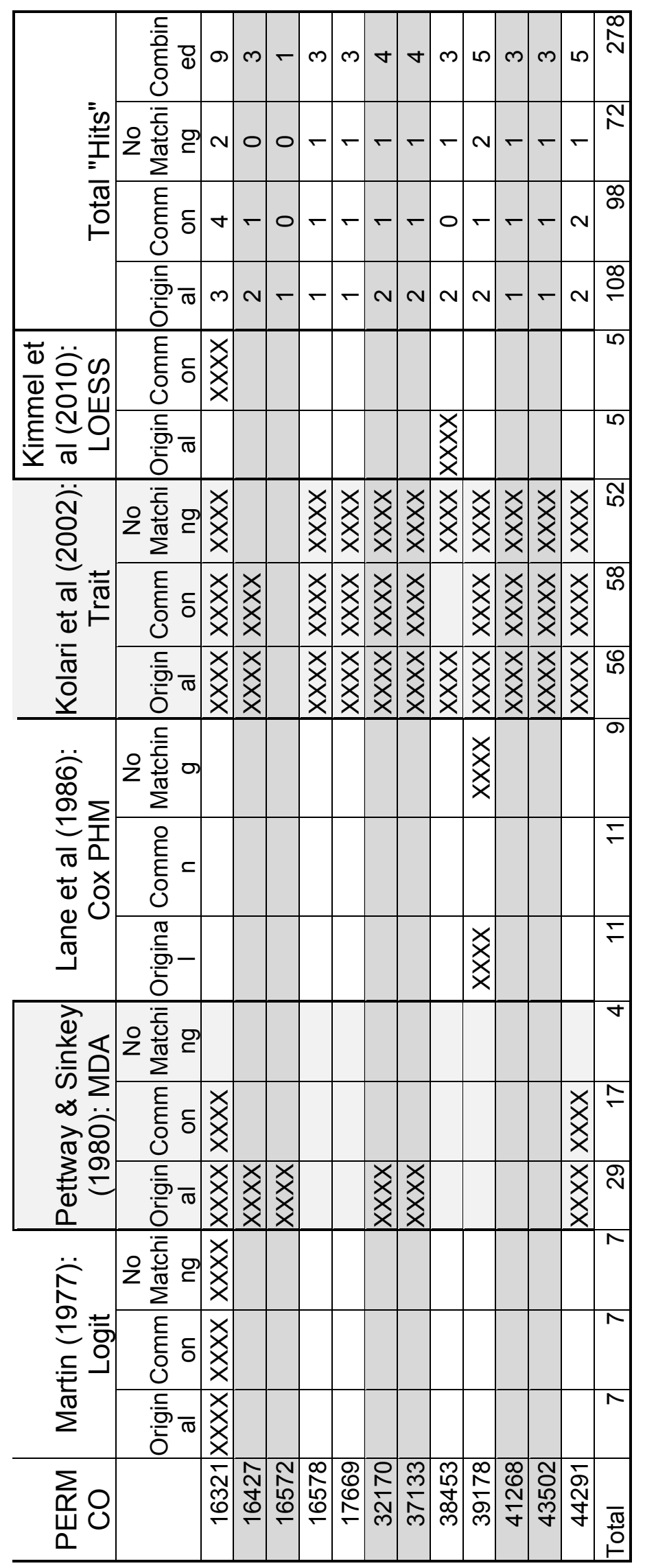


$\infty$
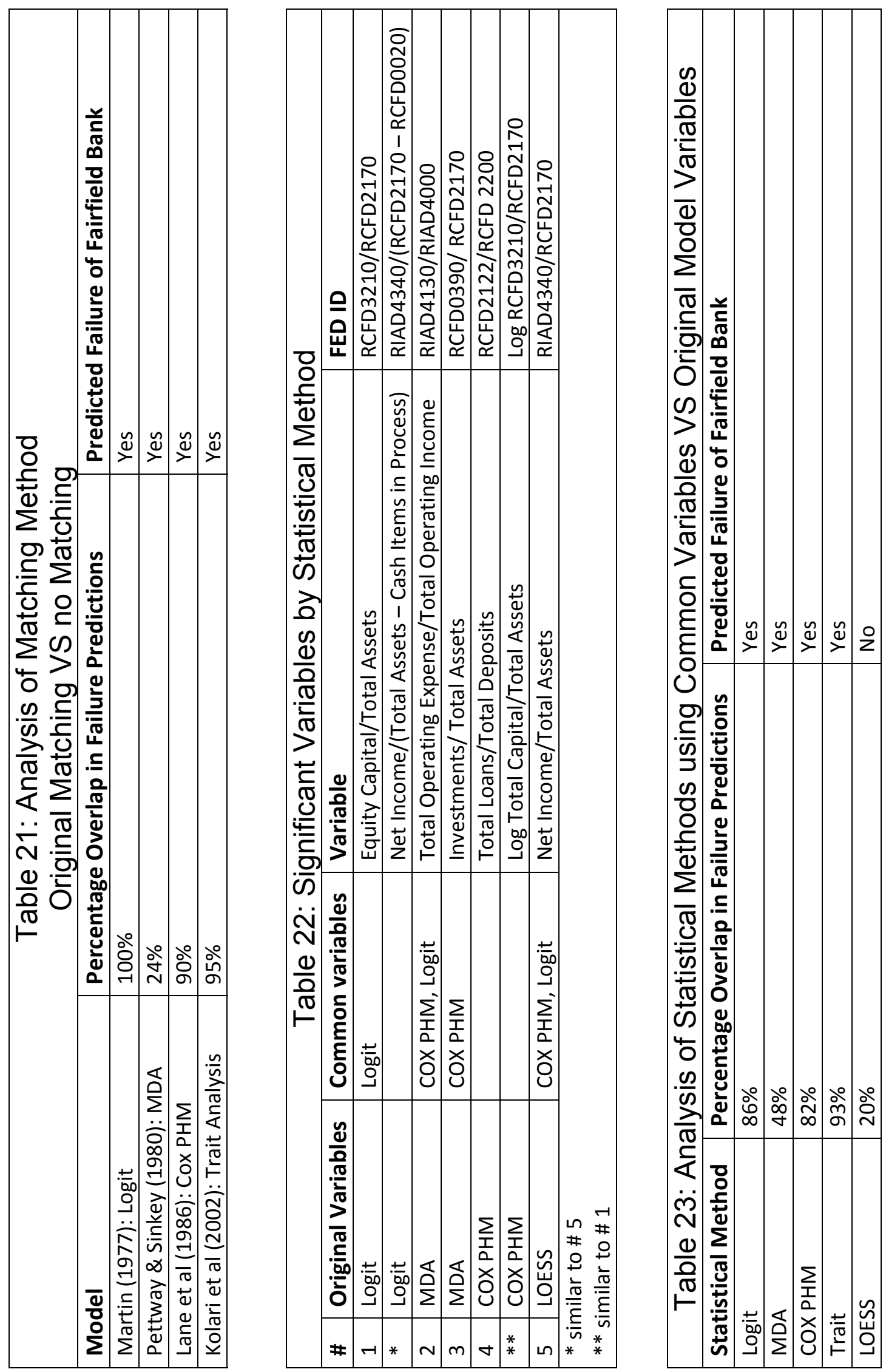